ASIPP - Opioid Guidelines 2012

\title{
American Society of Interventional Pain Physicians (ASIPP) Guidelines for Responsible Opioid Prescribing in Chronic Non-Cancer Pain: Part 2 - Guidance
}

Laxmaiah Manchikanti, MD1, Salahadin Abdi, MD, PhD², Sairam Atluri, MD³, Carl C. Balog, MD, Ramsin M. Benyamin, MD5, Mark V. Boswell, MD, PhD ${ }^{6}$, Keith R. Brown, PharmD7, Brian M. Bruel, MD ${ }^{8}$, David A. Bryce, MD , Patricia A. Burks, LPT ${ }^{10}$, Allen W. Burton, MD ${ }^{11}$, Aaron K. Calodney, MD ${ }^{12}$, David L. Caraway, $\mathrm{MD}^{13}$, Kimberly A. Cash, RT ${ }^{14}$, Paul J. Christo, MD ${ }^{15}$, Kim S. Damron, RN ${ }^{16}$, Sukdeb Datta, MD ${ }^{17}$, Timothy R. Deer, $\mathrm{MD}^{18}$, Sudhir Diwan, MD ${ }^{19}$, Ike Eriator, MD ${ }^{20}$, Frank J.E. Falco, MD ${ }^{21}$, Bert Fellows, MA ${ }^{22}$, Stephanie Geffert, MLIS23, Christopher G. Gharibo, MD24, Scott E. Glaser, MD²5, Jay S. Grider, DO, PhD², Haroon Hameed, MD27, Mariam Hameed, MD28, Hans Hansen, MD²9, Michael E. Harned, MD ${ }^{30}$, Salim M. Hayek, MD, PhD ${ }^{31}$, Standiford Helm II, MD ${ }^{32}$, Joshua A. Hirsch, MD ${ }^{33}$, Jeffrey W. Janata, PhD ${ }^{34}$, Adam M. Kaye, PharmD ${ }^{35}$, Alan D. Kaye, MD, PhD ${ }^{36}$, David S. Kloth, MD $^{37}$, Dhanalakshmi Koyyalagunta, MD ${ }^{38}$, Marion Lee, MD ${ }^{39}$, Yogesh Malla, MD ${ }^{40}$, Kavita N. Manchikanti, MD ${ }^{41}$, Carla D. McManus, RN, BSN ${ }^{42}$, Vidyasagar Pampati, MSc ${ }^{43}$, Allan T. Parr, MD ${ }^{44}$, Ramarao Pasupuleti, MD ${ }^{45}$, Vikram B. Patel, MD ${ }^{46}$, Nalini Sehgal, MD47, Sanford M. Silverman, MD ${ }^{48}$, Vijay Singh, MD ${ }^{49}$, Howard S. Smith, MD ${ }^{50}$, Lee T. Snook, MD ${ }^{51}$, Daneshvari R. Solanki, MD ${ }^{52}$, Deborah H. Tracy, MD³3, Ricardo Vallejo, MD, PhD ${ }^{54}$, Bradley W. Wargo, DO ${ }^{55}$

From: American Society of Interventional Pain Physicians

Complete author affiliations and disclosures listed on pages S98-S1oo.

Address Correspondence: ASIPP

81 Lakeview Drive Paducah, Kentucky 42003 E-mail: asipp@asipp.org

Disclaimer: The authors are solely responsible for the content of this article. No statement in this article should be construed as an official position of ASIPP.

Manuscript received: 06/22/2012 Accepted for publication: 07/02/2012

Free full manuscript: www.painphysicianjournal. com

\section{Results:}

Part 2 of the guidelines on responsible opioid prescribing provides the following recommendations for initiating and maintaining chronic opioid therapy of 90 days or longer.

1. A) Comprehensive assessment and documentation is recommended before initiating opioid therapy, including documentation of comprehensive history, general medical condition, psychosocial history, psychiatric status, and substance use history. (Evidence: good)

B) Despite limited evidence for reliability and accuracy, screening for opioid use is recommended, as it will identify opioid abusers and reduce opioid abuse. (Evidence: limited)

C) Prescription monitoring programs must be implemented, as they provide data on patterns of prescription usage, reduce prescription drug abuse or doctor shopping. (Evidence: good to fair)

D) Urine drug testing (UDT) must be implemented from initiation along with subsequent adherence monitoring to decrease prescription drug abuse or illicit drug use when patients are in chronic pain management therapy. (Evidence: good)

2. A) Establish appropriate physical diagnosis and psychological diagnosis if available prior to initiating opioid therapy. (Evidence: good)

B) Caution must be exercised in ordering various imaging and other evaluations, interpretation and communication with the patient; to avoid increased fear, activity restriction, requests for increased opioids, and maladaptive behaviors. (Evidence: good)

C) Stratify patients into one of the 3 risk categories - low, medium, or high risk.

D) A pain management consultation, may assist non-pain physicians, if high-dose opioid therapy is utilized. (Evidence: fair)

3. Essential to establish medical necessity prior to initiation or maintenance of opioid therapy. (Evidence: good)

4. Establish treatment goals of opioid therapy with regard to pain relief and improvement in function. (Evidence: good)

5. A) Long-acting opioids in high doses are recommended only in specific circumstances with severe intractable pain that is not amenable to short-acting or moderate doses of long-acting opioids, as there is no significant difference between long-acting and short-acting opioids for their effectiveness or adverse effects. (Evidence: fair)

B) The relative and absolute contraindications to opioid use in chronic non-cancer pain must be evaluated including respiratory instability, acute psychiatric instability, uncontrolled suicide risk, active or history of alcohol or substance abuse, confirmed allergy to opioid agents, 
coadministration of drugs capable of inducing life-limiting drug interaction, concomitant use of benzodiazepines, active diversion of controlled substances, and concomitant use of heavy doses of central nervous system depressants. (Evidence: fair to limited)

6. A robust agreement which is followed by all parties is essential in initiating and maintaining opioid therapy as such agreements reduce overuse, misuse, abuse, and diversion. (Evidence: fair)

7. A) Once medical necessity is established, opioid therapy may be initiated with low doses and short-acting drugs with appropriate monitoring to provide effective relief and avoid side effects. (Evidence: fair for short-term effectiveness, limited for long-term effectiveness)

B) Up to $40 \mathrm{mg}$ of morphine equivalent is considered as low dose, 41 to $90 \mathrm{mg}$ of morphine equivalent as a moderate dose, and greater than $91 \mathrm{mg}$ of morphine equivalence as high dose. (Evidence: fair)

C) In reference to long-acting opioids, titration must be carried out with caution and overdose and misuse must be avoided. (Evidence: good)

8. A) Methadone is recommended for use in late stages after failure of other opioid therapy and only by clinicians with specific training in the risks and uses. (Evidence: limited)

B) Monitoring recommendation for methadone prescription is that an electrocardiogram should be obtained prior to initiation, at 30 days and yearly thereafter. (Evidence: fair)

9. In order to reduce prescription drug abuse and doctor shopping, adherence monitoring by UDT and PMDPs provide evidence that is essential to the identification of those patients who are non-compliant or abusing prescription drugs or illicit drugs. (Evidence: fair)

10. Constipation must be closely monitored and a bowel regimen be initiated as soon as deemed necessary. (Evidence: good)

11. Chronic opioid therapy may be continued, with continuous adherence monitoring, in well-selected populations, in conjunction with or after failure of other modalities of treatments with improvement in physical and functional status and minimal adverse effects. (Evidence: fair)

Disclaimer: The guidelines are based on the best available evidence and do not constitute inflexible treatment recommendations. Due to the changing body of evidence, this document is not intended to be a "standard of care."

Key words: Chronic pain, persistent pain, non-cancer pain, controlled substances, substance abuse, prescription drug abuse, dependency, opioids, prescription monitoring, drug testing, adherence monitoring, diversion

Pain Physician 2012; 15:S67-S116

E vidence-based clinical practice guidelines for responsible opioid prescribing in non-cancer pain are statements developed to improve the quality of care, patient access, treatment outcomes, appropriateness of care, deficiency and effectiveness, and achieve cost containment by improving the costbenefit ratio. The objectives of these guidelines are to provide clear and concise guidelines to physicians to improve patient access and to avoid diversion and abuse. Part 1 of these guidelines describes evidence assessment (1), whereas Part 2 of these guidelines - the present manuscript, describes guidance for responsible opioid prescribing.

The global epidemic of chronic pain with its related disability and opioid use and its related fatalities, are the predominant issues of concern in modern medicine, specifically in the United States (2-40). The escalating use of therapeutic opioids in the United States is correlated to an increase in the supply of opioids, from 96 $\mathrm{mg}$ of morphine equivalence per person in the United States in 1997 to $710 \mathrm{mg}$ per person in $2010(34,41)$. This is equivalent to $7.1 \mathrm{~kg}$ of opioid medication per 10,000 population or enough to supply every adult American with $5 \mathrm{mg}$ of hydrocodone every 6 hours for 45 days. Sales have increased $280 \%$ for hydrocodone, $1,293 \%$ for methadone, and $866 \%$ for oxycodone from 1997 to 2007 (31), with the estimated number of prescriptions filled for opioids exceeding 256 million in the United States in 2009 (42-44). From 2006 to 2011, hydrocodone was the number one prescription in the United States (45). In 2007, based on a study by the International Narcotics Control Board (46), American's, constituting 4.6\% of the global population, accounted for over $99 \%$ of the global consumption of hydrocodone and $83 \%$ of the global consumption of oxycodone,.

The explosive use of therapeutic opioids, however, is accompanied by increasing fatalities and adverse consequences, and a lack of evidence regarding long-term effectiveness and safety in the treatment of chronic non-cancer pain (46-115). Even the Institute of Medicine (IOM) report, considered a blueprint for transforming prevention, care, education, and research on 
chronic pain recognizes the serious problem of diversion and abuse of opioid drugs and has questions about their long-term usefulness, all the while maintaining that effective pain management is a moral imperative, a professional responsibility, and the duty of the people in the healing professions $(4,47)$. Coinciding with the liberalization of laws governing opioid prescribing for the treatment of chronic non-cancer pain by the state medical boards in the late 1990s, opioid prescriptions have seen dramatic increases for non-cancer pain over the past 2 decades (116). In addition, the introduction of new pain management standards for inpatient and outpatient medical care implemented by the Joint Commission on Accreditation of Healthcare Organizations (JCAHO) in 2000 (117), multiple physicians and advocacy organizations promoting increased use of opioids in the treatment of chronic non-cancer pain, the introduction of long-acting opioids with aggressive marketing by the pharmaceutical industry, and a growing awareness of right to pain relief, empowered by JCAHO standards, have fueled the explosion in opioid use, at least in the United Sates (118-121). It has been alleged, however, that these positions are largely based on poor science and misinformation in relation to the safety and effectiveness of opioids when prescribed by a physician and taken appropriately $(51,60,62-65,118-132)$.
Opioid use for non-therapeutic purposes and also for chronic pain has increased over the years $(63,66-$ $68,70,76-79,85,106,127-176)$. It has been shown that $90 \%$ of patients present to pain management settings with prior opioid therapy, with a similar number of patients on opioids in treatment (159-174). Further, Deyo et al (30) illustrated that approximately $61 \%$ of patients with low back pain in primary care settings were on a course of opioids and that of these, $19 \%$ were longterm users. Multiple surveys have illustrated that the majority of prescriptions are from primary specialties, followed by surgical specialties rather than pain physicians (42-45). As shown in Figure 1, 42\% of immediate release opioids and $44 \%$ of long-acting opioids were prescribed by primary care physicians, whereas specialties identified as pain management, including anesthesiology and PMR, contributed to $6 \%$ of immediate release opioids and $23 \%$ of long-acting opioids (42-45).

Multiple guidelines have been published with advice for long-term opioid therapy in chronic non-cancer pain. Stein et al (59) assessed recently published guidelines, which included the guidelines by the American Pain Society (APS)-American Academy of Pain Medicine (AAPM) guidelines (50), British Pain Society's guidelines (52), Canadian National Opioid Use Guideline Group (NOUGG) (54), German guidelines (49), and guidelines
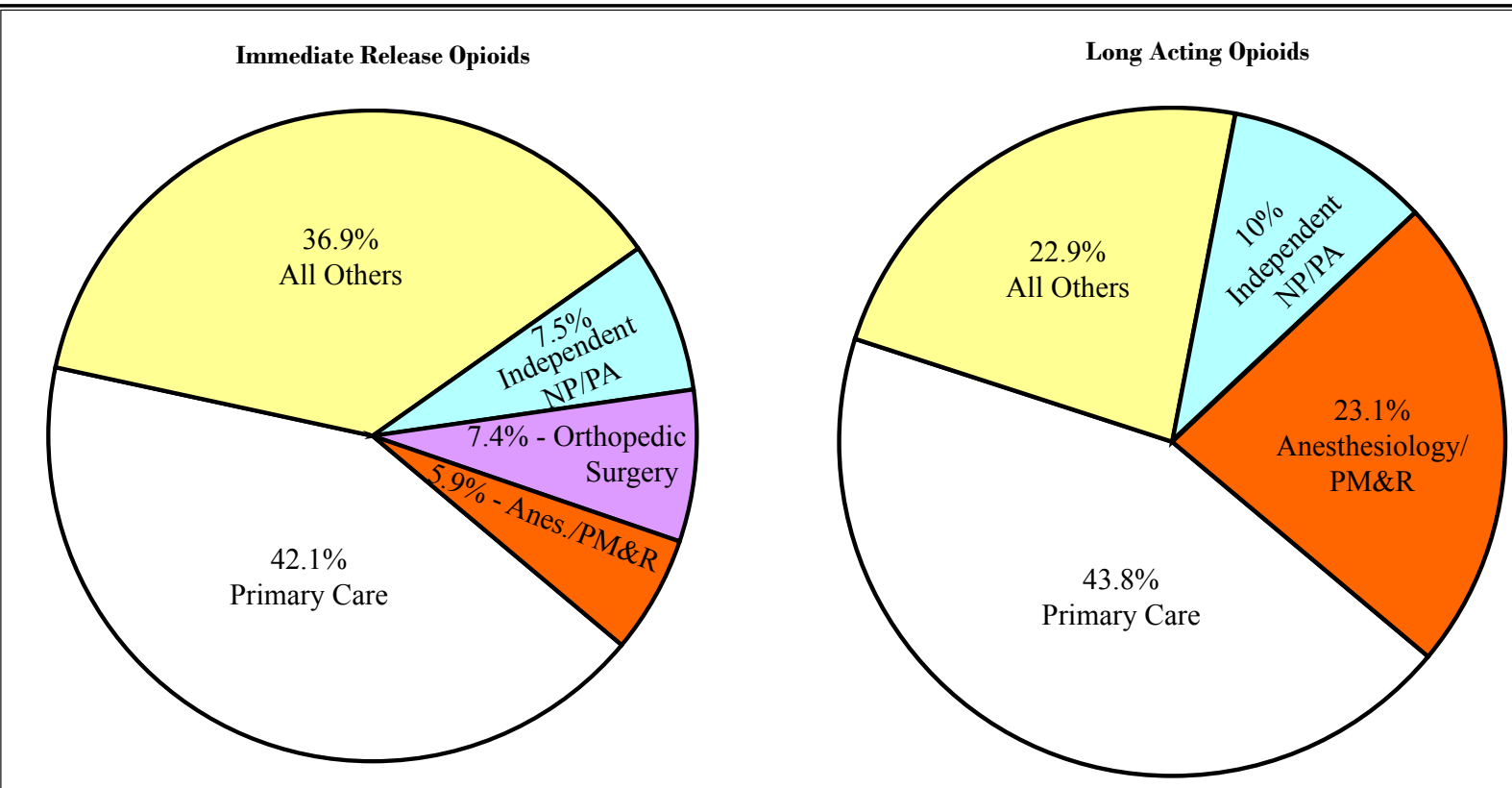

Fig. 1. Total number of prescriptions dispensed in the U.S. by various specialties for IR and ER/LA opioids in 2009 
by the American Society of Interventional Pain Physicians (55). It should be noted that this document serves, in part, to update the American Society of Interventional Pain Physicians' guidelines. Sorgatz and Maier (57) summarized that the 5 guidelines impact assessment of opioids in chronic non-cancer pain only in diction. They stated the following:

- APS-AAPM: "Although evidence is limited, an expert panel (...) concludes that chronic opioid therapy can be an effective therapy for carefully selected and monitored patients with chronic noncancer pain. However, opioids are also associated with potentially serious harms (...) "(50).

- The British Pain Society guidelines state "There is evidence from clinical trials that opioids can be effective in the short and medium term (...) However, the safety and efficacy of opioids in the long-term is uncertain (...)" (52).

- The guidelines by American Society of Interventional Pain Physicians state: "Opioids are commonly prescribed for chronic non-cancer pain and may be effective for short-term pain relief. However, longterm effectiveness of 6 months or longer is variable ..." (55).

- The Canadian guidelines National Opioid Use Guideline Group (NOUGG) state that "opioids showed only small to moderate benefits for nociceptive (...) neuropathic (...) improving function and relieving pain" (58).

In APS-AAPM guidelines for the use of chronic opioid therapy in chronic non-cancer pain $(50,51)$, despite scant evidence, the expert panel concluded that chronic opioid therapy could be effective therapy for carefully selected and monitored patients with chronic non-cancer pain. They provided recommendations and guidance on patient selection and risk stratification; informed consent and opioid management plans, initiation and titration of chronic opioid therapy, use of methadone, monitoring of patients on chronic opioid therapy, dose escalations, high-dose therapy, opioid rotation, and indications for discontinuation of therapy, prevention and management of opioid-related adverse effects, driving and work safety, identifying a medical home and when to obtain consultation, management of breakthrough pain, chronic opioid therapy in pregnancy and opioid-related policies.

Canadian Guidelines (54) for Safe and Effective Use of Opioids for Chronic Non-Cancer Pain have analyzed the evidence and have provided recommendations with
5 clusters. Cluster 1 dealt with deciding to initiate opioid therapy with comprehensive assessment, addiction-risk screening, urine drug screening, opioid efficacy, risks, adverse effects, complications, and benzodiazepine tapering. Cluster 2 dealt with conducting an opioid trial with titration and driving, stepped opioid selection, optimal dose, watchful dose, and opioid misuse. Cluster 3 described monitoring of long-term opioid therapy with monitoring, switching or discontinuing opioids, impact on driving, revisiting opioid trial steps, and collaborative care. Cluster 4 described treating specific populations with long-term opioid therapy including the elderly, adolescents, pregnant patients, and patients suffering with comorbid psychiatric conditions. Finally, Cluster 5 described managing opioid misuse and addiction with addiction treatment options, prescription fraud, unacceptable patient behavior, and acute care opioid prescribing policies.

The British Pain Society's Opioids for Persistent Pain (52) described the pharmacology of opioids, necessity to prescribe opioids, adverse effects of opioid therapy, practical aspects of prescribing, non-medical prescriptions of opioids, and opioids and problem drug use.

Hughes et al (177) also performed a systematic review of treatment guidelines, published in 2011. They included 6 clinical guidelines meeting inclusion criteria with one duplicate $(50,54,55,58,178-180)$. Three of the guidelines, including Canadian guidelines and APSAAPM guidelines were included by Stein et al (59), whereas 3 other guidelines were not included by Stein et al (178-180). Hughes et al (177) concluded that since evidence supporting efficacy for the use of opioids as treatment for chronic non-cancer pain was limited, opioids for chronic non-cancer pain should be reserved for select patients with moderate or severe pain that significantly affects function or quality of life. They also concluded that continuation of opioid therapy is indicated if documentation supports the opioid results in improvement in those limitations. Furthermore, their recommendations included a comprehensive pre-treatment assessment, identification of contraindications, obtaining informed consent, establishing a written treatment plan with goals and objectives, using an opioid treatment agreement, obtaining specialist referral when indicated, and establishing a follow-up plan that includes monitoring for adverse effects, titration and rotation of medication, prescription use monitoring, use of drug screening, and thorough record keeping which includes documentation of functional improvement.

However, the Interagency Guideline on Opioid 
Dosing for Chronic Non-Cancer Pain (53), also provided guidance sponsored by the Washington State Agency Medical Directors Group (AMDG). This guideline is provided in 2 parts: Part 1 included guidance for initiation, transition, and maintenance of oral opioids for chronic non-cancer pain, and Part 2 describes guidance for optimizing treatment and when opioid doses are greater than $120 \mathrm{mg}$ morphine equivalence per day.

Thus, in order to curtail opioid abuse but at the same time provide appropriate treatment for pain patients, the focus must be on misuse, abuse, and diversion, and should be addressed in 4 fronts: education, establishing medical necessity, supply, and drugs. These guidelines have been prepared with these aspects as the primary focus and with consideration of up-to-date literature, with special attention being given to the effectiveness of opioids in long-term therapy in conjunction with adverse consequences. Chronic opioid therapy has been defined as daily or near-daily use of opioids for at least 90 days, often indefinitely (50).

In fact, Franklin et al (181) showed that this guidance is effective in bending prescription opioid dosing and reducing mortality. In this study, Franklin et al (181) showed a substantial decline in both the morphine equivalent dose per day of long-acting Schedule II opioids by $27 \%$ and the proportion of workers on doses equal to or greater than $120 \mathrm{mg}$ per day of morphine equivalent dosage by $35 \%$, compared prior to 2007 . Further, there was also a $50 \%$ decrease from 2009 to 2010 in the number of deaths.

Opioid prescribing may be different for different specialities and settings based on the speciality and training. Consequently, additional modalities may be utilized instead of high dose opioid therapy, leading to low or moderate dose opioid therapy and avoiding multiple complications (182). These include various techniques of rehabilitation with therapeutic exercise programs, physical therapy, occupational therapy; cognitive behavioral therapy with psychological interventions, surgical interventions, or interventional techniques.

In interventional pain management, patients may receive not only opioid analgesics, but also other controlled or non-controlled drugs, to manage comorbid psychiatric and psychological disorders. Consequently, the effectiveness studies of opioids published thus far may not apply in the majority of interventional pain management patients. Indeed, in an interventional pain practice, controlled substances may be prescribed at lower doses, particularly opioid analgesics, in con- junction with interventional techniques (182). It has also been shown that interventional techniques may reduce psychological distress and improve functional status (183-201). More likely than not, the requirement for opioids and adjuvant drugs may be reduced or at least become stable. Hence, interventional pain physicians probably should not compare patients in their settings undergoing interventional techniques with others receiving drug therapy as mainstay treatment. Monotherapy, particularly with opioids, may be appropriate for only a small subgroup of those with chronic pain. Additionally, in interventional pain management, the majority of the patients are presented on opioid therapy and it is well understood that once patients are on opioids, they will not be weaned off of them regardless of reported improvements in pain relief and functional status.

The concept of "universal precautions," first seen in medicine with the explosion of HIV and hepatitis tainted blood, was introduced to counter the misconception that a provider would be able to predict "by looking" who might have a communicable blood-borne disease. This led to the use of "precautions" (gloves, etc.) for all patients, regardless of their age or socioeconomic class. A rational approach to the treatment of chronic pain with opioids has been described using a pain and addiction continuum and a substance use assessment in a pain patient leading to the implementation of "universal precautions" in pain medicine (202).

The current guidelines manuscript focuses on responsible chronic opioid therapy, chronic opioid prescribing of 90 days or longer in chronic non-cancer pain, in order to improve quality of care, patient access, treatment outcomes, appropriateness of care, efficiency and effectiveness and achieve cost containment by improving the cost-benefit ratio. The objectives of these guidelines are to provide clear and concise guidelines to physicians, to improve patient access and to avoid diversion and abuse. Consequently, these guidelines are developed to be used by physicians practicing interventional pain management/pain medicine or other specialists involved in chronic opioid therapy. Thus, the focus of these guidelines and also for physicians dealing with chronic opioid therapy should be to curtail the abuse of opioids without jeopardizing non-cancer pain management. These guidelines only recommend proper use and do not recommend total elimination of opioids in managing chronic pain. Various principles of opioid use with appropriate evidence-based recommendations are illustrated in Figure 2 showing guid- 
ance to opioid therapy. Since evidence supporting the efficacy for use of opioids as treatment of chronic noncancer pain is limited and based on short-term studies, long-term opioid therapy for chronic non-cancer pain should be reserved for select patients with moderate or severe pain that significantly affects function or quality of life. In addition, continuation of opioid therapy is indicated if documentation supports the opioid results in

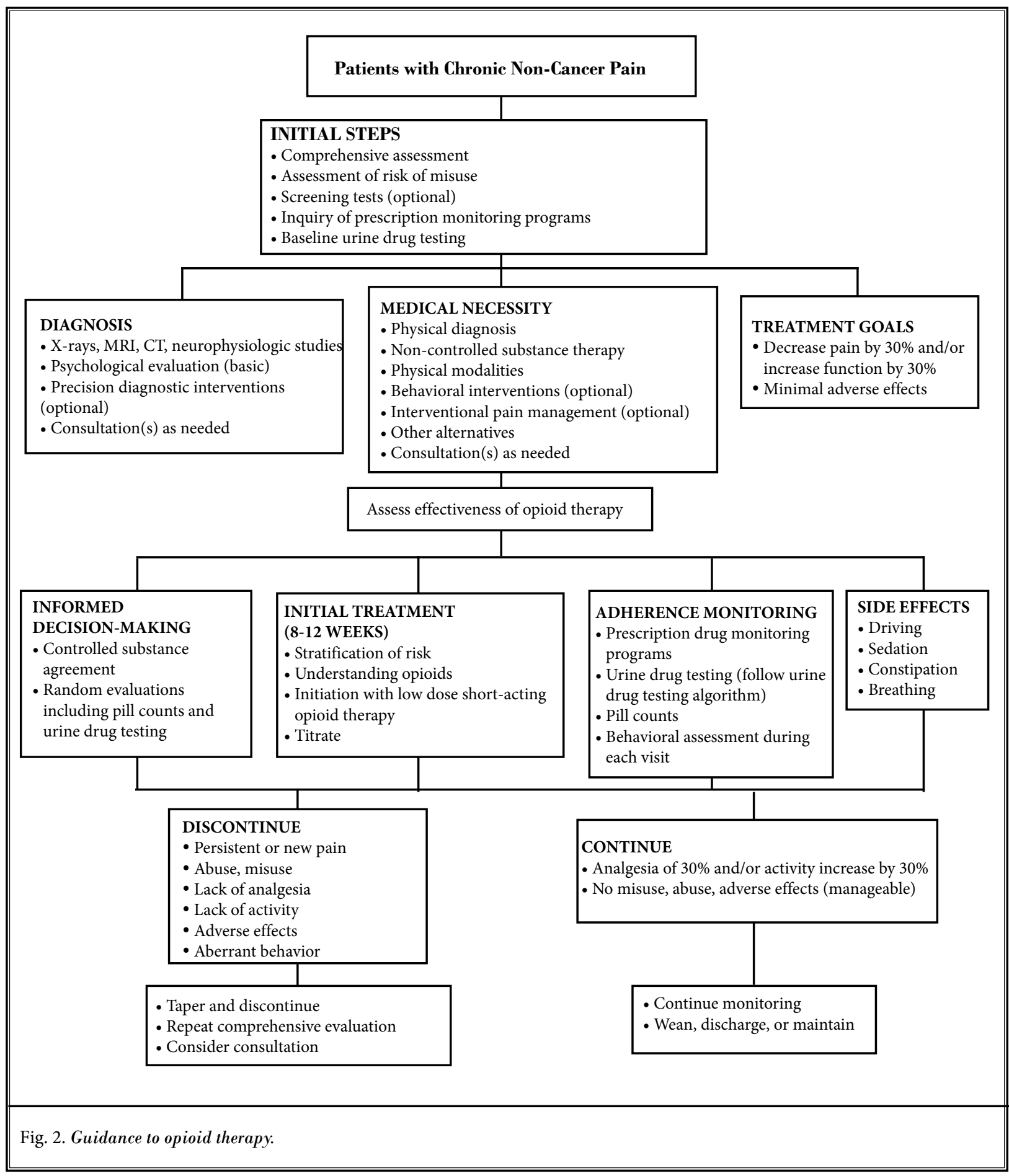


improvement in pain and function. If opioid therapy is indicated, for initiation or continuation, recommendations in this document may be followed.

\subsection{Initial Steps of Opioid Therapy}

Before the initiation of opioid therapy it is essential that comprehensive assessment and documentation of the patient's physical condition, general medical condition, psychological history, psychiatric status, substance use and abuse history of the patient and family be obtained $(50,52,53,55,58,177-180)$.

\subsection{Comprehensive Assessment}

\subsubsection{Pain Condition}

A thorough history and physical examination must be documented to determine the type, cause, and nature of the pain, including questions about past investigations and interventions for pain. This history also should include medication trials and the pain intensity and the functional impairment that arises from it (i.e., impact of pain on activities of daily living, work, and other aspects of life). In addition, various circumstances which increase or exacerbate the pain and conditions which lead to diminution of pain must be documented (203-206). A physical diagnosis must be established prior to initiating opioid therapy. The diagnosis should not be non-specific such as low back pain, knee pain etc., but should be objective and somewhat specific based on the type of pain and abnormalities identified. This will assist in future treatments based on whether the pain is nociceptive, neuropathic, somatic, radicular, widespread, or localized.

\subsubsection{General Medical History}

General medical history includes questions about general physical health, emotional health, and medication usage (203-206). Chronic pain patients tend to have multiple medical comorbid conditions which may increase the pain levels or may interact with multiple other drugs.

\subsubsection{Psychosocial History}

Psychosocial history includes information regarding their upbringing, family and social support, family obligations, work status, use of alcohol, smoking, and living arrangements.

\subsubsection{Functional Status}

A history of the functional status of a patient includes information about their ability to perform ac- tivities of daily living, work, play, and socialization. Assessment may be performed utilizing the Oswestry Disability Index, Neck Disability Index, or another measure.

\subsubsection{Sleep Patterns}

Sleeping is an important function, specifically in patients with generalized pain problems such as fibromyalgia and with the elderly.

\subsubsection{Psychological Evaluation}

Psychological evaluation may be performed with a simple evaluation for depression, anxiety, and somatization. Patients with major personality disorders need further evaluation and appropriate consultations (203-206).

Psychiatric status includes information regarding the patient's current and past history of psychiatric disorders and treatments and family history of psychiatric disorders.

\subsubsection{Substance Use History}

Substance use history includes multiple questions in reference to current, past, and family history of substance use, abuse, and addiction to alcohol, tobacco, prescription drugs, street drugs, illicit drugs, over-thecounter medications, solvents, etc. Furthermore, history in reference to attendance at a treatment program for addiction or treatment in an outpatient office detoxification etc., must be documented (203-206).

\subsubsection{Addiction Risk Screening}

Before initiating opioid therapy, a physician may consider using a screening tool to determine the patient's risk for opioid addiction. This evaluation is part of the comprehensive assessment. Comprehensive history also includes a thorough review of the patient's alcohol and other substance use. The history is important in assessing the patients risk for opioid misuse or addiction. Various screening tools may help with the determination. Most of the screening tools have not been studied in depth, validated, or been compared to each other. Thus, the evidence is poor as to their reliability $(1,40,77-79,207-214)$.

\subsubsection{Prescription Monitoring Programs}

Before initiating therapy, a physician must obtain data from the prescription monitoring program. If a prescription monitoring program is not available, the physician must request information from all previous 
physicians as well as pharmacies a patient uses or has used. While the evidence shows a general lack of reliability and accuracy for the multiple screening tools for opioid abuse, there is good evidence that prescription monitoring programs provide data on patterns of prescription usage, and fair evidence that prescription drug monitoring programs (PDMPs) can reduce prescription drug abuse or doctor shopping (1). However, the evidence that PDMPs reduce emergency room visits, drug overdoses, or deaths is poor. PDMPs collect statewide data about prescription drugs and track their flow (213,215-224). There are 3 components of these programs. The first component involves collecting data for prescriptions, documenting the physicians who wrote them and the pharmacies that dispensed them. With the enactment of the National All Schedules Electronic Reporting (NASPER) Act, physicians will have access to a database that has the capacity to monitor all transactions. In fact, some states are already mandating such use of prescription monitoring programs (221). To date, in the United States 38 states have functioning PDMPs, with 48 states with legislation passed (224), but there is a significant difference in the manner and frequency with which the data is collected.

\subsubsection{Urine Drug Screening}

In initiating and maintaining chronic opioid therapy, urine drug testing (UDT) must be used to establish a baseline measure of risk or to monitor compliance $(40,51,54,149,172,173,207-213,225-234)$. However, it is essential to understand pharmacology, pharmacodynamics, drug interactions, and to have knowledge of interpretation and a plan in place to use the results, without financial considerations as the driving force (235-239).

UDT has been described in Part I and other manuscripts $(40,53,54,225-231,237-240)$. Various details of interpretation of UDT are shown in Tables 1-3.

Physicians face multiple issues when utilizing UDT. In particular, the implication that the physician does not trust his or her patient. Information gained from UDT is limited regarding whether a patient is taking the dosages prescribed, or if they are a high metabolizer. UDT can reveal whether they are taking illicit substances.

- Drug screening should not imply that a physician does not trust the patients or that patients are not trustworthy. The literature, however, shows that self-reporting of drug use and behavioral monitor-

Table 1. Urine drug testing: Typical screening and confirmation cut-off concentrations and detection times for drugs of abuse.

\begin{tabular}{|c|c|c|c|c|}
\hline Drug & $\begin{array}{c}\text { Screening cut-off } \\
\text { concentrations ng/mL } \\
\text { urine }\end{array}$ & $\begin{array}{c}\text { Confirmation cut- } \\
\text { off concentrations } \\
\mathbf{n g} / \mathbf{m L}\end{array}$ & Urine detection time & $\begin{array}{c}\text { Immunoassay (I) } \\
\text { Chromatography (C) }\end{array}$ \\
\hline Hydrocodone & 300 & 50 & 1-2 days & I \& C \\
\hline Oxycodone & 100 & 50 & 1-3 days & I \& C \\
\hline Morphine & 300 & 50 & 3-4 days & I \& C \\
\hline Methadone & 300 & 100 & 5-10 days & I \& C \\
\hline Hydromorphone & 300 & 100 & 1-2 days & I \& C \\
\hline Meperidine & 300 & 100 & 1-2 days & I \& C \\
\hline Codeine & 300 & 50 & 1-3 days & I \& C \\
\hline Benzodiazepines & 200 & $20-50$ & Up to 30 days & I \\
\hline Barbiturates & 200 & 100 & $2-10$ days & I \& C \\
\hline Marijuana & 50 & 15 & $\begin{array}{l}1-3 \text { days for casual use; up to } \\
11 \text { weeks for chronic use }\end{array}$ & I \& C \\
\hline Cocaine & 300 & 50 & 1-3 days & I \& C \\
\hline Amphetamine & 1,000 & 100 & 2-4 days & I \& C \\
\hline Methamphetamine & 1,000 & 100 & 2-4 days & I \& C \\
\hline Heroin* & 10 & 25 & 1-3 days & I \& C \\
\hline Phencyclidine & 25 & 10 & 2-8 days & I \& C \\
\hline
\end{tabular}

${ }^{*} 6$-MAM, the specific metabolite is detected only for 6 hours. 
Table 2. Drug cross-reactants.

\begin{tabular}{|c|c|c|}
\hline Drug Group & Cross Reactivity Based on Product Insert & Cross Reactivity Based on Potential Cross-Reaction \\
\hline Cannabinoids & Dronabinol (Marinol) & $\begin{array}{l}\text { NSAIDs } \\
\text { Efavirenz (Sustiva) } \\
\text { Hemp Seed Oil (Cannabis seed) } \\
\text { Pantoprazole (Protonix) } \\
\text { Nexium } \\
\text { Prilosec }\end{array}$ \\
\hline Opioids & $\begin{array}{l}\text { 6-Acetylmorphine } \\
\text { Ethyl morphine } \\
\text { Oxymorphone } \\
\text { Oxycodone } \\
\text { Methadone } \\
\text { Dextromethorphan }\end{array}$ & $\begin{array}{l}\text { Fluoroquinolones } \\
\text { Ofloxacin (Floxin) } \\
\text { Papaverine } \\
\text { Poppy Seeds } \\
\text { Rifampicin \& Rifampin (Rimactane, Rifadin, Rofact) } \\
\text { Levofloxacin (Levaquin) }\end{array}$ \\
\hline Amphetamines & Dextroamphetamine + amphetamine (Adderall) & $\begin{array}{l}\text { Ephedrine } \\
\text { Methylphenidate } \\
\text { Trazodone } \\
\text { Bupropion } \\
\text { Desipramine } \\
\text { Amantadine } \\
\text { Ranitidine } \\
\text { Phenylpropanolamine } \\
\text { Vicks Vapor Spray } \\
\text { Phentermine (Adipex/Obenix/Oby-Trim) } \\
\text { Pseudoephedrine }\end{array}$ \\
\hline Methamphetamine & $\begin{array}{l}\text { d-Methamphetamine } \\
\text { d-Amphetamine } \\
\text { Chloroquine (Aralen) } \\
\text { Desoxyephedrine } \\
\text { MDMA (Ecstasy) } \\
\text { Methamphetamine (Desoxyn) }\end{array}$ & $\begin{array}{l}\text { Bupropion (Wellbutrin \& Zyban) } \\
\text { Chloroquine (Aralen) } \\
\text { Chlorpromazine (Thorazine, Largactil) } \\
\text { Desipramine (Norpramin) } \\
\text { Dextroamphetamine (Dexedrine) } \\
\text { Ephedrine (Ephedra and Ma Huang) } \\
\text { Fenfluramine (Fen Phen) } \\
\text { Labetalol (Labetalol) } \\
\text { Mexiletine (Mexitil) } \\
\text { n-acetyl procainamide (Procainamide) } \\
\text { Phenylephrine (Neo-synephrine) } \\
\text { Propranolol (Inderal) } \\
\text { Pseudoephedrine (Claritin-D) } \\
\text { Quinacrine (Atabrine, Mepacrine) } \\
\text { Ranitidine (Zantac) } \\
\text { Selegiline (Selegiline) } \\
\text { Trazodone (Desyrel, Desyrel Dividose) } \\
\text { Tyramine (Tyramine) }\end{array}$ \\
\hline PCP & None & $\begin{array}{l}\text { Chlorpromazine } \\
\text { Meperidine } \\
\text { Doxylamine } \\
\text { Dextromethorphan } \\
\text { Diphenhydramine (Benadryl) } \\
\text { Thioridazine (Mellaril) } \\
\text { Venlafaxine (Effexor) } \\
\end{array}$ \\
\hline Benzodiazepine & $\begin{array}{l}\text { Bromazepam (Tenix) } \\
\text { Clobazam (Mystan) } \\
\text { Estazolam (ProSom) }\end{array}$ & $\begin{array}{l}\text { Oxaprozin (Daypro) } \\
\text { Sertraline (Zoloft) } \\
\text { Some herbal agents }\end{array}$ \\
\hline Cocaine & $\begin{array}{l}\text { Benzoylecgonine } \\
\text { Ecgonine } \\
\text { Ecgonine Methyl Ester }\end{array}$ & TAC Solution (TAC Solution) \\
\hline ETOH & None & Asthma inhalers (sometimes) \\
\hline Methadone & None & $\begin{array}{l}\text { Propoxyphene } \\
\text { Seroquel }\end{array}$ \\
\hline
\end{tabular}


Table 2 (cont.). Drug cross-reactants.

\begin{tabular}{|l|l|l|}
\hline \multicolumn{1}{|c|}{ Drug Group } & \multicolumn{1}{|c|}{ Cross Reactivity Based on Product Insert } & Cross Reactivity Based on Potential Cross-Reaction \\
\hline Barbiturates & Alphenal & $\begin{array}{l}\text { Phenytoin (Dilantin) } \\
\text { Primidone (Mysoline) }\end{array}$ \\
\hline Oxycodone & $\begin{array}{l}\text { Hydrocodone } \\
\text { Hydromorphone (Dilaudid) } \\
\text { Oxymorphone (Numorphan) } \\
\text { Codeine (Codeine) }\end{array}$ & \\
\hline
\end{tabular}

Source: DrugCheck ${ }^{\circledR}$ Cross Reactivity Chart (www.drugcheck.com/_images/DC145_Cross-Reactivity_chart.pdf)

Table 3. Interpreting unexpected results of urine drug screens.

\begin{tabular}{|c|c|c|c|}
\hline & Unexpected Result & Possible Explanations & Actions for the Physician \\
\hline 1 & $\begin{array}{l}\text { UDS negative for } \\
\text { prescribed opioid. }\end{array}$ & $\begin{array}{l}\text { - False negative. } \\
\text { - Non-compliance. } \\
\text { - Diversion. }\end{array}$ & $\begin{array}{l}\text { - Repeat test using chromatography; specify the drug of interest } \\
\text { (e.g. oxycodone often missed by immunoassay). } \\
\text { - Take a detailed history of the patient's medication use for the } \\
\text { preceding } 7 \text { days (e.g., could learn that patient ran out several } \\
\text { days prior to test). } \\
\text { - Ask patient if they've given the drug to others. } \\
\text { - Monitor compliance with pill counts. }\end{array}$ \\
\hline 2 & $\begin{array}{l}\text { UDS positive for non- } \\
\text { prescribed opioid or } \\
\text { benzodiazepines. }\end{array}$ & $\begin{array}{l}\text { - False positive. } \\
\text { - Patient acquired opioids from other } \\
\text { sources (double doctoring, "street"). }\end{array}$ & $\begin{array}{l}\text { - Repeat UDS regularly. } \\
\text { - Ask the patient if they accessed opioids from other sources. } \\
\text { - Assess for opioid misuse/addiction. } \\
\text { - Review/revise treatment agreement. }\end{array}$ \\
\hline 3 & $\begin{array}{l}\text { UDS positive for illicit } \\
\text { drugs (e.g., cocaine, } \\
\text { cannabis). }\end{array}$ & $\begin{array}{l}\text { - False positive. } \\
\text { - Patient is occasional user or addicted to the } \\
\text { illicit drug. } \\
\text { - Cannabis is positive for patients taking } \\
\text { dronabinol (Marinol }{ }^{\circ} \text {, THC:CBD }\left(\text { Sativex }{ }^{\circ}\right) \\
\text { or using medical marijuana. }\end{array}$ & $\begin{array}{l}\text { - Repeat UDS regularly. } \\
\text { - Assess for abuse/addiction and refer for addiction treatment } \\
\text { as appropriate. } \\
\text { - Ask about medical prescription of dronabinol, THC:CBD or } \\
\text { medical marijuana access program. }\end{array}$ \\
\hline 4 & $\begin{array}{l}\text { Urine creatinine is } \\
\text { lower than } 2-3 \mathrm{mmol} / \\
\text { liter. }\end{array}$ & - Patient added water to sample. & $\begin{array}{l}\text { - Repeat UDS. } \\
\text { - Consider supervised collection or temperature testing. } \\
\text { - Take a detailed history of the patient's medication use for the } \\
\text { preceding } 7 \text { days. } \\
\text { - Review/revise treatment agreement. }\end{array}$ \\
\hline 5 & Urine sample is cold. & $\begin{array}{l}\text { - Delay in handling sample (urine cools } \\
\text { within minutes). } \\
\text { - Patient added water to sample. }\end{array}$ & $\begin{array}{l}\text { - Repeat UDS, consider supervised collection or temperature } \\
\text { testing. } \\
\text { - Take a detailed history of the patient's medication use for the } \\
\text { preceding } 7 \text { days. } \\
\text { - Review/revise treatment agreement. }\end{array}$ \\
\hline
\end{tabular}

UDS=urine drug screen; $\mathrm{THC}=$ Tetrahydrocannabinol; $\mathrm{CBD}=$ cannabidiol

Source: Canadian Guideline for Safe and Effective Use of Opioids for Chronic Non-Cancer Pain® 2010 National Opioid Use Guideline Group (NOUGG) (54).

ing fail to detect problems with drug misuse and abuse (53). Creating a UDT policy that is applicable universally and consistently with all patients assists to "de-stigmatize" UDT and can potentially convince patients that it has nothing to do with an individual patient or their trustworthiness $(53,54)$. Consequently, the practice can explain to patients that drug testing is a routine procedure for all patients starting or maintained on opioid therapy and it is an important tool for monitoring the safety of opioid therapy. The UDT not only provides adherence monitoring, but it is also a monitoring tool for safety.

- As it is very difficult to correlate urine drug concentration with a patient's dose, it is not feasible for the physician to ascertain whether or not a patient has taken the dose of opioid appropriately using UDT. UDT can, however, detect the parent drug and/or its metabolites and demonstrate recent use of prescribed drugs and illegal substances. UDT will 
not detect the amount of medication taken, when it was taken or identify the source of the drug.

- Some patients state that the expected drug is not found in the urine because they are high metabolizers. They may state that they are on diuretics and are drinking fluids to lose weight or on diet pills, and since they have so much fat, it cannot be detected. Most of the explanations are untrue, however, as only a small percentage of persons are considered ultra rapid metabolizers and may metabolize specific drugs more rapidly than typical patients (53). It would be rare for someone to take an opioid as prescribed and have a negative UDT. Moreover, diuretics, water intake, and excessive fat do not influence urine drug concentrations to an extent that one cannot influence urine drug concentrations. It is also crucial that the testing methodology used to identify the specific medication of interest have a low cut-off threshold. When possible, "no threshold" should be requested.

There is a misconception that short-acting opioids are not detected in the urine. In fact, most opioids are detectable in the body from one to 2 days. Shortacting opioids can be detected with no threshold testing.

- Confirmation of the results is a major issue. Proponents argue that each and every specimen must be sent to the lab and confirmed for a myriad of drugs; while others state that immunoassay testing is reliable and that confirmation should only be requested if there are questions with reference to results and patient history. If a patient admits that they have used a licit or illicit drug other than the prescriptions and if that drug is testing positive, there is no need to confirm this with laboratory testing. If, however, the patient denies any such use, it is essential that the result is confirmed through laboratory testing with LC/MS/MS. There is a significant correlation between immunoassay and chromatography for a majority of drugs $(172,173)$. However, on occasion, it should be noted that even confirmatory testing requires expert assistance for interpretation (53). Most importantly with confirmation testing, while noting that financial incentives are put aside, understanding the pharmacology and metabolism of the drugs is essential.

- Some of the most common questions arise when dealing with marijuana. While for many people marijuana is a highly controversial and complex is- sue, the Drug Enforcement Administration (DEA) currently classifies it as a Schedule I drug. For that reason, many providers do not prescribe opioids to patients using marijuana or give them one opportunity to stop using them. Other providers reference state "medical marijuana" laws (http://apps.leg. wa.gov/RCW/default.aspx?cite=69.51A\&full=true) (53) and feel comfortable prescribing opioids to marijuana users. Some providers adopt a "don't ask, don't tell" policy, whereas others request the lab to remove marijuana from the UDT so that positive results are not seen. While this may be a risky practice, physicians should create their office policies and disclose them to patients. These policies, should, of course, follow all state and federal regulations apart from policies addressing personal ethics and beliefs.

\subsection{Recommendations}

1. Comprehensive assessment and documentation is recommended before initiating opioid therapy, including documentation of comprehensive history, general medical condition, psychosocial history, psychiatric status, and substance use history. (Evidence: good)

2. Despite limited evidence for reliability and accuracy, screening for opioid use is recommended, as it will identify opioid abusers and reduce opioid abuse. (Evidence: limited)

3. Prescription monitoring programs must be implemented due to regulations, as they provide data on patterns of prescription usage, reduce prescription drug abuse or doctor shopping, and PDMPs may reduce emergency room visits, drug overdoses, or deaths. (Evidence: good to fair)

4. UDT must be implemented from initiation along with subsequent adherence monitoring, in an inoffice setting with immunoassay and confirmation for accuracy with chromatography in select cases, to identify patients who are non-compliant or abusing prescription drugs or illicit drugs, and UDT may decrease prescription drug abuse or illicit drug use when patients are in chronic pain management therapy. (Evidence: good)

\subsection{Establishing Diagnosis}

Diagnosis may be established by various means including physical examination, x-rays, magnetic resonance imaging (MRI), computed tomography (CT), and neurophysiologic studies. Furthermore, psychological 
evaluations and precision diagnostic interventions may also be applied. Diagnostic interventional techniques will assist in making the proper diagnosis by following an algorithmic approach. Research shows that in approximately $70 \%$ to $85 \%$ of patients with spinal pain, an accurate diagnosis may not be provided even with the available history, physical examination, electromyographic (EMG)/nerve conduction studies, and radiologic evaluation $(179,240-269)$. With precise diagnostic interventional techniques, the chances of an accurate diagnosis may be improved substantially, and proper treatment may be offered (270-273). Once the diagnosis is established, various modalities of therapy may be offered with interventional techniques or other techniques. Whatever opioids are required will be prescribed in low doses or eliminated.

Given the degree to which routine imaging has been criticized, it may be appropriate that physicians follow the recommendations provided by professional organizations and governmental organizations. In ordering various investigations, being conservative may be prudent, along with their interpretation, due to findings in asymptomatic patients and also the psychological factors and nocebo effect introduced in these patients with graphic description of asymptomatic abnormalities (252-292). Guidelines provided by specialty societies are appropriate if they were peer-reviewed and developed utilizing guidance from IOM criteria. Early imaging is discouraged in all circles. It is also crucial to realize that numerous abnormalities are generally found on imaging in asymptomatic subjects (262292). In the era of information disclosure and electronic media, findings which do not correlate with symptoms and do not provide certainty as a pathological entity should be addressed by qualified physicians, not by technologists and radiologists, without any clinical correlation. Irrelevant and non-corroborative findings create fear and activity avoidance, resulting in negative consequences including requests for increased opioid dosages.

The role of neurophysiologic testing is limited in chronic pain management, even though some insurers mistakenly focus on the neurophysiologic evaluation and findings $(252-256,275)$.

\subsection{Consultation(s)}

Physicians should be willing to refer a patient as clinically indicated for additional evaluation to achieve treatment objectives. Special attention should be given to those patients who are at risk of misusing their medi- cations and those whose living arrangements create a risk for medication misuse or diversion. The management of patients with a history of substance abuse or with a coexisting psychiatric disorder may require extra care, monitoring, documentation, and consultation with, or referral to, an addictionologist. The lack of well-trained psychologists and psychiatrists in chronic pain management in many regions of the country may make this referral difficult to obtain. Likewise, in many locations there are no clinically trained addiction specialists with whom to collaborate.

Interagency guidelines on opioid dosing for chronic non-cancer pain (53) have proven to be effective in reducing opioid usage and deaths, and include thresholds for pain consultation. The hallmark of this guideline (53) is a recommendation not to prescribe more than an average daily morphine equivalent dose of $120 \mathrm{mg}$ without either the patient demonstrating improvement in function and pain or first obtaining a consultation from a pain management expert. This concept was based on the results of a study by Dunn et al (135), which showed that patients receiving $100 \mathrm{mg}$ or more per day morphine equivalent doses had a 9-fold increase in overdose risk with $12 \%$ fatal overdoses and most overdoses being medically serious. Furthermore, high-dose opioid therapy can be ineffective and/or unsafe (53). Higher strength opioids may be associated with poorer functional outcomes and adverse consequences $(26,32,33,90,135,293-296)$.

\subsection{Recommendations}

1. Establish appropriate physical diagnosis and psychological diagnosis if available prior to initiating opioid therapy. (Evidence: good)

2. Caution must be exercised in ordering various imaging and other evaluations, and only appropriate information in the realm of clinical relevance shall be provided by the treating physician to the patients when there is correlation of the symptoms with findings; to avoid increased fear, activity restriction, requests for increased opioids, and maladaptive behaviors. (Evidence: good)

3. A pain management consultation, for non-pain physicians, if high-dose opioid therapy is being utilized. (Evidence: fair)

\subsection{Establishing Medical Necessity}

To establish medical necessity for opioid therapy, it is essential to have a physical diagnosis and information of multiple modalities of treatments available including 
conservative, various other alternatives, and consultations if necessary. These include non-controlled substance therapy, physical modalities, behavioral interventions, interventional pain management techniques, and any other alternatives.

Medical necessity is established only when the following criteria are met: pain of moderate to severe degree; suspected organic problem; documented failure to respond to non-controlled substance, adjuvant agents, physician ordered physical therapy, structured exercise program; and interventional techniques, specifically for long-term high-dose therapy.

Opioids may be used as a second-line treatment. For non-opioid controlled substance, appropriate documentation of psychological status must be documented.

Continued medical necessity depends on the following 4 "A's":

- Analgesia

- Activity

- Aberrant behavior

- Adverse effects

Behavioral interventions, interventional pain management, various other alternatives, and consultations as needed must be obtained.

\subsection{Recommendations}

It is essential to establish medical necessity prior to initiation or maintenance of opioid therapy. (Evidence: good)

\subsection{Establishing Treatment Goals}

It is essential to establish treatment goals. Treatment goals should combine pain relief with improvement in activity and minimal or no adverse effects. To achieve the treatment goals, outcomes assessment is essential. Outcomes may be assessed by numeric rating scale pain (0-10 scale), functional assessment using the Oswestry Disability Index (0-50 scale), Neck Disability Index (0-50 scale), employment status, and/or improvement in activity status. The minimum amount of change in pain score in order to be clinically meaningful has been described as a 2-point change on a scale of 0 to 10 (or 20 percentage points), based on findings in trials which have been commonly utilized studying general chronic pain (297), chronic musculoskeletal pain (298), and chronic low back pain (297-302). Consequently, for guideline purposes, it would be appropriate to use clinically meaningful pain relief of at least $30 \%$ and/or a 3-point change on an 11-point scale of $0-10$, or as clinically significant and/or functional status improvement of $30 \%$ or more. For interventional techniques, significant improvement has been defined as $50 \%$ reduction in pain scores and disability scores for evaluation purposes.

Before starting opioids, physicians should insure that the patient's expectations are realistic. The goal of opioid therapy for chronic non-cancer pain is rarely the elimination of pain, but rather an improvement in function or a reduction of pain intensity by at least $30 \%$. Before starting opioids, a discussion with the patient about specific goals related to pain reduction and functional improvement should address any unrealistic expectations. These goals, once established should be documented in the patient's record; they are critical in determining that opioids are effective and should be monitored over time (54).

\subsection{Recommendations}

It is essential to establish treatment goals of opioid therapy with regard to pain relief and improvement in function. (Evidence: good)

\subsection{Assessment Of Effectiveness Of Opioid Therapy}

The effectiveness of various types of opioids must be clearly defined. The evidence for various types of opioids is described as follows.

1. Nociceptive pain - Opioids showed only small to moderate benefits for nociceptive pain for improving function and relieving pain on a short-term basis of 3 months or less. If opioids are required, patients generally respond to moderate doses after failure of alternative techniques and non-opioid management $(1,49-58,62,68,73,76,90,91,132,302-316)$.

2. Neuropathic pain - Opioids showed only small to moderate benefits for neuropathic pain $(1,49-$ $58,73,90,132,303,317-319)$. However, it is the general belief that opioids are resistant in neuropathic pain and these patients may require higher opioid doses in combination with tricyclic antidepressants or anticonvulsants.

3. Widespread soft tissue pain - The benefit of the weak opioid tramadol for fibromyalgia was small. Other pain-relief options should be considered (54).

4. Headache and other problems - Opioids are not usually indicated for migraine or tension headaches, or for patients with functional gastrointestinal problems (316).

Multiple manuscripts, systematic and compre- 
hensive reviews, and guidelines have been published evaluating the effectiveness and safety of opioids $(1,49-58,62,68,73,76,90,91,132,302-319)$. With extensive review as shown in Part 1 (1), it was concluded that the short-term effectiveness of opioids is fair, whereas longterm effectiveness of opioids is limited or poor. There is also fair evidence for lack of significant difference in effectiveness or adverse effects between long-acting and short-acting opioids. The evidence for improvement in quality of life parameters is fair for short-term and poor for long-term. There is no published evidence for opioid rotation.

An evaluation of individual drugs also showed variable evidence with lack of available evidence for hydrocodone, fair for short-term, and poor for long-term for oxycodone, morphine, and fentanyl. The evidence for tramadol is fair in osteoarthritis. The evidence for methadone, oxymorphone, hydromorphone, tapentadol, codeine, and buprenorphine is limited for either short-term or long-term improvement.

An evaluation of the effectiveness, adverse effects, and indications in special populations showed the evidence is fair for short-term and poor for long-term in the elderly, poor in children, adolescents, and in patients with generalized anxiety disorder, depression, and high risk psychological disorders such as personality disorders.

\subsection{Recommendations}

1. Clinicians must understand the effectiveness and adverse consequences of long-term opioid therapy in chronic non-cancer pain and its limitations. (Evidence: fair for short-term, limited for long-term)

2. The long-acting opioids in high doses are recommended only in specific circumstances with severe intractable pain that is not amenable to short-acting or moderate doses of long-acting opioids, as there is no significant difference between long-acting and short-acting opioids for their effectiveness or adverse effects. (Evidence: fair)

3. A trial of opioid rotation may be considered for patients requiring escalating doses. (Evidence: limited)

4. It is recommended that contraindications to opioid use in chronic non-cancer pain must be evaluated including respiratory instability, acute psychiatric instability, uncontrolled suicide risk, active or history of alcohol or substance abuse, confirmed allergy to opioid agents, coadministration of drugs capable of inducing life-threatening drug interac- tion, concomitant use of benzodiazepines, active diversion of controlled substances, and concomitant use of heavy doses of central nervous system depressants, such as benzodiazepines. (Evidence: fair to limited)

\subsection{Informed Decision-Making}

Informed decision-making with appropriate consent is not only essential but mandatory. A discussion about potential benefits, adverse effects, complications, and risks helps the physician and patient make a joint decision on whether to proceed with the opioid therapy (54). There have been substantial descriptions in reference to informed consent and treatment agreements and their effectiveness (1,320-327).

The following must be explained to patients and understood by patients before starting on opioids:

1) Opioids are used to improve the ability to be active and reduce pain, if appropriate criteria are met, in conjunction with or without various other modalities of treatments including cognitive behavioral therapy, behavior modification, therapeutic exercise program, increased activity, positive attitudes, physical therapy, psychotherapy, other drug therapy, or interventional techniques.

2) Opioids may help on a short-term basis, but they have substantial risks.

3) Common side effects include nausea (28\%), constipation $(26 \%)$, drowsiness $(24 \%)$, dizziness $(18 \%)$, dry-skin/itching (15\%), and vomiting (15\%) (54). However, these side effects can be minimized by slowly increasing the dose of the drug and starting a bowel regimen to manage constipation which may be the most long-lasting side effect of all. More serious complications include the effect on driving, respiratory depression, drug dependency, drug addiction, hormonal deficiency, fatigue, weakness, impotency, sexual dysfunction, etc., overdose, and death. Patients and physicians must take these complications and adverse consequences very seriously. Managing side effects through polypharmacy and the combination of various sedative hypnotics may not be useful.

4) The development of tolerance, dependency, addiction, and hyperalgesia are a major concern. Although the majority of patients believe that they can not develop addiction, many patients believe they develop tolerance and request higher doses believing that they are entitled for increase in doses and frequency with continued pain manage- 
ment. However, physicians must educate patients on common aspects of addiction, hyperalgesia, and medication adjustment with emphasis on low dose or no opioid therapy and multidisciplinary management.

5) Abrupt stoppage of medication results in withdrawal states. Opioids overdoses are common, often resulting in various morbidities including death. Mixing opioids with alcohol or sedative drugs, such as antianxiety drugs and sleeping medications increase the risk of overdose significantly. Patients must understand the signs of overdosage.

6) Drugs prescribed to one patient may be disastrous to another person. Thus, medication should be safely secured by patients and never shared.

The informed consent and treatment agreement often includes clear descriptions of medication use and abuse, as well as the consequences for violating the contract, which are as follows:

1) One prescribing doctor and one designated pharmacy

2) Urine/serum drug screening when requested

3) No early refills and no medications called in

4) If medications are lost or stolen, then a police report could be required before considering additional prescriptions.

Additional items to be included in an agreement are listed in Table 4.

Overall, there is fair evidence to support the use of treatment agreements. Though in non-randomized studies (325), one found that treatment agreements

Table 4. Sample controlled substance agreement.

We are committed to doing all we can to treat your chronic pain condition. In some cases, controlled substances are used as a therapeutic option in the management of chronic pain and related anxiety and depression, which is strictly regulated by both state and federal agencies. This agreement is a tool to protect both you and your physician by establishing guidelines, within the laws, for proper controlled substance use. The words "we" and "our" refer to the facility, and the words "I", "you", "your", "me", or "my" refer to you, the patient.

1. i. I understand that chronic opioid therapy has been associated with not only addiction and abuse, but also multiple medical problems including the suppression of endocrine function resulting in low hormonal levels in men and women which may affect mood, stamina, sexual desire, and physical and sexual performance.

ii. For female patients: If I plan to become pregnant or believe that I have become pregnant while taking this medication, I am aware that, should I carry the baby to delivery while taking these medications; the baby will be physically dependent upon opioids. I will immediately call my obstetrician and this office to inform them of my pregnancy. I am also aware that opioids may cause a birth defect, even though it is extremely rare.

iii. I have been informed that long-term and/or high doses of pain medications may also cause increased levels of pain known as opioid induced hyperalgesia (pain medicine causing more pain) where simple touch will be predicted as pain and pain gradually increases in intensity and also the location with hurting all over the body. I understand that opioid-induced hyperalgesia is a normal, expected result of using these medicines for a long period of time. This is only treated with addition of non-steroidal anti-inflammatory drugs such as Advil, Ibuprofen, etc., or by reducing or stopping opioids.

iv. I understand that physical dependence is not the same as addiction. I am aware physical dependence means that if my pain medicine use is markedly decreased, stopped, or reversed by some of the agents mentioned above, I will experience a withdrawal syndrome. This means I may have any or all of the following: runny nose, yawning, large pupils, goose bumps, abdominal pain and cramping, diarrhea, irritability, aches throughout my body, and a flu-like feeling. I am aware that opioid withdrawal is uncomfortable, and could even result in heart attack, stroke, or death.

v. I am aware that tolerance to analgesia means that I may require more medicine to get the same amount of pain relief. I am aware that tolerance to analgesia does not seem to be a big problem for most patients with chronic pain; however, it has been seen and may occur to me. If it occurs, increasing doses may not always help and may cause unacceptable side effects. Tolerance or failure to respond well to opioids may cause my doctor to choose another form of treatment, reduce the dose, or stop it.

2. i. All controlled substances must come from the physician whose signature appears below or during his/her absence, by the covering physician, unless specific authorization is obtained for an exception.

ii. I understand that I must tell the physician whose signature appears below or during his/her absence, the covering physician, all drugs that I am taking, have purchased, or have obtained, even over-the-counter medications. Failure to do so may result in drug interactions or overdoses that could result in harm to me, including death.

iii. I will not seek prescriptions for controlled substances from any other physician, health care provider, or dentist. I understand it is unlawful to be prescribed the same controlled medication by more than one physician at a time without each physician's knowledge. 
Table 4 (cont.). Sample controlled substance agreement.

iv. I also understand that it is unlawful to obtain or to attempt to obtain a prescription for a controlled substance by knowingly misrepresenting facts to a physician or his/her staff or knowingly withholding facts from a physician or his/her staff (including failure to inform the physician or his/her staff of all controlled substances that I have been prescribed).

3. All controlled substances must be obtained at the same pharmacy where possible. Should the need arise to change pharmacies, our office must be informed. The pharmacy that you have selected is: Phone:

4. i. You may not share, sell, or otherwise permit others, including your spouse or family members, to have access to any controlled substances that you have been prescribed.

ii. Early refills will not be given. I will not consume excessive amount (I will follow prescribed instructions) and remain compliant to all aspects of treatment. Renewals are based upon keeping scheduled appointments. Please do not make phone calls for change in prescriptions unless you develop side effects or early refills and do not phone for refills after hours or on weekends.

iii. Medication changes will not be made between appointments unless medically necessary, which will be determined by the physician.

5. Unannounced pill counts, random urine or serum, or planned drug screening may be requested from you and your cooperation is required. Presence of unauthorized substances in urine or serum toxicology screens may result in your discharge from treatment by the facility and its physicians and staff.

6. I will not consume excessive amounts of alcohol in conjunction with controlled substances. I will not use, purchase, or otherwise obtain any other legal drugs except as specifically authorized by the physician whose signature appears below or during his/her absence, by the covering physician, as set forth in Section 1 above. I will not use, purchase, or otherwise obtain any illegal drugs, including marijuana, cocaine, etc. I understand that driving while under the influence of any substance, including a prescribed controlled substance or any combination of substances (e.g., alcohol and prescription drugs), which impairs my driving ability, may result in DUI charges.

7. Medications or written prescriptions may not be replaced if they are lost, stolen, get wet, are destroyed, left on an airplane, etc. If your medication has been stolen, it will not be replaced unless explicit proof is provided with direct evidence from authorities. A report narrating what you told the authorities is not enough.

8. In the event you are arrested or incarcerated related to legal or illegal drugs (including alcohol), refills on controlled substances will not be given.

9. I understand that failure to adhere to these policies may result in cessation of therapy with controlled substances prescribed by this physician and other physicians at the facility and that law enforcement officials may be contacted.

10. I also understand that the prescribing physician has permission to discuss all diagnostic and treatment details, including medications, with dispensing pharmacists, other professionals who provide your health care, or appropriate drug and law enforcement agencies for the purpose of maintaining accountability.

11. I affirm that I have full right and power to sign and to be bound by this agreement, that I have read it, and understand and accept all of its terms. A copy of this document has been given to me.

\section{Patient's full name}

Patient's signature

Date

Physician's signature

Date

improve compliance (326), while another found that primary-care physicians were more willing to prescribe opioids to patients if the pain medicine physician also signed an agreement ("tri-lateral contract") (327).
Informed consent or agreements also mandate that multiple random evaluations, including pill counts and UDT, must be performed. Furthermore, based on the state regulation, evaluation of prescription drug patterns are monitored by state controlled substance monitoring programs. 


\subsection{Recommendations}

A robust agreement which is followed by all parties is essential in initiating and maintaining opioid therapy, as such agreements reduce overuse, misuse, abuse, and diversion. (Evidence: fair)

\subsection{Initial Treatment}

Initiation of treatment is based on evaluation of stratification of risk, knowledge and understanding of opioids, initiation with low-dose, short-acting, opioid therapy, and titration during an 8 to 12 week period.

\subsection{Stratification of Risk}

Stratification of risk for patients initiated or maintained on chronic opioid therapy is crucial to prevent misuse and abuse. These principles may also be applied for patients who are treated for acute pain management, but also have other risk factors and for whom pain may become chronic. Chronic opioid therapy has been defined as therapy lasting for at least 90 days, on a daily, or on a near daily basis $(50,328)$. Consequently, all guidelines recommend that before initiating chronic opioid therapy for any patient and in high-risk patients for acute pain therapy, a clinician should conduct a history, physical examination, and appropriate testing, including an assessment of risk of substance abuse, misuse, or addiction. Chou et al (50) provided strong recommendation with low-quality evidence. In addition, they also recommended that a benefit to harm evaluation including a history, physical examination, and appropriate diagnostic testing, which should be performed and documented before initiation and on an on-going basis during chronic opioid therapy. Atluri et al (40) describe risk stratification of patients into different categories as the first step. The risk stratification is justified in all patients due to the significant proportion of misuse and abuse, which may range as high as $50 \%(50,150,207-$ 214,329). Chou et al (50) described that risk stratification pertaining to outcomes associated with abuse liability of opioids - misuse, abuse, addiction, and diversion - is a vital but relatively undeveloped skill for many clinicians $(50,330)$.All clinicians prescribing opioids, however, should be knowledgeable about the risk factors for opioid abuse. Moreover, it is also essential to perform an assessment of risks for opioid-associated adverse effects, given their high prevalence $(50,331)$, even though it is difficult to perform, often time consuming, and without any reliable evidence of tools. Atluri et al (40) described the 3 cornerstones for responsible prescribing or stratifying patients by using screening tools into high, medium, and low-risk groups; monitoring patients by using urine drug screening, prescription monitoring programs, and pill counts; and lastly, establishing dose limits.

Atluri et al (40) described that stratification of patients into different risk categories requires the use of existing screening tools designed specifically to screen for opioid misuse (subjective tools like Screener and Opioid Assessment for Patients with Pain (SOAPP) (332), Pain Medication Questionnaire (PMQ) (333), Prescription Drug Use Questionnaire-Patient Version (PDUQp) (334), or objective tools like Addiction Behaviors Checklist $(A B C)$ (214), Diagnosis, Intractability, Risk Efficacy (DIRE) Score (335), and the tool by Atluri and Sudarshan (211) to classify patients as high-risk, medium-risk, and low-risk. They described that objective tools may be better than subjective tools. Solanki et al (77) and Sehgal et al (79) concluded that there was no single screening tool that can be applied universally. Similarly, Chou and Huffman also (51) concluded that most of the studies evaluating the screening tools had methodological flaws. However, some believe that screening tools may play an important role in curbing abuse.

In risk stratification, it is important to utilize multiple models incorporating psychological and behavioral factors to explain the pain experience (336). Positive psychology has highlighted the importance of personal resources in adapting to stressful situations. Thus, resilience has been defined as the ability to adapt to stressful circumstances and has been strongly associated with decreased perceptions of stress (337). Some also have defined resilience as a multidimensional construct composed of a constitutional variable such as temperament and personality accompanied by specific skills (338). Others (339) have observed that resilience can be seen as synonymous with reduced vulnerability (340), with the ability to adapt to adversity (341), or coping $(342,343)$. In general, resilience is associated with less depression and greater wellbeing and mental health $(338,339,344)$. Thus, Ramírez-Maestre et al (336) showed that adjustment to chronic pain is mainly explained by psychological variables such as resilience, pain acceptance, and coping, not the length of time in pain. Resilience prevents patients with chronic spinal pain from suffering emotional distress, because higher levels of resilience are associated with lower levels of depression and anxiety. The study showed that resilience is an important resource for recovery from distress for individuals with chronic spinal pain. Furthermore, the study also concluded positive personality characteristics could play a crucial role in patient adjustment and that clinicians 
should take into account the positive path to improved capacity in order to better understand the chronic pain experience.

Based on the present evidence, regardless of use of screening tools, patients may be classified into 3 categories as follows:

- Low risk - Low risk patients include those with a definable physical pathology; objective signs and reliable symptoms; clinical correlation with diagnostic testing including MRI, physical examination, and interventional diagnostic techniques; with or without mild psychological comorbidities; with or without mild coexisting medical disorders; no or well defined and controlled personal or family history of alcoholism or substance abuse; age of 45 or greater; high levels of pain acceptance and active coping strategies; and well-motivated patients with willingness to participate in multimodal therapy and attempting to function at normal levels.

- Medium risk - Medium risk patients include those with significant pain problems with objective signs and symptoms confirmed by radiological evaluation, physical examination, or diagnostic interventions; with moderate psychological problems, well-controlled by medical therapy; moderate coexisting medical disorders well controlled by medical therapy and which are not affected by chronic opioid therapy such as central sleep apnea; those who develop mild tolerance but not hyperalgesia without physical dependence or addiction; past history of personal or family history of alcoholism or substance abuse; involvement of more than 3 regions of the body; with defined pathology with moderate levels of pain acceptance and coping strategies; and willing to participate in multimodal therapy and attempting to function in their normal daily lives.

- High-risk - High-risk patients include those with widespread pain without objective signs and symptoms (involvement of more than 3 regions of the body); aberrant drug-related behavior; history of misuse, abuse, addiction, diversion, dependency, tolerance and hyperalgesia and alcoholism; with major psychological disorders; age of less than 45; HIV related pain; high levels of pain exacerbation and low levels of coping strategies; unwilling to participate in multimodal therapy; and not functioning close to a near normal lifestyle.

The patients may be stratified into these categories with or without various tools, but with proper history, examination, and monitoring by PDMPs, UDT, and simple psychological evaluation.

\subsection{Understanding Opioids}

Table 5 shows commonly used opioids, and Table 6 shows commonly used benzodiazepines available in the United States with various generic and brand names. As illustrated in these tables, these drugs are available with multiple names. Consequently they may have multiple interactions with drugs $(53,345-364)$. The literature is highly variable on combinations of acetaminophen and the total dose of acetaminophen. However on January 13, 2011, the Food and Drug Administration (FDA) announced that there is no data that indicates that taking more than $325 \mathrm{mg}$ of acetaminophen per dosage unit provides more pain relief (345). Further, the FDA has stated that the maximum daily dose of acetaminophen be less than 4,000 $\mathrm{mg}$ for acute pain and 2,000 mg per day for chronic pain. The present consensus appears to be taking around 2,000 $\mathrm{mg}$ of acetaminophen per day (346-350,360). With recommended low-dose therapy, this should not be an issue unless patients take acetaminophen over the counter. Thus, they should be instructed not to use products with acetaminophen or take additional acetaminophen.Lower doses have been recommended specifically for tramadol and acetaminophen combinations as well as in patients with hepatic abnormalities and alcoholics.

Acetaminophen toxicity causes the majority of cases of acute renal failure in the United States $(346,347)$. Sub-clinical liver toxicity has been shown to occur with doses below 4 grams per day $(347,348)$. Alcohol also competes for the same metabolic pathway as acetaminophen placing heavy drinkers at higher risk for toxicity. Chronic alcohol use is an independent risk factor for mortality in acetaminophen poisoning (349).

\subsection{Dose Limits}

With overwhelming evidence for the misuse, abuse, and limited efficacy of chronic opioid therapy, the rationale for high-dose opioids is being reexamined $(40,49-55,57,98,181,363)$. Generally, it is believed that patients who do not respond to a low or medium-dose of opioids will not respond to larger doses although individual circumstances also exist (40). In 2007, the state of Washington issued interagency guidelines that include the daily dose should not exceed $120 \mathrm{mg}$ of morphine equivalent dose. The guidelines by APS and AAPM in 2009 defined the 
Table 5. Opioids with various generic and brand names available in the United States.

\begin{tabular}{|c|c|}
\hline DRUG (GENERIC NAME) & BRAND NAME(S) \\
\hline \multicolumn{2}{|l|}{ Hydrocodone } \\
\hline Hydrocodone with acetaminophen & 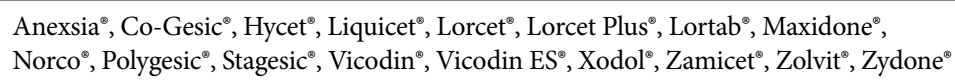 \\
\hline Hydrocodone with ibuprofen & Vicoprofen ${ }^{\star}$, Ibudone ${ }^{\bullet}$ \\
\hline Hydrocodone with aspirin & Lortab ASA \\
\hline \multicolumn{2}{|l|}{ Oxycodone } \\
\hline Oxycodone HCL & OxyContin ${ }^{\circledR}$, Oxy-IR ${ }^{\circledast}$, Roxicodone ${ }^{\circledast}$ \\
\hline Oxycodone HCL with acetaminophen & Endocet $^{\circ}$, Percocet ${ }^{\circ}$, Percocet-Demi ${ }^{\circ}$, Tylox ${ }^{\circ}$, Roxicet ${ }^{\circ}$ \\
\hline Oxycodone HCL/ ASA & Endodan ${ }^{\star}$, Percodan $^{\oplus}$, Percodan-Demi ${ }^{\oplus}$, Roxiprin ${ }^{\oplus}$ \\
\hline Oxycodone HCL with ibuprofen & Combunox $^{\oplus}$ \\
\hline \multicolumn{2}{|l|}{ Morphine } \\
\hline Morphine sulfate & 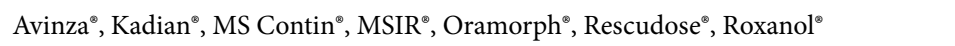 \\
\hline Morphine and Naltrexone & Embeda $^{\oplus}$ \\
\hline Fentanyl (transdermal) & Duragesic ${ }^{\circ}$, Actiq $q^{\circ}$, Fentora TM, Lazanda, Onsolis \\
\hline Methadone HCL & Dolophine $^{\circledR}$, Methadose ${ }^{\circledR}$ \\
\hline Hydromorphone HCL & Dilaudid $^{\circ}$, Exalgo ${ }^{\circ}$, Hydrostat ${ }^{\circ}$, Palladone ${ }^{\circ}$ \\
\hline Oxymorphone & Opana $^{\circ}$, Numorphan ${ }^{\circ}$ \\
\hline \multicolumn{2}{|l|}{ Codeine } \\
\hline Codeine monohydrate/sulphate trihydrate & Codeine \\
\hline Codeine phosphate/acetaminophen/ caffeine & Tylenol $^{\circledR}$ (No. 1, 2, 3) \\
\hline Codeine phosphate/acetaminophen without caffeine & Empracet $^{\oplus}$ \\
\hline Pentazocine HCL & Talwin ${ }^{\star}$, Talxin NX ${ }^{\oplus}$, Talacen ${ }^{\bullet}$ \\
\hline Meperidine & Demerol $^{\circ}$ \\
\hline \multicolumn{2}{|l|}{ Tramadol } \\
\hline Tramadol & Rybix $^{\oplus}$, Ryzolt ${ }^{\bullet}$, Ultram ${ }^{\bullet}$, Ultram ER ${ }^{\odot}$ \\
\hline Tramadol/ Acetaminophen & Ultracet $^{\oplus}$ \\
\hline Dronabinol & Marinol $^{\circledR}$ \\
\hline Buprenorphine & Buprenex ${ }^{\circ}$, Subutex ${ }^{\circ}$, Suboxone ${ }^{\circ}$, Norspan ${ }^{\circ}$ \\
\hline Tapentadol & Nucynta $^{\circledR}$, Nucynta ER ${ }^{\oplus}$ \\
\hline
\end{tabular}

"high doses" to $100 \mathrm{mg}$ morphine equivalent dose (51). The Canadian Guidelines in 2010 identified 200 mg morphine equivalent dose as a watchful dose (54). However, there has been only limited data verifying the safety of these recommended doses, especially in high-risk patients. Franklin et al (181) showed the effectiveness of dose limitation with reduction in dosage, frequency, and death rate. In addition, 5 studies showed that the rate of overdose was directly proportional to the prescribed opioid dose $(87,135,364-366)$.
Bohnert et al (87) in a national sample of Veterans Health Administration patients revealed that there was a dose-response relationship between the maximum daily prescribed dose of opioids and the risk of opioid overdose deaths. The overdose death rate for patients receiving a dose of less than $20 \mathrm{mg}$ morphine equivalent dose was 0.11 per 1,000 compared to those getting more than $100 \mathrm{mg}$ morphine equivalent dose, for whom the death rate was 1.24 . This difference was even higher in those with a history of substance 
Table 6. Benzodiazepines with various generic and brand names available in the United States.

\begin{tabular}{|c|c|}
\hline DRUG (GENERIC NAME) & BRAND NAME (S) \\
\hline Alprazolam & Xanax $^{\bullet}$, Niravam ${ }^{\circ}$ \\
\hline Chlordiazepoxide & Librium $^{\circ}$ \\
\hline Clonazepam & Klonopin ${ }^{\circ}$ \\
\hline Clorazepate & Tranxene $^{\infty}$ \\
\hline Diazepam & Valium ${ }^{\circ}$, Valrelease ${ }^{\bullet}$ \\
\hline Estazolam & ProSom $^{\oplus}$ \\
\hline Flurazepam & Dalmane \\
\hline Lorazepam & Ativan $^{\circ}$ \\
\hline Midazolam & Versed $^{\circ}$ \\
\hline Oxazepam & $\operatorname{Serax}^{\oplus}$ \\
\hline Quazepam & Doral $^{\circ}$ \\
\hline Temazepam & Restoril $^{\circledR}$ \\
\hline Triazolam & Halcion $^{\circ}$ \\
\hline
\end{tabular}

abuse with $0.54 \%$ versus $2.9 \%$. Based on these results, the authors concluded that the risk of opioid overdose increased when the opioid dose was equivalent to 50 mg morphine equivalent dose or higher. Dunn et al (135) in a population from a health maintenance organization (HMO) in Washington State, reported a 9-fold increase in opioid overdoses in patients receiving high dose opioids (> $100 \mathrm{mg}$ morphine equivalent dose) when compared to those getting low dose $(<20$ mg morphine equivalent dose). There was a 3.7-fold increase in overdose events in patients receiving doses between 50 to $99 \mathrm{mg}$ morphine equivalent doses versus those getting less than $20 \mathrm{mg}$ morphine equivalent dose. Paulozzi et al (364) found that compared to patients receiving lower opioid doses or no opioid prescriptions, the risk of overdose was greater if daily opioid doses were above $40 \mathrm{mg}$ morphine equivalent dose. Braden et al (366) found that patients in Arkansas receiving morphine equivalent doses of more than $120 \mathrm{mg}$ per day were more likely to have drug-related encounters than those getting lower doses. Gomes et al (365) found that patients from Ontario's Public Drug Plan receiving very high doses (> $400 \mathrm{mg}$ morphine equivalent dose) and high doses (200 to 400 morphine equivalent dose) had a much higher overdose death rate than those getting moderate doses ( $<200 \mathrm{mg}$ morphine equivalent dose). Moreover, they also showed that in very high and high dose patients the opioid-related mortality rates were 9.94 per 1,000 population for very high and 7.92 for high. However, the opioid-related mortality rate was 1.63 per 1,000 in those with moderate doses. In addition, the overall death rate from any cause was much higher in patients receiving opioids (20.05) when compared to those who were not receiving any opioids (4.0) per 1,000 population. Franklin et al (181) showed that appropriate guidelines with dose limitation considering $120 \mathrm{mg}$ morphine equivalent doses as high dose reduced overall opioids per day by $27 \%$ and long-acting Schedule II opioids by $37 \%$ in the proportion of the workers on doses of greater than $120 \mathrm{mg}$ per day morphine equivalent dosage. Moreover, the number of deaths was reduced by $50 \%$ from 2009 to 2010. Rome et al (363) in a report of outcomes of a chronic non-cancer pain rehabilitation program according to opioid use and status at admission stratified the participants into non-opioid grouping in 221 patients, low-dose (< $41 \mathrm{mg}$ per day) in opioid users in 71 patients, and high-dose ( $>41 \mathrm{mg}$ per day, an average of 137.48 mg per day) in opioid users in 64 patients. The outcomes at discharge showed that patients taking higher doses reported significantly greater catastrophizing and greater pain severity than the non-opioid group. Two other studies conducted in the worker's compensation population also showed similar results $(367,368)$. Adverse events were also reported more commonly at higher daily doses $(369,370)$. Pascual et al $(369)$ showed the increasing frequency of adverse effects of high dose tramadol (over $400 \mathrm{mg}$ ) compared with lower doses, with 2 patients ex- 
periencing seizures. Huse et al (370) in a randomized trial showed that attention deficit was more common during morphine treatment compared to placebo, which was more pronounced when a higher dose was taken. Other studies $(98,296,370-372)$ have shown that there was a dose-dependent relationship between chronic opioid use, specifically with high doses and sleep disorders. Ballantyne and Mao (296) in 2003 indicated that doses higher than $100 \mathrm{mg}$ of morphine equivalent dose per day have not been validated in clinical trials and should be considered excessive.

The above studies illustrate the dose-related effects at $40 \mathrm{mg}$ morphine equivalent dose (364), $50 \mathrm{mg}$ morphine equivalent dose $(87,135), 120 \mathrm{mg}$ morphine equivalent dose (177,366), and $200 \mathrm{mg}$ morphine equivalent dose (365). Thus far, it appears that all the available literature correlates increasing mortality with increasing doses. In addition, several studies have demonstrated that for patients with severe pain on high opioid doses, tapering resulted in reduced pain and improved mood (54,363,373-375).

In 2008, opioid pain relievers were involved in 14,800 drug overdose deaths in the United States compared to 11,500 of 27,500 fatal unintended drug overdose deaths in 2007 - an increase of 3,300 in just one year (34). Consequently, based on statistics, it has been concluded that opioid analgesics contributed to fatalities based on opioid abuse and increases, doctor shopping, and other aspects of drug abuse as illustrated in Figure 3. The Centers for Disease Control and Prevention (CDC) (34) also reported the percentage of prescription drug overdoses by risk group in the United States.

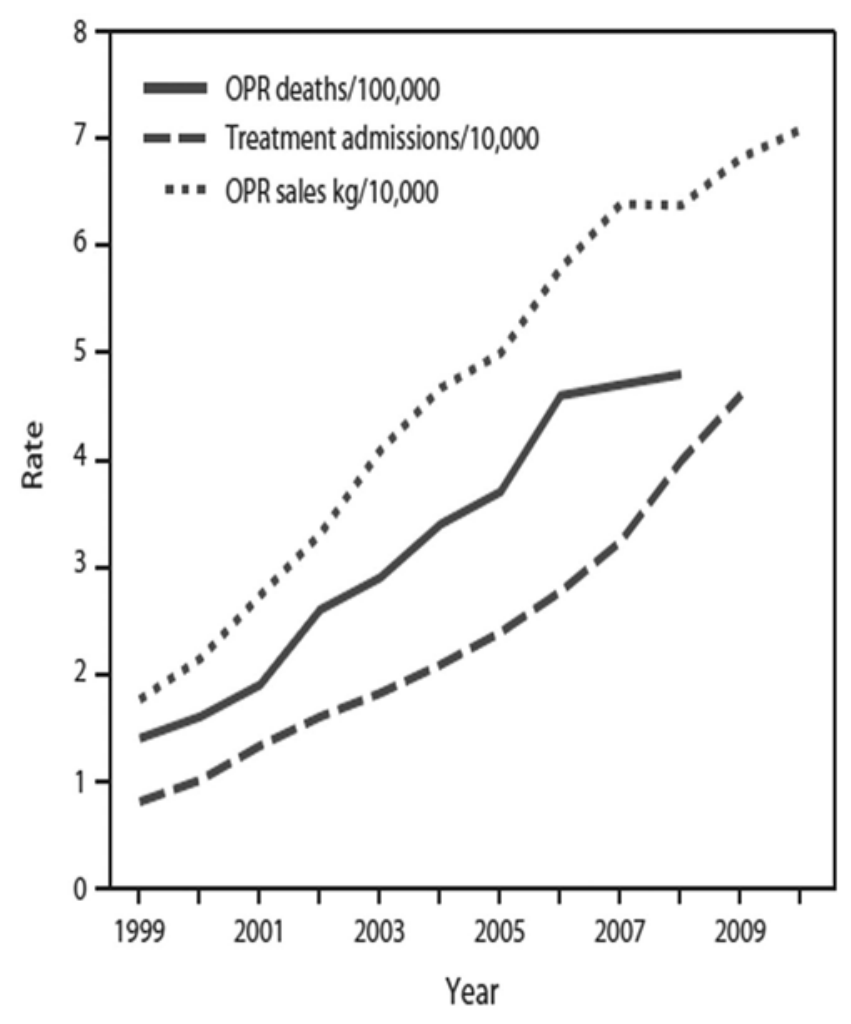

* Age-adjusted rates per 100,000 population for OPR deaths, crude rates per 10,000 population for OPR abuse treatment admissions, and crude rates per 10,000 population for kilograms of OPR sold.

Fig. 3. Rates of opioid pain reliever overdose death, opioid pain relief treatment admissions, and kilograms of opioid pain relievers sold - United States, 1999-2010.

Source: Centers for Disease Control and Prevention. Vital signs: Overdoses of prescription opioid pain relievers - United States, 1999-2008. MMWR Morb Mortal Wkly Rep 2011; 60:1487-1492 (83). 
This concluded that approximately $80 \%$ of prescribed low doses (less than $100 \mathrm{mg}$ morphine equivalent dose per day) were by a single practitioner, accounting for an estimated $20 \%$ of all prescription overdoses (Fig. 4). In contrast, among the remaining $20 \%$ of patients, $10 \%$ were prescribed high doses greater than $100 \mathrm{mg}$ of morphine equivalent dose per day (85-87) of opioids by single prescribers accounting for an estimated $40 \%$ of the prescription opioid overdoses $(87,135)$. The remaining $10 \%$ of patients seeing multiple doctors and typically involved in drug diversion contributed to $40 \%$ of overdoses (376).

Multiple studies in the literature have reported an association between opioid prescribing and overall health status, with increased disability, medical costs, subsequent surgery, and continued or late opioid use $(23,31,33,36,167,293-295,367,368,377-$ 387). Overall, epidemiologic studies are less positive with regards to improvement in function and quality of life with opioids in chronic pain patients $(23,31,33,36,49,55,56,57,133,167,293-295,367,368,377$ 389). In fact, in an epidemiologic study from Denmark by Breivik et al (23) where opioids were prescribed liberally for chronic pain, it was demonstrated that in patients receiving opioids, pain was worse, health care utilization was higher, and activity levels were lower compared to a matched cohort of chronic pain patients not using opioids. Eriksen et al (32) also reported worse pain, higher health care utilization, and lower activity levels in opioid-treated patients compared to matched cohort of chronic pain patients not using opioids. Sjøgren et al (33) in a population based cohort study on chronic pain and the role of opioids, showed that the odds of recovery from chronic pain were almost 4 times higher among individuals not using opioids compared with individuals using opioids. In addition, they also showed that use of strong opioids was associated with poor health-related quality of life and higher risk of death.

Therefore, we have reached a consensus on the following: low-dose is up to $40 \mathrm{mg}$ of morphine equivalent dose, moderate dose is 41 to $90 \mathrm{mg}$ morphine equivalent dose, and high dose is any dose after 91 or higher mg of morphine equivalent dosages. These doses are lower than described by the CDC, which shows $>100 \mathrm{mg}$ as high dose and Washington State guidelines, which show $120 \mathrm{mg}$ as the high dose, but considered reasonable, based on current evidence, and a cautious approach, specifically when a patient is receiving multimodal therapy.

\subsection{Initiation with Low-Dose Opioid Therapy}

A physician should follow the principles of prescribing a low opiate dose as reasonably achievable or ALARA (as low as reasonably achievable) similar to radiation exposure guidelines to provide therapeutic effect without major side effects (390-402).

Low dose therapy may be effective with a reduction in the rate of complications, side effects, and ad-

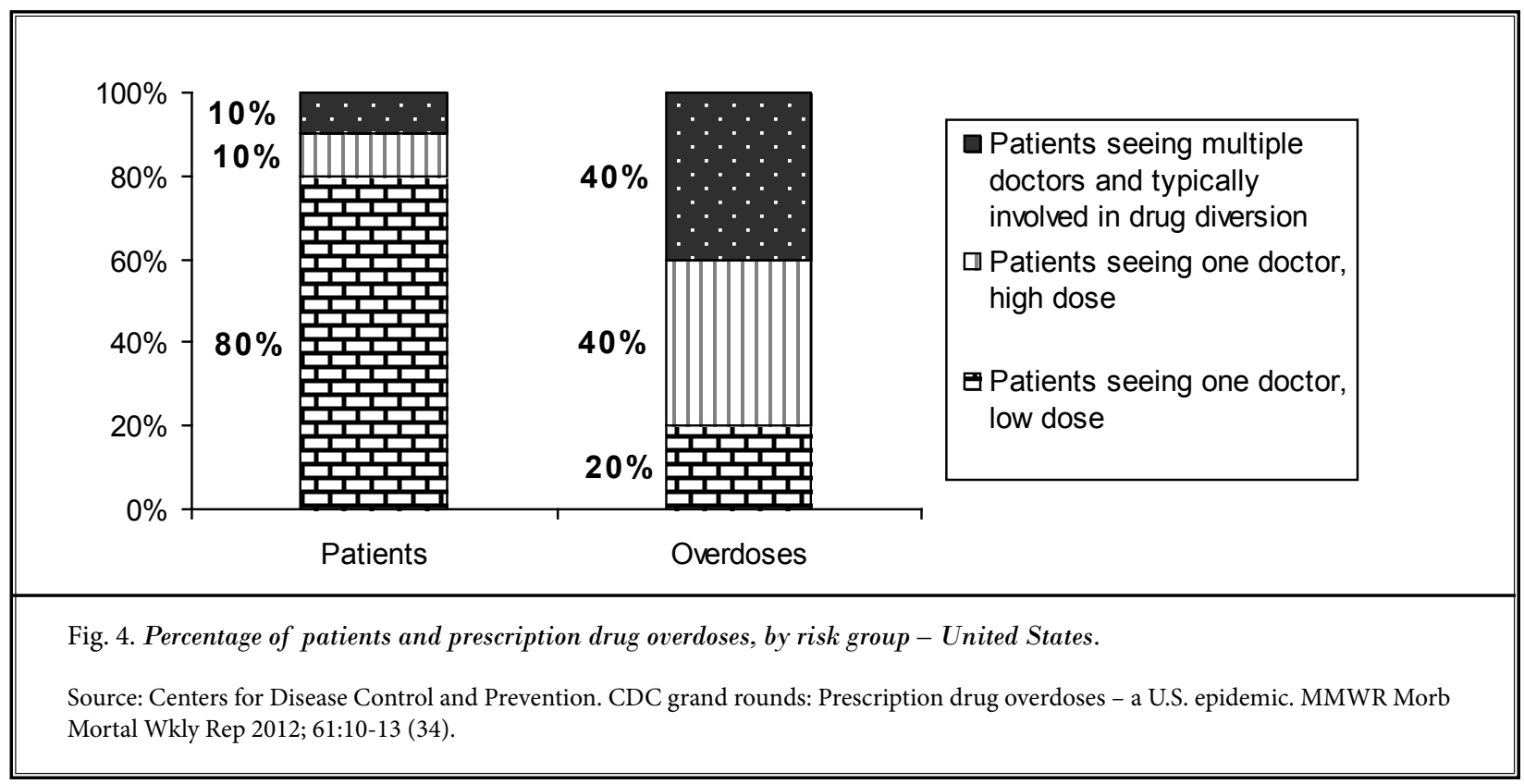


Table 7. Recommended low-dose opioid therapy for select opioids showing starting doses and maintenance doses.

\begin{tabular}{|c|c|c|c|}
\hline Opioid & $\begin{array}{l}\text { Recommended Starting } \\
\text { Dose For Opioid-Naive } \\
\text { Patients } \\
\end{array}$ & $\begin{array}{l}\text { Recommended Starting Dose For } \\
\text { Opioid Exposed Patient's High } \\
\text { Doses Leading To High Risks. }\end{array}$ & $\begin{array}{l}\text { Recommended } \\
\text { Maintenance Dose }\end{array}$ \\
\hline Hydrocodone & 5 to $10 \mathrm{mg}, 2$ to 3 times daily & 5 to $10 \mathrm{mg}, 3$ to 4 times daily & 30 to $40 \mathrm{mg}$ for 24 hours \\
\hline \multicolumn{4}{|l|}{ Morphine } \\
\hline Morphine Immediate Release & Not recommended & $10 \mathrm{mg}, 2$ to 3 times & 30 to $60 \mathrm{mg}$ per day \\
\hline Morphine Sustained Release & Not recommended & 15 to $30 \mathrm{mg}$ twice daily & 60 to $90 \mathrm{mg}$ daily \\
\hline \multicolumn{4}{|l|}{ Oxycodone } \\
\hline Oxycodone & 5 to $10 \mathrm{mg}, 2$ to 3 times daily & 5 to $10 \mathrm{mg}, 3$ to 4 times daily & 30 to $40 \mathrm{mg}$ per day \\
\hline Oxycodone Sustained Release & Not recommended & $10 \mathrm{mg}$ for 12 hours & 30 to $60 \mathrm{mg}$ for 24 hours \\
\hline Methadone & Not recommended & 2 to $5 \mathrm{mg}, 2$ to 3 times daily & 10 to $30 \mathrm{mg}$ per day \\
\hline Transdermal Fentanyl & Not recommended & 12.5 to $25 \mathrm{mcg} \mathrm{q} 72 \mathrm{~h}$ & 25 to $50 \mathrm{mcg}$ per 72 hours \\
\hline \multicolumn{4}{|l|}{ Hydromorphone } \\
\hline Hydromorphone Immediate Release & $2 \mathrm{mg}$ bid or tid & 2 to $4 \mathrm{mg}, 2$ to 3 times daily & 8 to $16 \mathrm{mg}$ per day \\
\hline Hydromorphone Sustained Release & Not recommended & $5 \mathrm{mg}$ to $10 \mathrm{mg}, 2$ times daily & 20 to $40 \mathrm{mg}$ daily \\
\hline Codeine & $15 \mathrm{mg}$ bid or tid & $30 \mathrm{mg}$ bid to qid & 120 to $160 \mathrm{mg}$ daily \\
\hline \multicolumn{4}{|l|}{ Oxymorphone } \\
\hline Oxymorphone Immediate Release & $5 \mathrm{mg}$ bid or tid & 5 to $10 \mathrm{mg} 2$ to 3 times daily & 30 to $40 \mathrm{mg}$ per day \\
\hline Oxymorphone Sustained Release & Not recommended & $10 \mathrm{mg} \mathrm{q} 12 \mathrm{~h}$ & 40 to $60 \mathrm{mg}$ per day \\
\hline \multicolumn{4}{|l|}{ Tramadol } \\
\hline Tramadol & $50 \mathrm{mg}$ bid or tid & $50 \mathrm{mg} 3$ to 4 times daily & 150 to $300 \mathrm{mg}$ per day \\
\hline Tramadol Sustained Release & Not recommended & $200 \mathrm{mg}$ daily & 200 to $350 \mathrm{mg}$ per day \\
\hline
\end{tabular}

verse effects, specifically when opioid therapy is combined with other modalities including interventional techniques. Consideration of higher dosage requires careful reassessment of the pain and risk of misuse, and frequent monitoring with evidence of improved patient outcomes if at all necessary.

Based on the available literature recommended low-dose therapy is shown in Table 7 for chronic noncancer pain along with a description of dosing thresholds for selected opioids $(1,49-55,58)$.

Thus, for mild to moderate pain, first line therapy should start with tramadol, codeine, or hydrocodone. For second line mild to moderate pain therapy, clinicians should start with hydrocodone or oxycodone. For severe pain, first line therapy may start with hydrocodone, oxycodone, hydromorphone, or morphine, with second line therapy leading to fentanyl and if absolutely necessary, the third line therapy for severe pain with methadone or buprenorphine (54). The literature illustrates that codeine and tramadol may have a lower abuse risk than more potent opioids (54,403-405).

Abuse rates measured from Drug Abuse Warning Network Data (DAWN) (405) showed that codeine and other low-potency opioids have low ratios of abuse to prescription use, related to oxycodone, hydromorphone, and hydrocodone. Tramadol also has a low risk of addiction, and experimental studies suggest that it has fewer psychoactive effects than other opioids $(403,404)$. However, neither tramadol nor codeine are readily tolerated by the majority of patients long-term. In chronic pain management settings, the majority of patients have allegedly used these drugs (Tramadol and codeine) and refuse to try them. Oxycodone, hydrocodone, and hydromorphone have been shown to have higher abuse liability than other opioids (54,405-411). Butler et al (407) in a study of the 14 most desirable opioid formulations, found that prescription opioid misusers ranked controlled release oxycodone, immediate release hydromorphone, and oxycodone as the most desirable. Cicero et al (408) in a national surveillance study of addiction experts, law enforcement agencies, and poison control centers, identified hydrocodone and oxycodone (immediate release and controlled) as by far the most commonly abused opioids in the United States.

Morphine can cause toxicity in patients with re- 
nal dysfunction $(54,406)$. It has been shown that M-6 glucuronide, an active metabolite of morphine, accumulates in the serum of patients and causes central nervous system and respiratory depression. The degree of accumulation was related to the morphine dose and the extent of renal impairment (412).

Fentanyl, 80-100 times as potent as morphine can cause significant central nervous system and respiratory depression and also has been shown to contribute to numerous overdose deaths (54,349,413-416). Fentanyl was a contributing cause in 100 overdose deaths in Ontario between 2002 and 2004 with fentanyl intoxication being the sole cause of death in 54 of the patients with therapeutic and illicit use of fentanyl including chewing and ingesting fentanyl patches (414). In addition, fentanyl-laced heroin appeared simultaneously in various parts of the United States, beginning in 2005, with 55 drug overdose cases resulting in 12 deaths in the first half of 2006 (415). Fentanyl toxicity was related to $92 \%$ of the fentanyl-related deaths and is attributed partially due to cytochrome P450 3A4*1B and 3A5*3 variant alleles, resulting in variable fentanyl metabolism. Furthermore, the FDA (417), in July of 2005, issued a public health advisory calling attention to an increase in the number of fentanyl-patch-related overdoses and deaths, particularly among patients ignoring the product's boxed warnings and instructions for use. Another issue has been that up to $10 \%$ of Caucasians lack the enzyme CYP450 2D6 that converts codeine to morphine. Consequently, when switching from codeine to fentanyl, regardless of the codeine dose, caution must be exercised as patients may have little or no opioid tolerance (418-421).

In reference to methadone, even though it has not been shown to be more effective than other opioids, it has been used extensively in the United States and associated with multiple adverse consequences including prolonged QT interval $(50,51,54,60,99,101,102,153,308,313,361,422-427)$. Methadone has been associated with numerous overdose deaths in pain patients with analgesic use increasing sharply in the United States, with a 1,293\% increase from 1997 to 2007 (31). Methadone is also, however, dispensed in methadone clinics with very little regulation and supervision.

Meperidine is not recommended in chronic pain settings due to adverse neurological events resulting in confusion and seizures with long-term treatment secondary to accumulation of toxic metabolite Normeperidine. The adverse events with meperidine are also increased with long-term use, renal insufficiency, and concurrent benzodiazepine use (428).

Long-acting opioids are generally provided in high dose formulations, increasing the risk of abuse and overdose. Furthermore, long-acting opioids can easily be converted to immediate release by crushing or biting the tablet. Thus, OxyContin $80 \mathrm{mg}$ tablet is equivalent to 16 Percocet tablets (54).

\subsection{Titrate}

Opioid medications must be started at low doses and titrated gradually to higher amounts if necessary. All attempts must be made to maintain patients on lower doses, including use of other drugs. Combinations of short- and long-acting, and high doses of long-acting opioids must be prescribed with extreme caution.

\subsection{Recommendations}

1. Once medical necessity is established, opioid therapy may be initiated with low doses and short-acting drugs with appropriate monitoring to provide effective relief and avoid side effects. (Evidence: fair for short-term effectiveness, limited for longterm effectiveness)

2. We are recommending up to $40 \mathrm{mg}$ of morphine equivalent doses as low dose, 41 to $90 \mathrm{mg}$ of morphine equivalent dose as a moderate dose, and greater than $91 \mathrm{mg}$ of morphine equivalence as high doses. (Evidence: fair)

3. In reference to long-acting opioids, titration must be carried out with caution and overdose and misuse must be avoided. (Evidence: good)

4. Methadone is recommended for use in late stages after failure of other opioid therapy and only by clinicians with specific training in the risks and uses. (Evidence: limited)

\subsection{Adherence Monitoring}

The role of adherence monitoring with various tools has been described as part of the initial evaluation. This must be continued through the treatment phase with PDMPs, UDT, pill counts, and behavioral assessment during each visit. Adherence monitoring is dependent on risk stratification. Monitoring based on risk stratification is illustrated in Figure 5 (40).An algorithmic approach to UDT is illustrated in Figure 6. However, regulations with stricter criteria take priority over these algorithmic approaches.

Aberrant drug-related behaviors, include alteration of prescriptions or the route of delivery, doctor shop- 


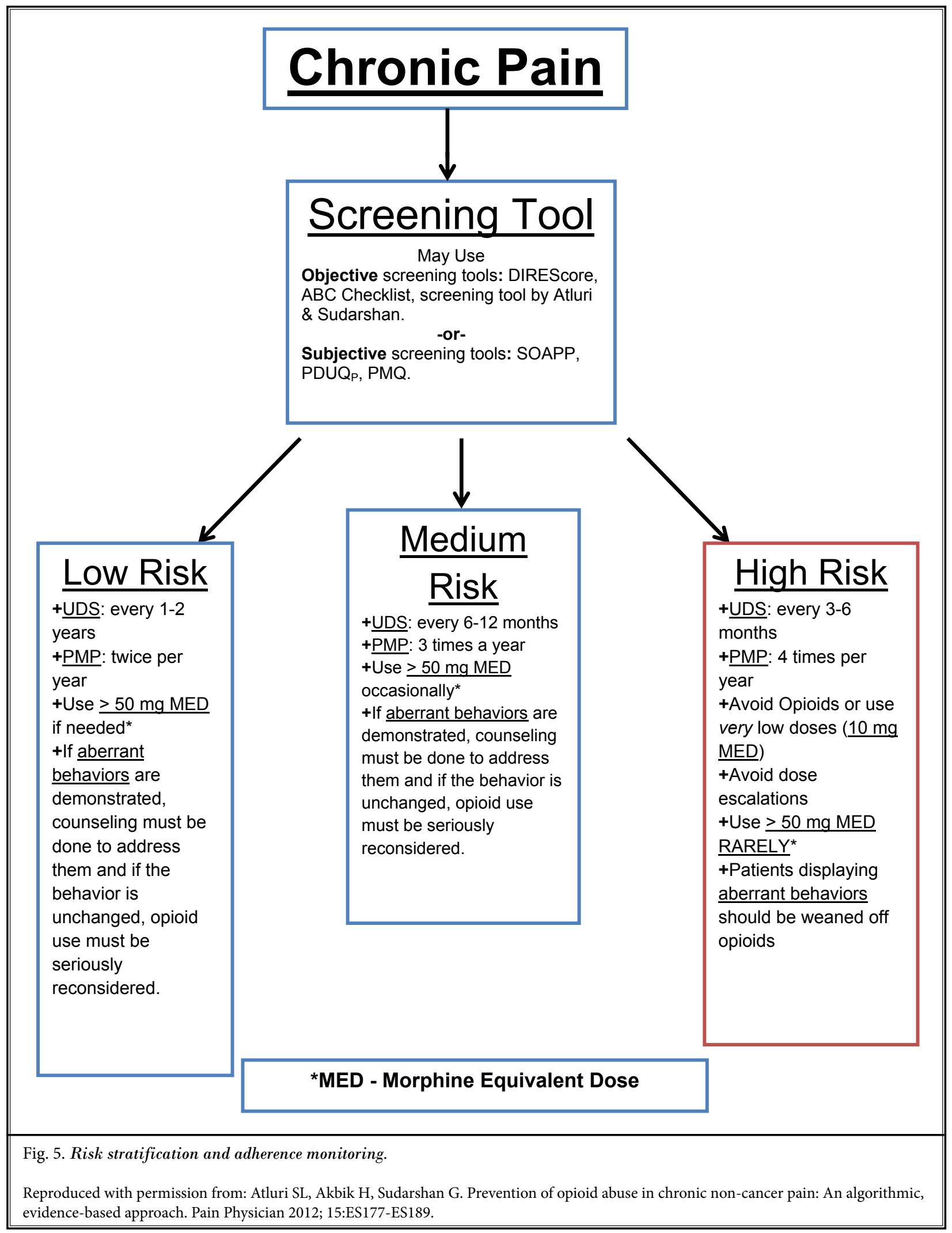


Pain Physician: Opioid Special Issue 2012; 15:S67-S116

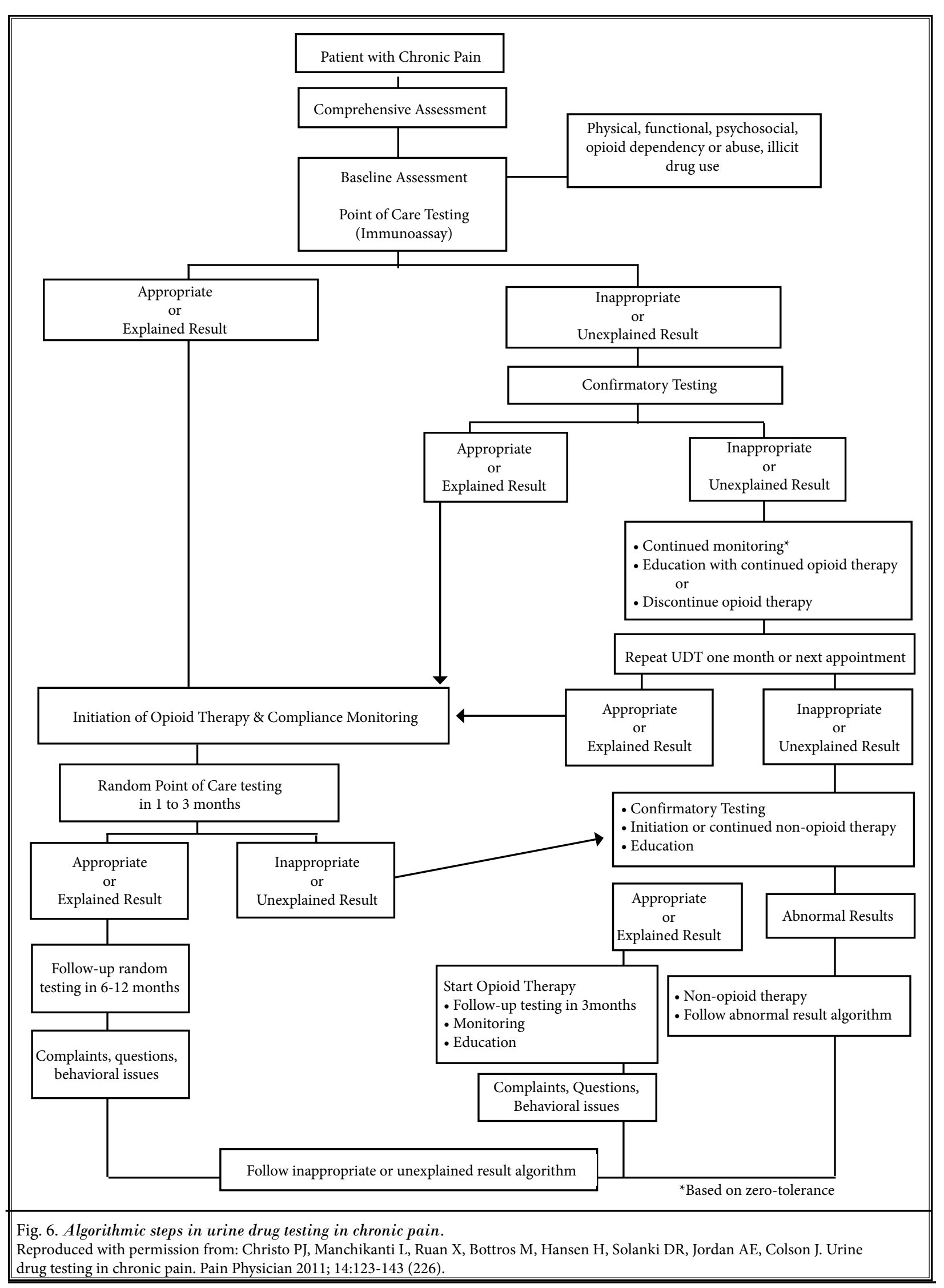


ping or accessing opioids from other sources, multiple unauthorized dose escalations, drug seeking behavior with focus on certain types of opioids and benzodiazepines, loss of prescriptions, requests for early refills, aggressive complaining, staff harassment, complaining about other patients, questioning rights and responsibilities, repeated withdrawal symptoms, exacerbation of underlying mood or anxiety disorders, alcohol use, poor social functioning, loss of job and loss of activities of daily living, emphatic views on opioid medication and illicit drugs as well as legalization of illicit drugs.

\subsection{Recommendations}

1. Monitoring recommendation for methadone prescription is that an electrocardiogram should be obtained prior to initiation, at 30 days and yearly thereafter. (Evidence: fair)

2. In order to reduce prescription drug abuse and doctor shopping, adherence monitoring by UDT and PMDPs provide evidence that is essential to the identification of those patients who are non-compliant or abusing prescription drugs or illicit drugs. (Evidence: fair)

\subsection{Monitoring and Managing Side EFfects}

Multiple side effects, including effect on driving, sedation, constipation, and breathing specifically in patients with respiratory disorders, must be monitored.

Adverse effects have been commonly reported with nausea in $28 \%$, constipation in $26 \%$, somnolence/ drowsiness in $24 \%$, dizziness/vertigo in 18\%, dry-skin/ itching/pruritus in 15\%, and vomiting in $15 \%$ of patients on relatively high-dose opioids. Low-dose opioids, however, have been accompanied by lesser complications (1,54,346-354,403-477). The majority of these adverse effects are resolved with continued treatment and dose adjustments. However, constipation may not be resolved and requires a bowel regimen. Furthermore, with long-term therapy and high doses, other complications may be noted including hypogonadism, neuroendocrine dysfunction, sleep disorders, and hyperalgesia (1,54,403-477). Other effects which are seen in less than $10 \%$ of the population include dry mouth, headache, sexual dysfunction, hot flashes, loss of appetite, abdominal pain, fatigue, sleeplessness/ insomnia, sweating, blurred vision/confusion, muscle contractions, diarrhea, ataxia, edema, difficulty urinating, restless legs, application site reaction, heartburn, anxiety, and weakness (54). The majority of these com- plications do resolve except for sexual dysfunction and fatigue, which increase with long-term treatment with hormonal imbalances. However, the complications are more frequent, longer lasting, and severe in long-term high-dose opioid therapy. Peripheral edema, though observed in a small proportion of patients, could be a major issue. Neuroendocrine abnormalities with erectile dysfunction must be taken into consideration and explained to the patient, with appropriate referral when indicated. Similarly sleep apnea and opioidinduced hyperalgesia (OIH) must be handled appropriately (1).

Neuroendocrine abnormalities and erectile dysfunction can be experienced with long-term opioid therapy in as many as $11 \%$ of the patients $(296,430$ 435). Some outdated reports essentially state that patients taking opioid medications reported better sexual function, which was likely an improvement of well-being (429). Thus, in the short-term, a patient may notice improvement in many aspects including sexual function, but in the long-term, opioids may cause neuroendocrine dysfunction.

Smith and Elliott (478) described that opioid-induced androgen deficiency (OPIAD) is characterized by the presence of inappropriate low levels of gonadotrophin (follicle-stimulating hormone and leuteinizing hormone) leading to the inadequate production of sex hormones, particularly testosterone. Symptoms that may manifest in patients with OPIAD include reduced libido, erectile dysfunction, fatigue, hot flashes, and depression. Physical findings may include reduced facial and body hair, anemia, decreased muscle mass, weight gain, and osteopenia or osteoporosis. While the literature regarding OPIAD remains limited, OPIAD can have a significant negative impact on the quality of life of opioid users. Thus, clinicians should anticipate the potential for its occurrence whenever long-term opioid prescribing is undertaken and develop appropriate management strategies. Once diagnosed, treatment for OPIAD may be offered utilizing a number of androgen replacement therapy options including a variety of testosterone preparations and, for female patients, dehydroepiandrosterone (DHEA) supplementation.

$\mathrm{OIH}$ and the treatment of breakthrough pain in chronic non-cancer pain are controversial issues. OIH is more commonly accepted even though the concept of breakthrough pain continues to be mired in beliefs of pseudoaddiction and undertreatment of pain. The evidence is in contrast to the fact that pain may be essentially overtreated in many countries, specifically 
with opioids, even though overall there may also be an undertreatment of pain in some regions and segments of the population $(75,95)$.

Opioids can aggravate not just central sleep apnea, but frequently may also significantly aggravate obstructive sleep apnea. High opioid doses may contribute to sleep movement disorders including myoclonus and sometimes choreiform movement, and in combination with benzodiazepines and other drugs may significantly contribute to oxygen desaturation (326,437-449). The most serious complications include respiratory depression and death, which may occur when initial doses are too high, opioids are titrated too rapidly, or opioids are combined with other drugs that are associated with respiratory depression or that may potentiate opioid-induced respiratory depression such as benzodiazepines or abuse of opioids with or without other drugs (472-477). Many herbals and over-the-counters, including diphenhydramine preparations can contribute to a dose-dependant respiratory depression. Patients with sleep apnea or with other pulmonary conditions may be at a higher risk for respiratory depression and opioids should be initiated, titrated, and monitored closely with as low a dose as possible. Furthermore, high opioid doses may contribute to sleep movement disorders including sleep apnea.

Part 1 with evidence assessment showed that the evidence is fair for existence of opioid hyperalgesia with chronic opioid therapy $(1,75,95)$. However, debate continues on this aspect. Tompkins and Campbell (454) questioned whether $\mathrm{OIH}$ is clinically relevant or an extraneous research phenomenon, nothing that not all evidence supports the clinical importance of $\mathrm{OIH}$, and that there is some doubt as to whether the phenomenon exists at all. Overall, there is growing evidence to support the presence and consequences of opioid hyperalgesia, along with the benefits of reducing opioid doses or weaning patients off of opioids.

Among the multiple side effects, constipation is one of the most common opioid-related adverse effects (331). Constipation may become a major issue with continued exposure to opioids in a significant proportion of patients. In addition, in older adults or other patients with additional reasons to develop constipation, constipation may be more frequent and also problematic. Consequently, a physician should consider the initiation of a bowel regimen even before the development of constipation and definitely after the development of constipation. Even though the evidence for bowel regimen is anecdotal, regimens, including increased fluid and fiber intake, stool softeners, and laxatives, are often simple and effective. Multiple publications have evaluated opioid antagonists in the prevention or treatment of opioid-induced bowel dysfunction $(479,480)$, but the evidence is insufficient to recommend such antagonists to prevent bowel dysfunction.

During dosage titration in a trial of opioid therapy, advise the patient to avoid driving a motor vehicle or dangerous activities such as use of heavy machinery, until a stable dosage is established, it is certain the opioid does not cause sedation; and when taking opioids with alcohol, benzodiazepines, or other sedating drugs (54). When assessing safety to drive in patients on long-term opioid therapy, consider factors that could impair cognition and psychomotor ability, such as a consistently severe pain rating, disordered sleep, and concomitant medications that increase sedation (54).

Wilhelmi and Cohen (481) in a focused review described a framework for "driving under the influence of drugs" policy for the opioid-using driver. Driving under the influence of drugs is a term used to designate the action of driving an automobile after the consumption of drugs or medications other than alcohol that interfere with the capacity to operate a vehicle safely. Unlike recreational drugs, prescription medications, specifically opioids and benzodiazepines, pose a unique challenge to those attempting to harness their benefits, yet protect the driving public. Wilhelmi and Cohen (481) concluded that a sizable percentage of the driving public has detectable levels of opioids within their bodies. The best available evidence demonstrates psychomotor impairment following acute administration of opioids or an increase in opioid dosage, but impairment diminishes with chronic, stable opioid dosage. Thus, it is essential to take into account the evidence in chronic pain patients when balancing the benefit of pain relief against the need for public roadway protection. Similarly, policy makers also should take into account these issues during drafting driving under the influence of drugs legislation.

\subsection{Recommendations}

1. It is essential to monitor for side effects and manage them appropriately including discontinuation of opioids if indicated. (Evidence: fair)

2. Constipation must be closely monitored and a bowel regimen be initiated as soon as deemed necessary. (Evidence: good)

3. It is recommended that a policy of driving under the influence of drugs be developed and monitored during initiation of therapy, changes in the dosages, and addition of other centrally acting agents. (Evidence: good) 


\subsection{The final Phase}

After initiation of opioid therapy and stable maintenance for 8 to 12 weeks with appropriate outcomes, it is essential to arrive at a conclusion to either continue or to discontinue the opioids.

If the patient continues with persistent pain or there is new pain, a comprehensive evaluation must be repeated or a referral may be made. Similarly, if there is any indication of abuse, misuse, lack of analgesia, lack of activity, adverse effects, or aberrant behavior, the physician must taper the drug therapy and discontinue. Alternate modalities must be pursued at this stage.

Opioid therapy is continued if appropriate analgesia and functional status is achieved either with opioid therapy alone or in conjunction with other modalities. Minimal requirements for continued opioid therapy are analgesia of at least $30 \%$, and/or activity improvement of $30 \%$ without misuse/abuse, or major adverse effects. However, if treatment is successful, one may attempt to wean from opioids if necessary. If necessary to continue, monitoring must be continued and the patient be discharged either with improvement or with any deficiencies.

Patients on high doses, obtaining inadequate analgesia, and with other issues may be converted to sublingual buprenorphine. Daitch et al (482) described conversion of chronic pain patients from full opioid agonists to sublingual buprenorphine. They described the results from clinical records of 100 chronic pain patients with 60 men and 44 women aged 21 to 78 and who had previously been treated with opioid agonist drugs. They were converted to buprenorphine sublingual tablet form during the study. After initiation of buprenorphine sublingual therapy for more than 2 months, the mean pain scores on a scale from 0 to 10 decreased by 3 points. However, patient quality of life was not significantly affected by buprenorphine sublingual therapy. The success rate was highest for patients using morphine, oxycodone, and fentanyl before buprenorphine sublingual induction. These patient groups had a 3.7-point decrease in pain for those taking morphine, a 2.5-point decrease in pain for those taking oxycodone, and a 2.2-point decrease for those taking fentanyl. The smallest pain reduction was seen in the patient groups using oxymorphone. In addition, patients taking between 100 to $199 \mathrm{mg}$ morphine equivalent per day experienced the greatest reduction (2.7 points) in pain scores. Patients taking between 200 to $299 \mathrm{mg}$ of morphine equivalent before buprenorphine sublingual induction exhibited a decrease of over 2 points on average. Patients taking greater than $400 \mathrm{mg}$ morphine equivalent reported the smallest reduction in pain scores, on average a 1.1 point decrease.

In patients with dependency, office-based opioid dependence treatment may be provided. In a narrative review, Colson et al (483) described that office-based opioid dependence treatment is a viable alternative to methadone treatment or rehabilitation programs. However, office-based treatment of opioid dependency requires a special licensure from the DEA. Thus, for physicians providing opioid management of pain, the use of buprenorphine/naloxone is an important tool to consider for opioid dependence issues, which arise in treating chronic pain.

If it is required, tapering or discontinuation of opioid therapy may be considered; however, for a patient who has not been taking medication on a long-term basis, tapering or weaning is not necessary and discontinuation may be carried out. Tapering may be carried out slowly with a decrease by $10 \%$ of the original dose per week. This is generally well tolerated with minimal adverse physiological effects. However, some patients can be tapered or weaned more rapidly without any major problems over a 6 to 8 week period. During this period, if opioid abstinence syndrome is encountered, it is rarely medically serious, even though symptoms may be quite unpleasant. The symptoms of abstinence syndrome, including nausea, diarrhea, muscle pain, and myoclonus, can be managed with clonidine 0.1 to $0.2 \mathrm{mg}$ orally every 6 hours or clonidine transdermal patch $0.1 \mathrm{mg}$ - 24 hours weekly during the taper. Patients should be monitored often for significant hypotension and anticholinergic side effects. While rare, in some patients it may be necessary to slow the tapering and weaning timeline from weekly to monthly dosage adjustments. If the patient is not following the tapering dosages and abusing them, then tapering is going to be unsuccessful and patients must be referred to detoxification facilities or advised to do so.

Symptoms of mild opioid withdrawal occasionally may persist for 6 months after opioids have been discontinued. The physician may also consider using adjuvant agents such as antidepressants to manage irritability and sleep disturbance, or antiepileptics for neuropathic pain. However, physicians should be cautious and preferably not treat withdrawal symptoms with opioids or benzodiazepines once the weaning process or discontinuation of opioids is started. The patient may be referred for counseling or other support during the weaning period if there are significant behavioral issues. If such issues arise, the physician should refer the patient to a chemical dependency center for complicated withdrawal symptoms. 
Physicians not trained in pain management may refer their patients with these issues to pain management specialists or addictionologists.

\subsection{Recommendations}

1. Chronic opioid therapy may be continued, with continuous adherence monitoring, modified at any time during this phase, with fair evidence showing effectiveness of opioids in well-selected populations, in conjunction with or after failure of other modalities of treatments with improvement in physical and functional status and minimal adverse effects. (Evidence: fair)

2. Methadone is recommended for use in late stages after failure of other opioid therapy and only by clinicians with specific training in the risks and uses. (Evidence: limited)

3. A trial of opioid rotation may be considered for patients requiring escalating doses. (Evidence: limited)

4. Chronic opioid therapy should be monitored for adverse effects and to manage them appropriately. (Evidence: good)

\subsection{Documentation}

The physician should keep accurate and complete medical records, which include all aspects of interventional pain management and medical care. These comprise, but are not limited to:

- Medical history and physical examination

- Diagnostic, therapeutic, and laboratory results

- Evaluations and consultations

- Treatment objectives

- Discussion of risks, benefits, and limitations of treatments

- Details of different treatments and medications, including date, type, dosage, and quantity prescribed

- Instructions to the patient

- Periodic reviews of outcomes, including documentation of functional status, preferably using validated tools.

Records should remain current and be maintained in an accessible manner and readily available for review, not only for the physician and other members of the practice, but also for authorities.

To be in compliance with controlled substance laws and regulations required to prescribe, dispense, or administer controlled substances, the physician must have an active license in the state and comply with applicable federal and state regulations. Various licensure boards have published regulations and recommendations for prescribing controlled substances. Physicians are advised to refer to those regulations for their respective state. Physicians should not prescribe scheduled drugs for themselves or immediate family except in emergency situations.

The following criteria should be considered carefully in providing controlled substances:

1. Complete initial evaluation, including history and physical examination

2. Psychological evaluation

3. Physiological and functional assessment, as necessary and feasible

4. Indications and medical necessity

5. The use of the lowest possible dose to provide adequate analgesia with minimum side effects should be the goal of opioid therapy

6. In general, do not combine opioids with sedativehypnotics, benzodiazepines, or barbiturates for chronic, non-cancer pain unless there is a specific medical indication for the combination

7. Adherence to the controlled substance agreement with patients understanding the risks and benefits of controlled substances and the policy and regulations of the practitioner, including controlled substances being prescribed by only one practitioner and being obtained from only one pharmacy

8. Monitoring for drug abuse or diversion should be routine, and if confirmed, referral to rehabilitation centers may be made, with termination of prescriptions of controlled substances.

\subsection{SUMmary}

The evidence synthesis and guidance preparation provides the following recommendations with 10 steps to opioid therapy:

\subsection{Initial Steps of Opioid Therapy}

- Comprehensive assessment and documentation is recommended before initiating opioid therapy, documentation of comprehensive history, general medical condition, psychosocial history, psychiatric status, and substance use history. (Evidence: good)

- Despite limited evidence for reliability and accuracy, screening for opioid use is recommended, as it will identify opioid abusers and reduce opioid abuse. (Evidence: limited)

- Prescription monitoring programs must be implemented due to regulations, AS they provide data on patterns of prescription usage, reduce prescrip- 
tion drug abuse or doctor shopping, and PDMPs may reduce emergency room visits, drug overdoses, or deaths. (Evidence: good to fair)

- $\quad$ UDT must be implemented from initiation along with subsequent adherence monitoring, in an inoffice setting with immunoassay and confirmation for accuracy with chromatography in select cases, to identify patients who are non-compliant or abusing prescription drugs or illicit drugs, and UDT may decrease prescription drug abuse or illicit drug use when patients are in chronic pain management therapy. (Evidence: good)

\subsection{Establish Diagnosis}

- Establish appropriate physical diagnosis and psychological diagnosis if available prior to initiating opioid therapy. (Evidence: good)

- Caution must be exercised in ordering various imaging and other evaluations, and only appropriate information in the realm of clinical relevance shall be provided by the treating physician to the patients when there is correlation of the symptoms with findings, to avoid increased fear, activity restriction, requests for increased opioids, and maladaptive behaviors. (Evidence: good)

- A pain management consultation, for non-pain physicians, if high-dose opioid therapy is being utilized. (Evidence: fair)

\subsection{Establishing Medical Necessity}

It is essential to establish medical necessity prior to initiation or maintenance of opioid therapy. (Evidence: good)

\subsection{Establishing Treatment Goals}

It is essential to establish treatment goals of opioid therapy with regard to pain relief and improvement in function. (Evidence: good)

\subsection{Assessment of Effectiveness of Opioid Therapy}

- Clinicians must understand the effectiveness and adverse consequences of long-term opioid therapy in chronic non-cancer pain and its limitations. (Evidence: fair for short-term, limited for long-term)

- The long-acting opioids in high doses are recommended only in specific circumstances with severe intractable pain that is not amenable to short-acting or moderate doses of long-acting opioids, as there is no significant difference between long-act- ing and short-acting opioids for their effectiveness or adverse effects. (Evidence: fair)

- A trial of opioid rotation may be considered for patients requiring escalating doses. (Evidence: limited)

- It is recommended that contraindications to opioid use in chronic non-cancer pain must be evaluated including respiratory instability, acute psychiatric instability, uncontrolled suicide risk, active or history of alcohol or substance abuse, confirmed allergy to opioid agents, coadministration of drugs capable of inducing life-limiting drug interaction, concomitant use of benzodiazepines, active diversion of controlled substances, and concomitant use of heavy doses of central nervous system depressants, such as benzodiazepines. (Evidence: fair to limited)

\subsection{Informed Decision-Making}

A robust agreement which is followed by all parties is essential in initiating and maintaining opioid therapy as such agreements reduce overuse, misuse, abuse, and diversion. (Evidence: fair)

\subsection{Initial Treatment}

- Once medical necessity is established, opioid therapy may be initiated with low doses and short-acting drugs with appropriate monitoring to provide effective relief and avoid side effects. (Evidence: fair for short-term effectiveness, limited for longterm effectiveness)

- We are recommending up to $40 \mathrm{mg}$ of morphine equivalent doses as low dose, 41 to $90 \mathrm{mg}$ of morphine equivalent dose as a moderate dose, and greater than $91 \mathrm{mg}$ of morphine equivalence as high doses. (Evidence: fair)

- In reference to long-acting opioids, titration must be carried out with caution and overdose and misuse must be avoided. (Evidence: good)

- Methadone is recommended for use in late stages after failure of other opioid therapy and only by clinicians with specific training in the risks and uses. (Evidence: limited)

\subsection{Adherence Monitoring}

- Monitoring recommendation for methadone prescription is that an electrocardiogram should be obtained prior to initiation, at 30 days and yearly thereafter. (Evidence: fair)

- In order to reduce prescription drug abuse and doctor shopping, adherence monitoring by UDT 
and PMDPs provide evidence that is essential to the identification of those patients who are non-compliant or abusing prescription drugs or illicit drugs. (Evidence: fair)

\subsection{Monitoring and Managing Side Effects}

- It is essential to monitor for side effects and manage them appropriately including discontinuation of opioids if indicated. (Evidence: fair)

- Constipation must be closely monitored and a bowel regimen be initiated as soon as deemed necessary. (Evidence: good)

- It is recommended that a policy of driving under the influence of drugs be developed and monitored during initiation of therapy, changes in the dosages, and addition of other centrally acting agents. (Evidence: good)

\subsection{The Final Phase}

- Chronic opioid therapy may be continued, with continuous adherence monitoring, modified at any time during this phase, with fair evidence showing effectiveness of opioids in well-selected populations, in conjunction with or after failure of other modalities of treatments with improvement in physical and functional status and minimal adverse effects. (Evidence: fair)

- Methadone and buprenorphine are recommended for use in late stages after failure of other opioid therapy and only by clinicians with specific training in the risks and uses. (Evidence: limited)

- A trial of opioid rotation may be considered for patients requiring escalating doses. (Evidence: limited)

- Chronic opioid therapy should be monitored for adverse effects and to manage them appropriately. (Evidence: good)

\subsection{CONCLUSION}

These guidelines were developed based on an extensive review of the literature, consensus among the panelists, and practice patterns. There are numerous fatalities with increasing therapeutic use and abuse, this may be related to a lack of understanding and education in the proper application of opioid therapy. Furthermore, the evidence supporting efficacy for use of opioids as a treatment for chronic non-cancer pain is fair for short-term to improve pain and function, whereas it is limited due to lack of literature in reference to longterm efficacy or effectiveness. For practitioners considering opioid use, multiple recommendations for opioid management are summarized. The majority of treatment recommendations are based on evidence consensus and practice patterns, rather than high quality evidence alone. Thus, opioids for chronic non-cancer pain should be reserved for select patients with moderate or severe pain that significantly affects function or quality of life. Appropriate evaluation, documentation, screening, and risk stratification is indicated from initiation through the continuation of opioid therapy.

In conclusion, the focus of these guidelines has been to objectively evaluate the evidence with the application of consensus and practice patterns to curb opioid abuse, misuse, and overuse, and at the same time maintain access to opioids for patients who are in need of them.

\section{Acknowledgments}

The authors wish to thank Sekar Edem for assistance in the search of the literature; Alvaro F. Gómez, MA, and Tom Prigge, MA, for manuscript review; and Tonie $M$. Hatton and Diane E. Neihoff, transcriptionists, for their assistance in preparation of this manuscript. We would like to thank the editorial board of Pain Physician for review and criticism in improving the manuscript.

\section{Disclosures}

Funding: There was no external funding in the preparation of this manuscript. Internal funding provided by the American Society of Interventional Pain Physicians was limited to travel and lodging expenses of the authors.

Editorially, appropriate measures were taken to avoid any conflicting opinions from authors receiving funding from the industry. The panel was multidisciplinary with academicians, practitioners, and geographically diverse. Of the 55 members involved in preparing the guidelines, there were 2 pharmacists, 2 psychologists, 2 registered nurses, one statistician, one physical therapist, 2 research coordinators, one librarian, one academic radiologist, 3 residents or fellows, and the remaining (40) were practicing interventional pain physicians, either in an academic setting or in private practice. Many of the practitioners are also involved in drug detoxification.

Author withdrawals: The first author of the 2008 opioid guidelines, Andrea Trescot, MD, who has not participated initially, has withdrawn her name due to time constraints. A second author, Xiulu Ruan, MD, who participated sporadically, withdrew his name due to time constraints and lack of appropriate involvement.

\section{Conflicts of Interest:}

Ten of the 55 authors provided information that they 
received funding from the industry; however, of these, only 2 (less than 4\%) were receiving funding from drug makers and with multidisciplinary authorships (18\%) receiving funding for research or engaged in speaking from the industry.

Dr. Benyamin is a clinical investigator with Epimed and receives research support from Cephalon/Teva, BioDelivery Sciences International, Inc., Mundipharma Research GmbH \& Co., AstraZeneca, Purdue Pharma, $\mathrm{LP}$, and Theravance.

Dr. Burton is a consultant for Medtronic and Boston Scientific. He serves on the Speaker's Bureau for Johnson \& Johnson, Archimedes, Cephalon, and Jazz.

Dr. Caraway is a consultant for Medtronic, Inc., Spinal Modulation, Inc., and Vertos, Inc.

Dr. Datta receives research support from Sucampo Pharmaceuticals and an honorarium from Smith and Nephew.

Dr. Deer is a consultant and research advisor for Bioness, Medtronic, St. Jude, Spinal Modulation, and Vertos.

Dr. Falco is a Consultant for St. Jude Medical Inc. and Joimax Inc.

Dr. Grider is an educational trainer for Vertos Medical

Dr. Hayek is a consultant for Boston Scientific.

Dr. Helm is a clinical investigator with Epimed and receives research support from Cephalon/Teva, AstraZeneca, and Purdue Pharma, LP.

Dr. Hirsch is a consultant for CareFusion and receives royalties for products related to vertebral augmentation. He also participated in an Aetrium focus group and received compensation.

Dr. A. Kaye is a speaker for Depomed, Inc.

Dr. Silverman is a Speaker for Purdue Pharma and Reckit Benckiser

Dr. Vallejo receives research support from Cephalon/Teva, BioDelivery Sciences International, Inc., Mundipharma Research GmbH \& Co., AstraZeneca, Purdue Pharma, LP, and Theravance.

\section{Author Affiliations}

Note: All authors after the first author are listed in alphabetical order.

1. Laxmaiah Manchikanti, MD is Medical Director of the Pain Management Center of Paducah, Paducah, KY and Clinical Professor, Anesthesiology and Perioperative Medicine, University of Louisville, Louisville, KY drm@asipp.org

2. Salahadin Abdi, MD, PhD is Chief, Division of Pain Medicine at Beth Israel Deaconess Medical Center, Brookline, MA, and Associate Professor of Anesthesiology, Harvard Medical School, Boston, MA. sabdi@bidmc. harvard.edu

3. Sairam Atluri, MD is Medical Director, Tri-State Spine Care Institute, Cincinnati, OH saiatluri@gmail.com

4. Carl C. Balog, MD is an interventional pain physician at Oregon Pain Associates, Portland, OR drcsaba@comcast.net

5. Ramsin M. Benyamin, MD is the Medical Director, Millennium Pain Center, Bloomington, IL, and Clinical Assistant Professor of Surgery, College of Medicine, University of Illinois, Urbana-Champaign, IL ramsinbenyamin@yahoo.com

6. Mark V. Boswell, MD, PhD is Chairman, Department of Anesthesiology and Perioperative Medicine, University of Louisville, Louisville, KY mark.boswell@louisville.edu

7. Keith R. Brown, PharmD is a pharmacist at Murray Calloway County Hospital, Murray, KY krbrownrph@aol. com

8. Brian M. Bruel, MD is Assistant Professor, Departments of Physical Medicine \& Rehabilitation and Anesthesiology \& Pain Management, McDermott Center for Pain Management, UTSW Spine Center, University of Texas Southwestern Medical Center, Dallas, TX bbruel@mdanderson.org

9. David A. Bryce, MD is from Advanced Pain Management, Madison, Wl. tonys09@gmail.com

10. Patricia A. Burks, LPT is a licensed physical therapist at the Pain Management Center of Paducah, Paducah, KY clinicaldirector@thepainmd.com

11. Allen W. Burton, MD is a Professor and Chairman, Department of Pain Medicine, University of Texas MD Anderson Cancer Center, Houston, TX awburton@ houstonpainassociates.com

12. Aaron K. Calodney, MD is a Staff Physician and Director and Research Coordinator Implantable Therapies at NeuroCare Network, Tyler, TX aaroncalodney@ me.com

13. David L. Caraway, MD is with St. Mary's Pain Relief Center, Huntington, WV carawaymd@aol.com

14. Kimberly A. Cash, RT is a Research Coordinator at the Pain Management Center of Paducah, Paducah, KY kcash@thepainmd.com

15. Paul J. Christo, MD is Associate Professor, Johns Hopkins University School of Medicine, Director, Multidisciplinary Pain Fellowship (2003-2011), Director, Blaustein Pain Treatment Center (2003-2008), Division of Pain Medicine, Department of Anesthesiology and Critical Care Medicine, Baltimore, MD. pchristo@jhmi.edu

16. Kim S. Damron, RN is a Nursing Administrator at the Pain Management Center of Paducah, Paducah, KY kim@thepainmd.com 
17. Sukdeb Datta, MD is Medical Director, Laser Spine \& Pain Institute, New York, NY sdattamd@gmail.com

18. Timothy R. Deer, MD is Medical Director, The Center for Pain Relief and Clinical Professor, Anesthesiology, West Virginia University School of Medicine, Charleston, WV doctdeer@aol.com

19. Sudhir Diwan, MD is Executive Director of The Spine and Pain Institute of New York. sudhir.diwan63@ gmail.com

20. Ike Eriator, MD is Associate Professor of Public Health, Jackson State University, Jackson, MS, Director of the Pain Program, University of Mississippi Medical Center, Jackson, MS ikeijen@yahoo.com

21. Frank J.E. Falco, MD is Medical Director of the Mid Atlantic Spine \& Pain Physicians of Newark, DE, Director, Pain Medicine Fellowship, Temple University Hospital, Philadelphia, PA, and Associate Professor, Department of PM\&R, Temple University Medical School, Philadelphia, PA. cssm01@aol.com

22. Bert Fellows, MA is Director Emeritus of Psychological Services at the Pain Management Center of Paducah, Paducah, KY bert@thepainmd.com

23. Stephanie Geffert, MLIS is Director of Research and Education and Administrative Assistant at Mid Atlantic Spine \& Pain Physicians of Newark, DE and Fellowship Coordinator at Temple University Hospital, Philadelphia, PA sgeffert@midatlanticspine.com

24. Christopher G. Gharibo, MD is Medical Director of Pain Medicine and Associate Professor of Anesthesiology and Orthopedics, Department of Anesthesiology, NYU Langone-Hospital for Joint Diseases, NYU School of Medicine, New York, NY. Cgharibo@usa.net

25. Scott E. Glaser, MD is the Medical Director of Pain Specialists of Greater Chicago, Burr Ridge, IL. sglaser@ painchicago.com

26. Jay S. Grider, DO, PhD is Medical Director, UK Healthcare Pain Services, Division Chief, Pain and Regional Anesthesia and Associate Professor, Department of Anesthesiology, University of Kentucky, Lexington, KY jsgrid2@email.uky.edu

27. Haroon Hameed, MD is with the Department of Physical Medicine and Rehabilitation, The Johns Hopkins University School of Medicine, Baltimore, MD. hhameed1@jhmi.edu

28. Mariam Hameed, MD is with the Department of Physical Medicine and Rehabilitation, The Johns Hopkins University School of Medicine, Baltimore, MD mhameed1@jhmi.edu

29. Hans Hansen, MD is the Medical Director of The Pain Relief Centers, Conover, NC. hans@hippocrates.org 30. Michael E. Harned, MD is Assistant Professor, Depart- ment of Anesthesiology, Division of Pain Medicine, University of Kentucky, Lexington, KY. mharned@ me.com

31. Salim M. Hayek, MD, PhD is Associate Professor, Department of Anesthesiology, Chief of the Division of Pain Medicine, University Hospitals of Cleveland, Cleveland, $\mathrm{OH}$; and a member of the Outcomes Research Consortium, Cleveland, OH. Salim.hayek@uhhospitals.org

32. Standiford Helm II, MD is Medical Director, The Helm Center for Pain Management, Laguna Hills, CA. drhelm@thehelmcenter.com

33. Joshua A. Hirsch, MD is Chief of Minimally Invasive Spine Surgery, Depts. of Radiology and Neurosurgery, Massachusetts General Hospital and Associate Professor of Radiology, Harvard Medical School, Boston, MA. hirsch@snisonline.org

34. Jeffrey W. Janata, PhD is Associate Professor of Psychiatry, Director, Behavioral Medicine Program University Hospitals of Cleveland Case Western Reserve University, Cleveland, OH jeffrey.janata@case.edu

35. Adam M. Kaye, PharmD is Clinical Professor, Thomas J. Long School of Pharmacy and Health Sciences, University of the Pacific, Stockton, CA. akaye@pacific.edu

36. Alan D. Kaye, MD, PhD is Chairman and Professor, Dept of Anesthesia LSU Health Science Center, New Orleans, LA alankaye44@hotmail.com

37. David S. Kloth, MD is Medical Director of Connecticut Pain Care, Danbury, CT. dkmd@ctpaincare.com

38. Dhanalakshmi Koyyalagunta, MD is Associate Professor, Medical Director, Pain Management Center University of Texas, MD Anderson Cancer Center, Dept. of Anesthesiology \& Pain Medicine, Houston, TX dkoyyala@mdanderson.org

39. Marion Lee, MD is Director of Centers for Pain Management, Tifton, GA painanswers@aol.com

40. Yogesh Malla, MD is an Interventional Pain Physician at the Pain Management Center of Paducah, Paducah, KY. Yogesh@thepainmd.com

41. Kavita N. Manchikanti, MD is a second year resident in Physical Medicine and Rehabilitation at the University of Kentucky, Lexington, KY kavita.manchikanti@ gmail.com

42. Carla D. McManus, RN, BSN is a Nursing Administrator at the Pain Management Center of Paducah, Paducah, KY carla@thepainmd.com

43. Vidyasagar Pampati, MSc is a Statistician at the Pain Management Center of Paducah, Paducah, KY sagar@thepainmd.com

44. Allan T. Parr, MD is Medical Director, Premier Pain Center, Covington, LA alparr@alparr.com 
45. Ramarao Pasupuleti, MD is Medical Director, Center for Pain Management, Bowling Green, KY rampasupuleti@yahoo.com

46. Vikram Patel, MD is Medical Director of ACMI Pain Care, Algonquin, IL. vikpatel1@yahoo.com

47. Nalini Sehgal, MD is Medical Director, Interventional Pain Program, University of Wisconsin School of Medicine and Public Health and Associate Professor, Department of Orthopedics and Rehabilitation Medicine, Madison, WI. Sehgal@rehab.wisc.edu

48. Sanford M. Silverman, MD is Medical Director of Comprehensive Pain Medicine, Pompano Beach, FL sanfordsilverman@cpmedicine.com

49. Vijay Singh, MD is Medical Director, Spine Pain Diagnostics Associates, Niagara, Wl. vj@wmpnet.net

50. Howard S. Smith, MD is Professor and Academic Director of Pain Management for Albany Medical College
Department of Anesthesiology, Albany, NY

51. Lee T. Snook, MD is Medical Director of Metropolitan Pain Management Consultants, Inc., Sacramento, CA. Isnook@pain-mpmc.com

52. Daneshvari R. Solanki, MD is Professor of Anesthesia and Pain Management, University of Texas Medical Branch, Galveston, TX. dsolanki@utmb.edu

53. Deborah H. Tracy, MD is Medical Director, Institute of Interventional Pain Management, Brooksville, FL. tracypain@tampabay.rr.com

54. Ricardo Vallejo, MD, PhD is Director of Research, Millennium Pain Center, Bloomington, IL; and Adjunct Professor of Biology, Illinois State University, Normal, IL. vallejo1019@yahoo.com

55. Bradley W. Wargo, DO is an interventional pain physician at the McFarland Clinic, Mary Greeley Medical Center, Ames, IA. bwargo@pol.net

\section{References}

1. Manchikanti L, Abdi S, Atluri S, Balog CC, Benyamin RM, Boswell MV, Brown $\mathrm{KR}$, Bruel BM, Bryce DA, Burks PA, Burton AW, Calodney AK, Caraway DL, Cash KA, Christo PJ, Colson J, Damron KS, Datta S, Deer TR, Diwan S, Eriator I, Falco FJE, Fellows B, Geffert S, Gharibo CG, Glaser SE, Grider JS, Hameed $H$, Hameed M, Hansen HC, Harned M, Hayek SM, Helm II S, Hirsch JA, Janata JW, Kaye AM, Kaye AD, Koyyalagunta $D$, Lee M, Manchikanti KN, McManus CD, Pampati V, Parr AT, Pasupuleti R, Patel V, Pope JE, Sehgal N, Silverman SM, Singh V, Smith HS, Solanki DR, Tracy DH, Vallejo R, Wargo BW. American Society of Interventional Pain Physicians (ASIPP) guidelines for responsible opioid prescribing in chronic non-cancer pain: Part 1 - Evidence assessment. Pain Physician 2012; 15:S1-S66.

2. Manchikanti L, Singh V, Datta S, Cohen SP, Hirsch JA. Comprehensive review of epidemiology, scope, and impact of spinal pain. Pain Physician 2009; 12:E35E7o.

3. Gureje O, Von Korff M, Simon GE, Gater R. Persistent pain and well-being: $A$ World Health Organization study in primary care. JAMA 1998; 280:147-151.

4. Institute of Medicine (IOM). Relieving Pain in America: A Blueprint for Transforming Prevention, Care, Education, and Research. The National Academies Press, Washington, DC, 2011.

5. Martin BI, Turner JA, Mirza SK, Lee MJ, Comstock BA, Deyo RA. Trends in health care expenditures, utilization, and health status among US adults with spine problems, 1997-2006. Spine (Phila Pa 1976) 2009: 34:2077-2084.

6. Harkness EF, Macfarlane GJ, Silman AJ, McBeth J. Is musculoskeletal pain more common now than 40 years ago?: Two population-based cross-sectional studies. Rheumatology (Oxford) 2005; 44:890895 .

7. Freburger JK, Holmes GM, Agans RP, Jackman AM, Darter JD, Wallace AS, Castel LD, Kalsbeek WD, Carey TS. The rising prevalence of chronic low back pain. Arch Intern Med 2009; 169:251-258.

8. Hoy DG, Bain C, Williams G, March L, Brooks P, Blyth F, Woolf A, Vos T, Buchbinder R. A systematic review of the global prevalence of low back pain. Arthritis Rheum Jan 9. [Epub ahead of print] (2012).

9. Hoy DG, Protani M, De R, Buchbinder R. The epidemiology of neck pain. Best Pract Res Clin Rheumatol 2010; 24:783792.

10. Reid KJ, Harker J, Bala MM, Truyers C, Kellen E, Bekkering GE, Kleijnen J. Epidemiology of chronic non-cancer pain in Europe: Narrative review of prevalence, pain treatments and pain impact. Curr Med Res Opin 2011; 27:449-462.

11. Bekkering GE, Bala MM, Reid K, Kellen E, Harker J, Riemsma R, Huygen FJ, Kleijnen J. Epidemiology of chronic pain and its treatment in The Netherlands. Neth J Med 2011; 69:141-153.

12. Langley PC. The prevalence, correlates and treatment of pain in the European Union. Curr Med Res Opin 2011; 27:463480.
13. Tosato M, Lukas A, van der Roest HG, Danese P, Antocicco M, Finne-Soveri H, Nikolaus T, Landi F, Bernabei R, Onder G. Association of pain with behavioral and psychiatric symptoms among nursing home residents with cognitive impairment: Results from the SHELTER study. Pain 2012; 153:305-310.

14. Clark JD. Chronic pain prevalence and analgesic prescribing in a general medical population. J Pain Symptom Manage 2002; 23:131-137.

15. Eriksen J. Epidemiology of chronic nonmalignant pain in Denmark. Pain 2003; 106:221-228.

16. Moulin DE, Clark AJ, Speechley M, Morley-Forster PK. Chronic pain in Canada - prevalence, treatment, impact and the role of opioid analgesia. Pain Res Manag 2002; 7:179-184.

17. Sjøgren $P$, Ekholm O, Peuckmann V, Grønbæk M. Epidemiology of chronic pain in Denmark: An update. Eur J Pain 2009; 13:287-292.

18. Elliott AM, Smith BH, Penny KI, Smith WC, Chambers WA. The epidemiology of chronic pain in the community. Lancet 1999; 354:1248-1252.

19. Eriksen J, Ekholm O, Sjøgren P, Rasmussen NK. Development of and recovery from long-term pain. A 6-year follow-up study of a cross-section of the adult Danish population. Pain 2004; 108:154-162.

20. Lawrence RC, Helmick CG, Arnett FC. Estimates of the prevalence of arthritis and selected musculoskeletal disorders in the United States. Arthritis Rheum 
1998; 41:778-799.

21. Verhaak PF, Kerssens JJ, Dekker J, Sorbi MJ, Bensing JM. Prevalence of chronic benign pain disorder among adults: A review of the literature. Pain 1998; 77:231-239.

22. Torrance N, Smith BH, Bennett MI, Lee AJ. The epidemiology of chronic pain of predominantly neuropathic origin. Results from a general population survey. ] Pain 2006; 7:281-289.

23. Breivik H, Collett B, Ventafridda V, Cohen R, Gallacher D. Survey of chronic pain in Europe: Prevalence, impact on daily life, and treatment. Eur J Pain 2006; 10:287-333.

24. Blyth FM, Rochat S, Cumming RG Creasey H, Handelsman DJ, Le Couteur DG, Naganathan V, Sambrook PN, Seibel MJ, Waite LM. Pain, frailty and comorbidity on older men: The CHAMP study. Pain 2008; 140:224-230.

25. Cassidy JD, Carroll LJ, Côté P. The Saskatchewan Health and Back Pain Survey. The prevalence of low back pain and related disability in Saskatchewan adults. Spine (Phila Pa 1976) 1998; 23:1860-1867.

26. Côté P, Cassidy JD, Carroll L. The Saskatchewan Health and Back Pain Survey. The prevalence of neck pain and related disability in Saskatchewan adults. Spine (Phila Pa 1976) 1998; 23:1689-1698.

27. Leboeuf-Yde C, Nielsen J, Kyvik KO, Fejer R, Hartvigsen J. Pain in the lumbar, thoracic or cervical regions: Do age or gender matter? A population-based study of 34,902 Danish twins 20-71 years of age. BMC Musculoskeletal Disorders 2009; 10:39.

28. Côté P, Cassidy JD, Carroll L. The factors associated with neck pain and its related disability in the Saskatchewan population. Spine (Phila Pa 1976) 2000; 25:11091117 .

29. Manchikanti L, Benyamin R, Datta S, Vallejo R, Smith HS. Opioids in chronic noncancer pain. Expert Rev Neurother 2010; 10:775-789.

30. Deyo RA, Smith DH, Johnson ES, Donovan M, Tillotson CJ, Yang X, Petrik AF, Dobscha SK. Opioids for back pain patients: Primary care prescribing patterns and use of services. J Am Board Fam Med 2011; 24:717-727.

31. Manchikanti L, Fellows B, Ailinani H, Pampati V. Therapeutic use, abuse, and nonmedical use of opioids: A ten-year perspective. Pain Physician 2010; 13:401435.

32. Eriksen J, Sjøgren P, Bruera E, Ekholm
O, Rasmussen NK. Critical issues on opioids in chronic non-cancer pain: An epidemiological study. Pain 2006; 125:172-179.

33. Sjøgren P, Grønbæk M, Peuckmann V, Ekholm O. A population-based cohort study on chronic pain: The role of opioids. Clin J Pain 2010; 26:763-769.

34. Centers for Disease Control and Prevention. CDC grand rounds: Prescription drug overdoses - a U.S. epidemic. MMWR Morb Mortal Wkly Rep 2012; 61:10-13.

35. Ballantyne J, LaForge K. Opioid dependence and addiction during opioid treatment of chronic pain. Pain 2007; 129:235-255.

36. US Government Accountability Office: Report to Congressional Requesters. Prescription Pain Reliever Abuse. December 2011. www.gao.gov/assets/590/587301.pdf

37. Toblin RL, Mack KA, Perveen G, Paulozzi LJ. A population-based survey of chronic pain and its treatment with prescription drugs. Pain 2011; 152:1249-1255.

38. Okie S. A flood of opioids, a rising tide of deaths. N Engl J Med 2010; 363:19811985 .

39. Manchikanti L, Helm S, Fellow B, Pampati V, Boswell MV. Epidemic of opioid use in the United States. Pain Physician 2012; 15:ES9-ES38.

40. Atluri SL, Akbik H, Sudarshan G. Prevention of opioid abuse in chronic noncancer pain: An algorithmic, evidencebased approach. Pain Physician 2012; 15:ES177-ES189.

41. United States Department of Justice, Drug Enforcement Administration. Automation of Reports and Consolidated Orders System (ARCOS). Springfield, VA, 2011.

www.deadiversion.usdoj.gov/arcos/index.html

42. Volkow ND, McLellan TA, Cotto JH. Characteristics of opioid prescriptions in 2009. JAMA 2011; 305:1299-1301.

43. Governale L. Outpatient prescription opioid utilization in the U.S., years 2000 - 2009. Drug Utilization Data Analysis Team Leader, Division of Epidemiology, Office of Surveillance and Epidemiology. Presentation for U.S. Food and Drug Administration, July 22, 2010.

44. SDI Vector One ${ }^{\circledR}$ : National.

45. IMS Institute for Healthcare Informatics. The use of medicines in the United States: Review of 2011. April 2012.
www.imshealth.com/ims/Global/Content/Insights/IMS\%2olnstitute\%20 for\%2oHealthcare\%2olnformatics/ IHII_Medicines_in_U.S_Report_2011. pdf

46. Report of the International Narcotics Control Board 2008. New York, United Nations, 2009. www.incb.org/pdf/annual-report/2008/en/AR_08_English.pdf

47. Pizzo PA, Clark NM. Alleviating suffering 101 - pain relief in the United States. N Engl J Med 2012; 366:197-199.

48. A fresh view of opioids. The BackLetter 2011; 26:4, 37.

49. Reinecke $H$, Sorgatz H; German Society for the Study of Pain (DGSS). S3 guideline LONTS. Long-term administration of opioids for non-tumor pain. Schmerz 2009; 23:440-447.

50. Chou R, Fanciullo GJ, Fine PG, Adler JA, Ballantyne JC, Davies P, Donovan MI, Fishbain DA, Foley KM, Fudin J, Gilson AM, Kelter A, Mauskop A, O'Connor PG, Passik SD, Pasternak GW, Portenoy RK, Rich BA, Roberts RG, Todd KH, Miaskowski C; American Pain Society-American Academy of Pain Medicine Opioids Guidelines Panel. Clinical guidelines for the use of chronic opioid therapy in chronic noncancer pain. J Pain 2009; 10:113-130.

51. Chou R, Huffman L. Use of Chronic Opioid Therapy in Chronic Non-cancer Pain: Evidence Review. American Pain Society, Glenview, IL, 2009. www.ampainsoc. org/library/pdf/Opioid_Final_Evidence_ Report.pdf

52. British Pain Society. Opioids for persistent pain: Good practice. A consensus statement prepared on behalf of the British Pain Society, the Royal College of Anaesthetists, the Royal College of General Practitioners and the Faculty of Addictions of the Royal College of Psychiatrists. London, UK, The British Pain Society, January 2010.

53. Agency Medical Directors Group. Interagency Guidelines on Opioid Dosing for Chronic Non-cancer Pain: An educational aid to improve care and safety with opioid therapy. 2010 Update.

www.agencymeddirectors.wa.gov/Files/ OpioidGdline.pdf

54. National Opioids Use Guideline Group (NOUGG). Canadian guidelines for safe and effective use of opioids for chronic non-cancer pain, Recommendations for Practice, Version 5.6. April 30, 2010.

http://nationalpaincentre.mcmaster.ca/ documents/opioid_guideline_part_b_ 
v5_6.pdf

55. Trescot AM, Helm S, Hansen H, Benyamin R, Adlaka R, Patel S, Manchikanti L. Opioids in the management of chronic non-cancer pain: An update of American Society of Interventional Pain Physicians' (ASIPP) guidelines. Pain Physician 2008; 11:S5-S62.

56. Chou R, Huffman LH; American Pain Society; American College of Physicians. Medications for acute and chronic low back pain: A review of the evidence for an American Pain Society/American College of Physicians clinical practice guideline. Ann Intern Med 2007; 147:505514.

57. Sorgatz $\mathrm{H}$, Maier C. Nothing is more damaging to a new truth than an old error: Conformity of new guidelines on opioid administration for chronic pain with the effect prognosis of the DGSS S3 guidelines LONTS (long-term administration of opioids for non-tumor pain). Schmerz 2010; 24:309-312.

58. National Opioids Use Guideline Group (NOUGG). Canadian guidelines for safe and effective use of opioids for chronic non-cancer pain, Executive Summary and Background, Version 4.5. April 30, 2010.

59. Stein C, Reinecke H, Sorgatz H. Opioid use in chronic noncancer pain: Guidelines revisited. Curr Opin Anaesthesiol 2010; 23:598-601.

6o. Chou R, Fanciullo GJ, Fine PG, Miaskowski C, Passik SD, Portenoy RK. Opioids for chronic noncancer pain: Prediction and identification of aberrant drugrelated behaviors: A review of the evidence for an American Pain Society and American Academy of Pain Medicine clinical practice guideline. J Pain 2009; 10:131-146.

61. Boulanger L, Wu N, Chen SY, Nagar S, Fraser K, Bernauer MJ, Zhao Z, Zhao Y. Predictors of pain medication selection among patients diagnosed with fibromyalgia. Pain Pract 2012; 12:266-275.

62. Letter to Janet Woodcock, MD, Director, Center for Drug Evaluation and Research, U.S Food and Drug Administration, from Physicians for Responsible Opioid Prescribing RE Docket No. FDA2011-D-0771, Draft Blueprint for Prescriber Education for Long-Acting/Extended Release Opioid Class-Wide Risk Evaluation and Mitigation Strategies. 2 December, 2011.

63. Manchikanti L, Pampai S, Damron KS, Cash KA, McManus CD, Fellows B. Identification of doctor shoppers with
KASPER: A comparative evaluation over a decade in Western Kentucky. J KY Med Assoc 2012; 110:13-21.

64. Fauber J. UW a force in pain drug growth. JSOnline. April 2, 2011.

65. Fauber J. Academics profit by making the case for opioid painkillers. MedPage Today. April 3, 2011.

66. Dhalla IA, Persaud N, Juurlink DN. Facing up to the prescription opioid crisis. BM] 2011; 343:d5142.

67. Fauber J. Painkiller boom fueled by networking. Journal Sentinel, Feb. 18, 2012. http://m.jsonline.com/more/ news/139609053.htm

68. Martell BA, O'Connor PG, Kerns RD, Becker WC, Morales KH, Kosten TR, Fiellin DA. Systematic review: Opioid treatment for chronic back pain: Prevalence, efficacy, and association with addiction. Ann Intern Med 2007; 146:116127.

69. Zerzan JT, Morden NE, Soumerai $S$, Ross-Degnan D, Roughead E, Zhang F, Simoni-Wastila L, Sullivan SD. Trends and geographic variation of opiate medication use in state Medicaid feefor-service programs, 1996 to 2002. Med Care 2006; 44:1005-1010.

70. Gupta A, Patton C, Diskina D, Cheatle $M$. Retrospective review of physician opioid prescribing practices in patients with aberrant behaviors. Pain Physician 2011; 14:383-389.

71. Dhalla IA, Mamdani MM, Sivilotti ML, Kopp A, Qureshi O, Juurlink DN. Prescribing of opioid analgesics and related mortality before and after the introduction of long-acting oxycodone. CMA] 2009; 181:891-896.

72. Toblin RL, Paulozzi LJ, Logan JE, Hall AJ, Kaplan JA. Mental illness and psychotropic drug use among prescription drug overdose deaths: A medical examiner chart review. J Clin Psychiatry 2010; 71:491-496.

73. Manchikanti L, Ailinani $\mathrm{H}$, Koyyalagunta D, Datta S, Singh V, Eriator I, Sehgal N, Shah RV, Benyamin RM, Vallejo R, Fellows B, Christo PJ. A systematic review of randomized trials of long-term opioid management for chronic non-cancer pain. Pain Physician 2011; 14:91-121.

74. Colson J, Koyyalagunta D, Falco FJE, Manchikanti L. A systematic review of observational studies on the effectiveness of opioid therapy for cancer pain. Pain Physician 2011; 14:E85-E102.

75. Lee M, Silverman SM, Hansen $\mathrm{H}, \mathrm{Pa}$ tel VB, Manchikanti L. A comprehensive review of opioid-induced hyperalgesia. Pain Physician 2011; 14:145-161.

76. Manchikanti L, Vallejo R, Manchikanti KN, Benyamin RM, Datta S, Christo PJ. Effectiveness of long-term opioid therapy for chronic non-cancer pain. Pain Physician 2011; 14:E133-E156.

77. Solanki DR, Koyyalagunta D, Shah RV, Silverman SM, Manchikanti L. Monitoring opioid adherence in chronic pain patients: Assessment of risk of substance misuse. Pain Physician 2011; 14:E119-E131.

78. Koyyalagunta D, Bruera E, Solanki D, Nouri KH, Burton AW, Perez MT, Bruel B, Manchikanti L. A systematic review of randomized trials of the effectiveness of opioids for cancer pain. Pain Physician 2012; 15:ES39-ES58.

79. Sehgal N, Manchikant L, Smith HS. Prescription opioid abuse in chronic pain: A review of opioid abuse predictors and strategies to curb opioid abuse. Pain Physician 2012; 15: ES67-ES92.

8o. Vallejo R, Barkin RL, Wang VC. Pharmacology of opioids in the treatment of chronic pain syndromes. Pain Physician 2011; 14E343-E360.

81. Koyyalagunta D, Burton AW, Toro MP, Driver L, Novy DM. Opioid abuse in cancer pain: Report of two cases and presentation of an algorithm of multidisciplinary care. Pain Physician 2011; 14:E361-E371.

82. Ballantyne JC. Opioid analgesia: Perspectives on right use and utility. Pain Physician 2007; 10:479-491.

83. Centers for Disease Control and Prevention. Vital signs: Overdoses of prescription opioid pain relievers - United States, 1999-2008. MMWR Morb Mortal Wkly Rep 2011; 60:1487-1492.

84. Martin BC, Fan MY, Edlund MJ, Devries A, Braden JB, Sullivan MD. Long-term chronic opioid therapy discontinuation rates from the TROUP study. J Gen Intern Med 2011; 26:1450-1457.

85. Edlund MJ, Martin BC, Fan MY, Braden JB, Devries A, Sullivan MD. An analysis of heavy utilizers of opioids for chronic noncancer pain in the TROUP Study. J Pain Symptom Manage 2010; 40:279-289.

86. Katz N, Panas L, Kim M, Audet AD, Bilansky A, Eadie J, Kreiner P, Paillard FC, Thomas C, Carrow G. Usefulness of prescription monitoring programs for surveillance-analysis of Schedule II opioid prescription data in Massachusetts, 1996-2006. Pharmacoepidemiol Drug Safety 2010; 19:115-123. 
87. Bohnert AS, Valenstein $M$, Bair $M J$, Ganoczy D, McCarthy JF, Ilgen MA, Blow FC. Association between opioid prescribing patterns and opioid overdoserelated deaths. JAMA 2011; 305:1315-1321.

88. Ohio Department of Health. Ohio drug poisoning fact sheet: Epidemic of prescription drug overdoses in Ohio.

www.healthyohioprogram.org/vipp/ drug/dpoison.aspx

89. Lanier WA. Prescription opioid overdose deaths-Utah, 2008-2009. Presented at: 59th Annual Epidemic Intelligence Service Conference. Atlanta, GA, April 19-23, 2010.

90. Furlan AD, Sandoval JA, Mailis-Gagnon A, Tunks E. Opioids for chronic noncancer pain: A meta-analysis of effectiveness and side effects. Can Med Assoc J 2006; 174:1589-1594.

91. Kalso E, Edwards JE, Moore RA, McQuay $\mathrm{HJ}$. Opioids in chronic non-cancer pain: Systematic review of efficacy and safety. Pain 2004; 112:372-380.

92. Warner M, Chen LH, Makuc DM, Anderson RN, Miniño AM. Drug poisoning deaths in the United States, 1980-2008. NCHS data brief, no. 81. National Center for Health Statistics, Hyattsville, MD, 2011.

93. Sullivan MD. Limiting the potential harms of high-dose opioid therapy: Comment on "Opioid dose and drugrelated mortality in patients with nonmalignant pain." Arch Intern Med 2011; 171:691-693.

94. Katz $\mathrm{MH}$. Long-term opioid treatment of nonmalignant pain: A believer loses his faith. Arch Intern Med 2010; 170:14221424 .

95. Manchikanti L, Singh V, Caraway DL, Benyamin RM. Breakthrough pain in chronic non-cancer pain: Fact, fiction, or abuse. Pain Physician 2011; 14:E103E117.

96. Macintyre PE, Loadsman JA, Scott DA. Opioids, ventilation and acute pain management. Anaesth Intensive Care 2011; 39:545-558.

97. Webster LR, Cochella S, Dasgupta N, Fakata KL, Fine PG, Fishman SM, Grey T, Johnson EM, Lee LK, Passik SD, Peppin J, Porucznik CA, Ray A, Schnoll SH, Stieg RL, Wakeland W. An analysis of the root causes for opioid-related overdose deaths in the United States. Pain Med 2011; 12:S26-S35.

98. Walker JM, Farney RJ, Rhondeau SM, Boyle KM, Valentine K, Cloward TV, Shilling KC. Chronic opioid use is a risk fac- tor for the development of central sleep apnea and ataxic breathing. J Clin Sleep Med 2007; 3:455-461.

99. Perrin-Terrin A, Pathak A, Lapeyre-Mestre M. QT interval prolongation: Prevalence, risk factors and pharmacovigilance data among methadone-treated patients in France. Fundam Clin Pharmacol 2011; 25:503-510.

100. Anchersen K, Hansteen V, Gossop M, Clausen T, Waal H. Opioid maintenance patients with QTc prolongation: Congenital long QT syndrome mutation may be a contributing risk factor. Drug Alcohol Depend 2010; 112:216-219.

101. Modesto-Lowe V, Brooks D, Petry N. Methadone deaths: Risk factors in pain and addicted populations. J Gen Intern Med 2010; 25:305-309.

102. Mayet S, Gossop M, Lintzeris N, Markides V, Strang J. Methadone maintenance, QTc and torsade de pointes: Who needs an electrocardiogram and what is the prevalence of QTc prolongation? Drug Alcohol Rev 2011; 30:388-396.

103. Saunders KW, Dunn KM, Merrill JO, Sullivan M, Weisner C, Braden JB, Psaty BM, Von Korff M. Relationship of opioid use and dosage levels to fractures in older chronic pain patients. J Gen Intern Med 2010; 25:310-315.

104. Solomon DH, Rassen JA, Glynn RJ, Lee J, Levin R, Schneeweiss S. The comparative safety of analgesics in older adults with arthritis. Arch Intern Med 2010; 170:1968-1976.

105. Paulozzi LJ, Weisler RH, Patkar AA. A national epidemic of unintentional prescription opioid overdose deaths: How physicians can help control it. J Clin Psychiatry 2011; 72:589-592.

106. Degenhardt L, Hall W. Extent of illicit drug use and dependence, and their contribution to the global burden of disease. Lancet 2012; 379:55-70.

107. National Health Services, The National Treatment Agency for Substance Misuse. Addiction to Medicine. An investigation into the configuration and commissioning of treatment services to support those who develop problems with prescription-only or over-the-counter medicine. May 2011. www.nta.nhs. uk/uploads/addictiontomedicinesmay2011a.pdf

108. Wunsch MJ, Nakamoto K, Behonick G, Massello W. Opioid deaths in rural Virginia: A description of the high prevalence of accidental fatalities involving prescribed medications. Am J Addict
2009; 18:5-14.

109. Unintentional Drug Poisoning in the United States. Centers for Disease Control and Prevention. July 2010.

www.cdc.gov/HomeandRecreationalSafety/pdf/poison-issue-brief.pdf

110. De Maddalena $C D$, Bellini $M$, Berra $M$, Meriggiola C, Aloisi AM. Opioid induced hypogonadism. Why and how to treat it. Pain Physician 2012; 15:ES111ES118.

111. McCarberg BH. Chronic pain: Reducing costs through early implementation of adherence testing and recognition of opioid misuse. Postgrad Med 2011; 123:132-139.

112. Wysowski DK, Schober SE, Wise RP, Kopstein A. Mortality attributed to misuse of psychoactive drugs, 1979-88. Public Health Rep 1993; 108:565-570.

113. Paulozzi LJ, Xi Y. Recent changes in drug poisoning mortality in the United States by urban-rural status and by drug type. Pharmacoepidemiol Drug Saf 2008; 17:997-1005.

114. U.S. General Accounting Office. Prescription Drugs: State Monitoring Programs Provide Useful Tool to Reduce Diversion. Washington, DC, U.S. General Accounting Office, 2002. Report No. GAO-02-634.

115. U.S. Department of Justice Drug Enforcement Administration. Prescription drug monitoring programs. www.deadiversion.usdoj.gov/faq/rx_monitor.htm

116. Federation of State Medical Boards of the US. Model guidelines for the use of controlled substances for the treatment of pain: A policy document of the Federation of State Medical Boards of the United States, Inc. Dallas, TX, 1998.

117. Phillips DM. JCAHO pain management standards are unveiled. Joint Commission on Accreditation of Healthcare Organizations. JAMA 2000; 284:428-429.

118. Brennan F, Carr DB, Cousins M. Pain management: A fundamental human right. Anesth Analg 2007; 105:205-221.

119. Frasco PE, Sprung J, Trentman TL. The impact of the Joint Commission for Accreditation of Healthcare Organizations pain initiative on perioperative opiate consumption and recovery room length of stay. Anesth Analg 2005; 100:162-168.

120. Cohen MZ, Easley MK, Ellis C, Hughes B, Ownby K, Rashad BG, Rude M, Taft E, Westbrooks JB. JCAHO cancer pain management and the JCAHO's pain standards: An institutional challenge. J 
Pain Symptom Manage 2003; 25:519-527.

121. Mularski RA, White-Chu F, Overbay D, Miller L, Asch SM, Ganzini L. Measuring pain as the 5 th vital sign does not improve quality of pain management. J Gen Intern Med 2006; 21:607-612.

122. Nickerson JW, Attaran A. The inadequate treatment of pain: Collateral damage from the war on drugs. PLoS Med 2012; 9:e1001153.

123. Gilson AM, Maurer MA, Joranson DE. State medical board members' beliefs about pain, addiction, and diversion and abuse: $A$ changing regulatory environment. J Pain 2007; 8:682-691.

124. Lipman AG. Pain as a human right: The 2004 Global Day Against Pain. J Pain Palliat Care Pharmacother 2005; 19:85100.

125. Lohman D, Schleifer R, Amon JJ. Access to pain treatment as a human right. BMC Med 2010; 8:8.

126. Inadequate pain treatment is a public health crisis. Drug war shouldn't claim new victims. StarTribune, April 21, 2011. www.startribune.com/opinion/editorials/120420264.html

127. Becker WC, Fiellin DA, Gallagher RM, Barth KS, Ross JT, Oslin DW. The association between chronic pain and prescription drug abuse in veterans. Pain Med 2009; 10:531-536.

128. War on Drugs. Report of the Global Commission on Drug Policy. June 2011. www.globalcommissionondrugs.org/reports/

129. Gómez-Batiste X, Porta-Sales J, Pascual A, Nabal M, Espinosa J, Paz S, Minguell C, Rodríguez D, Esperalba J, Stjernswärd J, Geli M; Palliative Care Advisory Committee of the Standing Advisory Committee for Socio-Health Affairs, Department of Health, Government of Catalonia. Catalonia WHO palliative care demonstration project at 15 Years (2005). J Pain Symptom Manage 2007; 33:584-590.

130. Dasgupta N, Mandl K, Brownstein J. Breaking the news or fueling the epidemic? Temporal association between news media report volume and opioid-related mortality. PLOS ONE 2009; 4:e7758.

131. Painful drug war victory. The Washington Times. August 16, 2007. www.washingtontimes.com/news/2007/aug/16/painful-drug-war-victory/?page=all

132. Noble M, Tregear SJ, Treadwell JR, Schoelles K. Long-term opioid therapy for chronic noncancer pain: A system- atic review and meta-analysis of efficacy and safety. J Pain Symptom Manage 2008; 35:214-228.

133. Substance Abuse and Mental Health Services Administration. Results from the 2010 National Survey on Drug Use and Health: Summary of National Findings. NSDUH Series H-41, HHS Publication No. (SMA) 11-4658. Substance Abuse and Mental Health Services Administration, Rockville, MD, 2011.

w w w. s a m h s a.gov/dat a / NSDUH/2kıoNSDUH/2kıoResults.pdf

134. Becker WC, Tobin DG, Fiellin DA. Nonmedical use of opioid analgesics obtained directly from physicians: Prevalence and correlates. Arch Intern Med 2011; 171:1034-1036.

135. Dunn KM, Saunders KW, Rutter CM, Banta-Green CJ, Merrill JO, Sullivan MD, Weisner CM, Silverberg MJ, Campbell Cl, Psaty BM, Von Korff M. Overdose and prescribed opioids: Associations among chronic non-cancer pain patients. Ann Intern Med 2010; 152:85-92.

136. Fishbain DA, Cole B, Lewis J, Rosomoff $\mathrm{HL}$, Rosomoff RS. What percentage of chronic nonmalignant pain patients exposed to chronic opioid analgesic therapy develop abuse/addiction and/or aberrant drug-related behaviors? A structured evidence-based review. Pain Med 2008; 9:444-459.

137. Fleming MF, Balousek SL, Klessig CL, Mundt MP, Brown DD. Substance use disorders in a primary care sample receiving daily opioid therapy. J Pain 2007; 8:573-582.

138. Sullivan MD, Edlund MJ, Fan MY, Devries A, Brennan Braden J, Martin BC. Risks for possible and probable opioid misuse among recipients of chronic opioid therapy in commercial and medicaid insurance plans: The TROUP Study. Pain 2010; 150:332-339.

139. Inciardi JA, Surratt HL, Cicero TJ, Beard RA. Prescription opioid abuse and diversion in an urban community: The results of an ultrarapid assessment. Pain Med 2009; 10:537-548.

140. United Kingdom. Department of Health. Prescription drug addiction addressed. May 11, 2011. www.dh.gov.uk/en/MediaCentre/Pressreleases/DH_126674

141. Ruetsch C. Empirical view of opioid dependence. J Manag Care Pharm 2010; 16:S9-S13.

142. Butler SF, Black RA, Serrano JM, Wood ME, Budman SH. Characteristics of prescription opioid abusers in treatment:
Prescription opioid use history, age, use patterns, and functional severity. J Opioid Manag 2010; 6:239-241, 246-252.

143. Ling W, Mooney L, Hillhouse M. Prescription opioid abuse, pain and addiction: Clinical issues and implications. Drug Alcohol Rev 2011; 30:300-305.

144. Medicare prescription drug abuse a problem: GAO. Washington, October 4, 2011.

www.reuters.com/article/2011/10/04/ u s - m ed i c a re - fra u d - id U S TRE7935LD20111004

145. Brown J, Setnik B, Lee K, Wase L, Roland CL, Cleveland JM, Siegel S, Katz N. Assessment, stratification, and monitoring of the risk for prescription opioid misuse and abuse in the primary care setting. J Opioid Manag 2011; 7:467-483.

146. Macey TA, Morasco BJ, Duckart JP, Dobscha SK. Patterns and correlates of prescription opioid use in OEF/OIF veterans with chronic noncancer pain. Pain Med 2011; 12:1502-1509.

147. Weisner CM, Campbell Cl, Ray GT, Saunders K, Merrill JO, Banta-Green C, Sullivan MD, Silverberg MJ, Mertens $J R$, Boudreau D, Von Korff M. Trends in prescribed opioid therapy for non-cancer pain for individuals with prior substance use disorders. Pain 2009; 145:287293.

148. Campbell Cl, Weisner C, Leresche L, Ray GT, Saunders K, Sullivan MD, Banta-Green CJ, Merrill JO, Silverberg MJ, Boudreau D, Satre DD, Von Korff M. Age and gender trends in long-term opioid analgesic use for noncancer pain. Am J Public Health 2010; 100:2541-2547.

149. Pesce A, Rosenthal M, West R, West C, Crews B, Mikel C, Almazan P, Latyshev $S$. An evaluation of the diagnostic accuracy of liquid chromatography-tandem mass spectrometry versus immunoassay drug testing in pain patients. Pain Physician 2010; 13:273-281.

150. Manchikanti L, Malla Y, Wargo BW, Cash KA, Pampati V, Damron KS, McManus $\mathrm{CD}$, Brandon DE. Protocol for accuracy of point of care $(P O C)$ or in-office urine drug testing (immunoassay) in chronic pain patients: A prospective analysis of immunoassay and liquid chromatography tandem mass spectometry (LC/MS/ MS). Pain Physician 2010; 13:E1-E22.

151. McCarberg BH. A critical assessment of opioid treatment adherence using urine drug testing in chronic pain management. Postgrad Med 2011; 123:124-131.

152. Manchikanti L, Pampati V, Damron KS, 
Beyer CD, Barnhill RC, Fellows B. Prevalence of prescription drug abuse and dependency in patients with chronic pain in western Kentucky. J KY Med Assoc 2003; 101:511-517.

153. Manchikanti L, Manchukonda R, Pampati V, Damron KS. Evaluation of abuse of prescription and illicit drugs in chronic pain patients receiving shortacting (hydrocodone) or long-acting (methadone) opioids. Pain Physician 2005; 8:257-261.

154. Manchikanti L, Cash KA, Damron KS, Manchukonda R, Pampati V, McManus CD. Controlled substance abuse and illicit drug use in chronic pain patients: An evaluation of multiple variables. Pain Physician 2006; 9:215-226.

155. Ives TJ, Chelminski PR, Hammett-Stabler CA, Malone RM, Perhac JS, Potisek NM, Shilliday BB, DeWalt DA, Pignone MP. Predictors of opioid misuse in patients with chronic pain: A prospective cohort study. BMC Health Serv Res 2006; 6:46.

156. Manchikanti L, Pampati V, Damron KS, McManus CD. Evaluation of variables in illicit drug use: Does a controlled substance abuse screening tool identify illicit drug use? Pain Physician 2004; 7:7175.

157. Manchikanti L, Manchukonda R, Damron KS, Brandon D, McManus CD, Cash $\mathrm{KA}$. Does adherence monitoring reduce controlled substance abuse in chronic pain patients? Pain Physician 2006; 9:5760.

158. Couto JE, Romney MC, Leider HL, Sharma S, Goldfarb NI. High rates of inappropriate drug use in the chronic pain population. Popul Health Manage 2009; 12:185-190.

159. Manchikanti L, Damron KS, McManus CD, Barnhill RC. Patterns of illicit drug use and opioid abuse in patients with chronic pain at initial evaluation: A prospective, observational study. Pain Physician 2004; 7:431-437.

160. Manchikanti L, Damron KS, Pampati V, McManus CD. Prevalence of illicit drug use among individuals with chronic pain in the Commonwealth of Kentucky: An evaluation of patterns and trends. J Ky Med Assoc 2005; 103:55-62.

161. Vaglienti RM, Huber SJ, Noel KR, Johnstone RE. Misuse of prescribed controlled substances defined by urinalysis. WV Med J 2003; 99:67-70.

162. Michna E, Jamison RN, Pham LD, Ross EL, Janfaza D, Nedeljkovic SS, Narang S
Palombi D, Wasan AD. Urine toxicology screening among chronic pain patients on opioid therapy: Frequency and predictability of abnormal findings. Clin J Pain 2007; 23:173-179.

163. Manchikanti L, Manchukonda R, Pampati V, Damron KS, Brandon DE, Cash KA, McManus CD. Does random urine drug testing reduce illicit drug use in chronic pain patients receiving opioids? Pain Physician 2006; 9:123-129.

164. Katz NP, Sherburne S, Beach M, Rose RJ, Vielguth J, Bradley J, Fanciullo GJ. Behavioral monitoring and urine toxicology testing in patients receiving longterm opioid therapy. Anesth Analg 2003; 97:1097-1102.

165. Manchikanti L, Giordano J, Boswell MV, Fellows B, Manchukonda R, Pampati V. Psychological factors as predictors of opioid abuse and illicit drug use in chronic pain patients. J Opioid Manage 2007; 3:89-100.

166. Cone EJ, Caplan YH, Black DL, Robert T, Moser F. Urine drug testing of chronic pain patients: Licit and illicit drug patterns. J Anal Toxicol 2008; 32:530-543.

167. Manchikanti L, Damron KS, Beyer CD, Pampati V. A comparative evaluation of illicit drug use in patients with or without controlled substance abuse in interventional pain management. Pain Physician 2003; 6:281-285.

168. Manchikanti L, Pampati V, Damron KS, Beyer CD, Barnhill RC. Prevalence of illicit drug use in patients without controlled substance abuse in interventional pain management. Pain Physician 2003; 6:173-178.

169. Chelminski PR, Ives TJ, Felix KM, Prakken SD, Miller TM, Perhac JS, Malone RM, Bryant ME, DeWalt DA, Pignone MP. A primary care, multi-disciplinary disease management program for opioid-treated patients with chronic noncancer pain and a high burden of psychiatric comorbidity. BMC Health Serv Res 2005; 5:3.

170. Manchikanti L, Damron KS, Pampati V, McManus CD, Weaver SE. Prospective evaluation of patients with increasing opiate needs: Prescription opiate abuse and illicit drug use. Pain Physician 2004; 7:339-344.

171. Gilbert JW, Wheeler GR, Mick GE, Storey $B B$, Herder SL, Richardson GB, Watts E, Gyarteng-Dakwa K, Marino BS, Kenney CM, Siddiqi M, Broughton PG. Importance of urine drug testing in the treatment of chronic noncancer pain:
Implications of recent Medicare policy changes in Kentucky. Pain Physician 2010; 13:167-186.

172. Manchikanti L, Malla Y, Wargo BW, Fellows B. Comparative evaluation of the accuracy of immunoassay with liquid chromatography tandem mass spectrometry (LC/MS/MS) of urine drug testing (UDT) opioids and illicit drugs in chronic pain patients. Pain Physician 2011; 14:175-187.

173. Manchikanti L, Malla Y, Wargo BW, Fellows B. Comparative evaluation of the accuracy of benzodiazepine testing in chronic pain patients utilizing immunoassay with liquid chromatography tandem mass spectrometry (LC/MS/MS) of urine drug testing. Pain Physician 2011; 14:259-270.

174. Pesce A, West C, West R, Crews B, Mikel C, Almazan P, Latyshev S, Rosenthal M, Horn P. Reference intervals: A novel approach to detect drug abuse in a pain patient population. J Opioid Manage 2010; 6:341-350.

175. Gilbert JW, Wheeler GR, Mick GE, Storey BB, Herder SL, Richardson GB, Watts E, Gyarteng-Dakwa K, Marino BS, Kenney CM, Siddiqi M, Broughton PG. Urine drug testing in the treatment of chronic noncancer pain in a Kentucky private neuroscience practice: The potential effect of Medicare benefit changes in Kentucky. Pain Physician 2010; 13:187-194.

176. Tormoehlen LM, Mowry JB, Bodle JD, Rusyniak DE. Increased adolescent opioid use and complications reported to a poison control center following the 2000 JCAHO pain initiative. Clin Toxicol (Phila) 2011; 49:492-498.

177. Hughes MA, Biggs JJ, Thiese MS, Graziano K, Robbins RB, Effiong AC. Recommended opioid prescribing practices for use in chronic non-malignant pain: A systematic review of treatment guidelines. J Manage Care Med 2011; 14:52-58.

178. Department of Veterans Affairs, Department of Defense. Va/DoD Clinical Practice Guideline for Management of Opioid Therapy for Chronic Pain, 2010. www.healthquality.va.gov/index.asp

179. American College of Occupational and Environmental Medicine (ACOEM) Chronic Pain. In: Occupational Medicine Practice Guidelines: Evaluation and Management of Common Health Problems and Functional Recovery of Workers. Second Edition. American College of Occupational and Environmental Medicine Press, Elk Grove Village, 2008. 
180. American Society of Anesthesiologists Task Force on Chronic Pain Management, American Society of Regional Anesthesia and Pain Medicine. Practice guidelines for chronic pain management: An updated report by the American Society of Anesthesiologists Task Force on Chronic Pain Management and the American Society of Regional Anesthesia and Pain Medicine. Anesthesiology 2010; 112:810-833.

181. Franklin GM, Mai J, Turner J, Sullivan M, Wickizer T, Fulton-Kehoe D. Bending the prescription opioid dosing and mortality curves: Impact of the Washington State opioid dosing guideline. Am J Ind Med 2012; 55:325-331.

182. Manchikanti L, Manchikanti KN, Pampati V, Cash KA. Prevalence of side effects of prolonged low or moderate dose opioid therapy with concomitant benzodiazepine and/or antidepressant therapy in chronic non-cancer pain. Pain Physician 2009; 12:259-267.

183. Manchikanti L, Boswell MV, Singh V, Benyamin RM, Fellows B, Abdi S, Buenaventura RM, Conn A, Datta S, Derby R, Falco FJE, Erhart S, Diwan S, Hayek SM, Helm S, Parr AT, Schultz DM, Smith HS, Wolfer LR, Hirsch JA. Comprehensive evidence-based guidelines for interventional techniques in the management of chronic spinal pain. Pain Physician 2009; 12:699-802.

184. Manchikanti L, Buenaventura RM, Manchikanti KN, Ruan X, Gupta S, Smith HS, Christo PJ, Ward SP. Effectiveness of therapeutic lumbar transforaminal epidural steroid injections in managing lumbar spinal pain. Pain Physician 2012; 15:E199-E245.

185. Manchikanti L, Singh V, Falco FJE, Cash KA, Pampati V. Evaluation of lumbar facet joint nerve blocks in managing chronic low back pain: A randomized, doubleblind, controlled trial with a 2-year follow-up. Int J Med Sci 2010; 7:124-135.

186. Manchikanti L, Singh V, Falco FJE, Cash KA, Fellows B. Comparative outcomes of a 2-year follow-up of cervical medial branch blocks in management of chronic neck pain: A randomized, double-blind controlled trial. Pain Physician 2010; 13:437-450.

187. Manchikanti L, Singh V, Falco FJE, Cash KA, Pampati V, Fellows B. Comparative effectiveness of a one-year follow-up of thoracic medial branch blocks in management of chronic thoracic pain: A randomized, double-blind active controlled trial. Pain Physician 2010; 13:535-548.
188. Manchikanti L, Cash KA, McManus CD, Pampati V, Smith HS. One year results of a randomized, double-blind, active controlled trial of fluoroscopic caudal epidural injections with or without steroids in managing chronic discogenic low back pain without disc herniation or radiculitis. Pain Physician 2011; 14:25-36.

189. Manchikanti L, Singh V, Cash KA, Pampati $\mathrm{V}$, Damron KS, Boswell MV. A randomized, controlled, double-blind trial of fluoroscopic caudal epidural injections in the treatment of lumbar disc herniation and radiculitis. Spine (Phila Pa 1976) 2011; 36:1897-1905.

190. Manchikanti L, Singh V, Cash KA, Pampati $V$, Datta $S$. Management of pain of post lumbar surgery syndrome: Oneyear results of a randomized, double double-blind, active controlled trial of fluoroscopic caudal epidural injections. Pain Physician 2010; 13:509-521.

191. Manchikanti L, Cash RA, McManus CD, Pampati V, Fellows B. Fluoroscopic caudal epidural injections with or without steroids in managing pain of lumbar spinal stenosis: One year results of randomized, double-blind, active-controlled trial. J Spinal Disord 2012; 25:226234.

192. Simopoulos TT, Manchikanti L, Singh V, Gupta S, Hameed H, Diwan S, Cohen SP. A systematic evaluation of prevalence and diagnostic accuracy of sacroiliac joint interventions. Pain Physician 2012; 15:E305-E344.

193. Hansen H, Manchikanti L, Simopoulous TT, Christo PJ, Gupta S, Smith HS, Hameed $\mathrm{H}$, Cohen SP. A systematic evaluation of the therapeutic effectiveness of sacroiliac joint interventions. Pain Physician 2012; 15:E247-E278.

194. Manchikanti L, Cash KA, McManus CD, Damron KS, Pampati V, Falco FJE. Lumbar interlaminar epidural injections in central spinal stenosis: Preliminary results of a randomized, double-blind, active control trial. Pain Physician 2012; 15:51-63.

195. Parr AT, Manchikanti L, Hameed $\mathrm{H}$, Conn A, Manchikanti KN, Benyamin RM, Diwan S, Singh V, Abdi S. Caudal epidural injections in the management of chronic low back pain: A systematic appraisal of the literature. Pain Physician 2012; 15:E159-E198.

196. Manchikanti L, Cash KA, Pampati V, Wargo BW, Malla Y. The effectiveness of fluoroscopic cervical interlaminar epidural injections in managing chron- ic cervical disc herniation and radiculitis: Preliminary results of a randomized, double-blind, controlled trial. Pain Physician 2010; 13:223-236.

197. Manchikanti L, Malla Y, Cash KA, McManus $C D$, Pampati V. Fluoroscopic epidural injections in cervical spinal stenosis: Preliminary results of a randomized, double-blind, active control trial. Pain Physician 2012; 15: E59-E70.

198. Manchikanti L, Malla Y, Cash KA, McManus CD, Pampati V. Fluoroscopic cervical interlaminar epidural injections in managing chronic pain of cervical postsurgery syndrome: Preliminary results of a randomized, double-blind active control trial. Pain Physician 2012; 15:1326.

199. Manchikanti L, Cash KA, McManus CD, Pampati V, Benyamin RM. A preliminary report of a randomized double-blind, active controlled trial of fluoroscopic thoracic interlaminar epidural injections in managing chronic thoracic pain. Pain Physician 2010; 13:E357-E369.

200. Manchikanti L, Cash KA, McManus CD, Pampati V, Singh V, Benyamin RM. The preliminary results of a comparative effectiveness evaluation of adhesiolysis and caudal epidural injections in managing chronic low back pain secondary to spinal stenosis: A randomized, equivalence controlled trial. Pain Physician 2009; 12:E341-E354.

201. Manchikanti L, Singh V, Cash KA, Pampati V, Datta S. A comparative effectiveness evaluation of percutaneous adhesiolysis and epidural steroid injections in managing lumbar post surgery syndrome: A randomized, equivalence controlled trial. Pain Physician 2009; 12: $\mathrm{E}_{355}$-E368.

202. Gourlay DL, Heit HA, Almahrezi A. Universal precautions in pain medicine: $A$ rational approach to the treatment of chronic pain. Pain Med 2005; 6:107-112.

203. Manchikanti L, Singh V, Pampati V, Boswell MF, Benyamin RM, Hirsch JA. Description of documentation in the management of chronic spinal pain. Pain Physician 2009: 12:E199-E224.

204. Manchikanti L, Benyamin RM. Documentation for evaluation and management services. In: Manchikanti L, Christo PJ, Trescot AM, Falco FJE (eds). Foundations of Pain Medicine and Interventional Pain Management: A Comprehensive Review. ASIPP Publishing, Paducah, KY, 2011, pp 455-470.

205. Manchikanti L, Singh V, Hirsch JA. Documentation for interventional tech- 
niques. In: Manchikanti L, Christo PJ, Trescot AM, Falco FJE (eds). Foundations of Pain Medicine and Interventional Pain Management: A Comprehensive Review. ASIPP Publishing, Paducah, KY, 2011, pp 471-486.

206. Manchikanti L, Helm S, Singh V, Benyamin RM, Datta S, Hayek S, Fellows B, Boswell MV. An algorithmic approach for clinical management of chronic spinal pain. Pain Physician 2009; 12:E225E264.

207. Turk DC, Swanson KS, Gatchel RJ. Predicting opioid misuse by chronic pain patients: A systematic review and literature synthesis. Clin J Pain 2008; 24:497508.

208. Passik SD, Kirsh KL, Whitcomb L, Portenoy RK, Katz NP, Kleinman L, Dodd SL, Schein JR. A new tool to assess and document pain outcomes in chronic pain patients receiving opioid therapy. Clin Ther 2004; 26:552-561.

209. Passik SD, Kirsh KL, Whitcomb L, Schein JR, Kaplan MA, Dodd SL, Kleinman L, Katz NP, Portenoy RK. Monitoring outcomes during long-term opioid therapy for noncancer pain: Results with the Pain Assessment and Documentation Tool. J Opioid Mang 2005; 1:257-266.

210. Butler SF, Budman SH, Fernandez KC, Houle B, Benoit C, Katz N, Jamison RN. Development and validation of the Current Opioid Misuse Measure. Pain 2007; 130:144-156.

211. Atluri SL, Sudarshan G. Development of a screening tool to detect the risk of inappropriate prescription opioid use in patients with chronic pain. Pain Physician 2004; 7:333-338.

212. Manchikanti L, Singh V, Damron KS, Beyer CD, Pampati V. Screening for controlled substance abuse in interventional pain management settings: Evaluation of an assessment tool. Pain Physician 2003; 6:425-433.

213. Manchikanti L, Atluri S, Trescot AM, Giordano J. Monitoring opioid adherence in chronic pain patients: Tools, techniques, and utility. Pain Physician 2008; 11:S155-S180.

214. Wu SM, Compton P, Bolus R, Schieffer B, Pham Q, Baria A, Van Vort W, Davis F, Shekelle P, Naliboff BD. The addiction behaviors checklist: Validation of a new clinician-based measure of inappropriate opioid use in chronic pain. J Pain Symptom Manage 2006; 32:342-351.

215. Manchikanti L, Whitfield E, Pallone F. Evolution of the National All Sched- ules Prescription Electronic Reporting Act (NASPER): A public law for balancing treatment of pain and drug abuse and diversion. Pain Physician 2005; 8:335347.

216. Wang J, Christo PJ. The influence of prescription monitoring programs on chronic pain management. Pain Physician 2009; 12:507-515.

217. Gugelmann HM, Perrone J. Can prescription drug monitoring programs help limit opioid abuse? JAMA 2011; 306:2258-2259.

218. Yokell MA, Green TC, Rich JD. Prescription drug monitoring programs. JAMA 2012; 307:912; author reply 912-913.

219. Paulozzi LJ, Kilbourne EM, Desai HA. Prescription drug monitoring programs and death rates from drug overdose. Pain Med 2011; 12:747-754.

220. Peirce GL, Smith MJ, Abate MA, Halverson J. Doctor and pharmacy shopping for controlled substances. Med Care 2012 Mar 8. [Epub ahead of print]

221. Kentucky State $\mathrm{HB}$. An act relating to controlled substances. Tuesday, April 24, 2012.

222. United States General Accounting Office. GAO-04-524T. Prescription Drugs, State Monitoring Programs May Help to Reduce Illegal Diversion. May 4, 2004. www.gao.gov/assets/120/110650.pdf

223. Reifler LM, Droz D, Bailey JE, Schnoll SH, Fant R, Dart RC, Bucher Bartelson B. Do prescription monitoring programs impact state trends in opioid abuse/misuse? Pain Med 2012; 13:434442.

224. Prescription drug monitoring programs: A brief overview National Alliance for Model State Drug Laws (NAMSDL), June 3, 2011.

www.namsdl.org/documents/BriefOverviewPMPLaws-6-3-11.pdf

225. Owen GT, Burton AW, Schade CM, Passick S. Urine drug testing: Current recommendations and best practices. Pain Physician 2012; 15:ES19-ES133.

226. Christo PJ, Manchikanti L, Ruan X, Bottros $M$, Hansen $H$, Solanki DR, Jordan $\mathrm{AE}$, Colson J. Urine drug testing in chronic pain. Pain Physician 2011; 14:123143.

227. Liebschutz JM, Saitz R, Weiss RD, Averbuch T, Schwartz S, Meltzer EC, Claggett-Borne E, Cabral H, Samet JH. Clinical factors associated with prescription drug use disorder in urban primary care patients with chronic pain. J Pain 2010; 11:1047-1055.
228. Levy S, Harris SK, Sherritt L, Angulo M, Knight JR. Drug testing of adolescents in ambulatory medicine: Physician practices and knowledge. Arch Pediatr Adolesc Med 2006; 160:146-150.

229. Pergolizzi J, Pappagallo M, Stauffer J, Gharibo C, Fortner N, de Jesus M, Brennan MJ, Richmond C, Hussey D. The role of urine drug testing for patients on opioid therapy. Pain Pract 2010; 10:497507.

230. Reisfield GM, Webb FJ, Bertholf RL, Sloan PA, Wilson GR. Family physicians' proficiency in urine drug test interpretation. J Opioid Manag 2007; 3:333-337.

231. Nafziger AN, Bertino JS. Utility and application of urine drug testing in chronic pain management with opioids. Clin J Pain 2009; 25:73-79.

232. Pesce A, West C, Rosenthal M, West R, Crews B, Mikel C, Almazan P, Latyshev $S$, Horn PS. Marijuana correlates with use of other illicit drugs in a pain patient population. Pain Physician 2010; 13:283287.

233. West R, Pesce A, West C, Crews B, Mikel C, Almazan P, Rosenthal M, Latyshev S. Comparison of clonazepam compliance by measurement of urinary concentration by immunoassay and LC-MS/MS in pain management population. Pain Physician 2010; 13:71-78.

234. Tellioglu T. The use of urine drug testing to monitor patients receiving chronic opioid therapy for persistent pain conditions. Med Health R I 2008; 91:279-280, 282.

235. Manchikanti L, Singh V, Boswell MV. Interventional pain management at crossroads: The perfect storm brewing for a new decade of challenges. Pain Physician 2010; 13:Eı11-E140.

236. Benyamin RM, Datta S, Falco FJE. A perfect storm in interventional pain management: Regulated, but unbalanced. Pain Physician 2010; 13:109-116.

237. CMS Manual System. Pub 100-04 Medicare claims processing, Transmittal 1884, Change Request 6657. Calendar Year (CY) 2010 Annual Update for Clinical Laboratory Fee Schedule and Laboratory Services Subject to Reasonable Charge Payment. December 23, 2009.

238. Centers for Medicare and Medicaid Services. (2009) Calendar year 2010. New Clinical Laboratory Fee Schedule Test Codes and Final Payment Determinations.

239. Collen M. Profit-driven drug testing. J Pain Palliat Care Pharmacother 2012; 
26:13-17.

240. Manchikanti L, Boswell MV, Singh V, Derby R, Fellows B, Falco FJE, Datta S, Smith HS, Hirsch JA. Comprehensive review of neurophysiologic basis and diagnostic interventions in managing chronic spinal pain. Pain Physician 2009; 12:E71-E120.

241. Manchikanti L, Singh V, Pampati V, Damron KS, Barnhill RC, Beyer CD, Cash KA. Evaluation of the relative contributions of various structures in chronic low back pain. Pain Physician 2001; 4:308-316.

242. Bogduk N. Low back pain. In: Clinical Anatomy of the Lumbar Spine and Sacrum. 4th edition. Churchill Livingstone, New York, 2005, pp 183-216.

243. Bogduk N. Medical Management of Acute Cervical Radicular Pain: An Evidencebased Approach. 1st edition. Cambridge Press, Newcastle, 1999.

244. Bogduk N, Govind J. Medical Management of Acute Lumbar Radicular Pain: An Evidence-Based Approach. Cambridge Press, Newcastle 1999.

245. Rubinstein SM, Pool J, van Tulder MW, Riphagen II, de Vet HC. A systematic review of the diagnostic accuracy of provocative tests of the neck for diagnosing cervical radiculopathy. Eur Spine ] 2007; 16:307-319.

246. Laslett M, McDonald B, Tropp H, Aprill $\mathrm{CN}$, Oberg B. Agreement between diagnoses reached by clinical examination and available reference standards: A prospective study of 216 patients with lumbopelvic pain. BMC Musculoskelet Disord 2005; 6:28.

247. Petersen $T$, Olsen $S$, Laslett $M$, Thorsen $\mathrm{H}$, Manniche C, Ekdahl C, Jacobsen S. Inter-tester reliability of a new diagnostic classification system for patients with non-specific low back pain. Aust J Physiother 2004; 50:85-94.

248. Laslett M, McDonald B, Aprill CN, Tropp H, Oberg B. Clinical predictors of screening lumbar zygapophyseal joint blocks: Development of clinical prediction rules. Spine ] 2006; 6:370-379.

249. Young S, Aprill C, Laslett M. Correlation of clinical examination characteristics with three sources of chronic low back pain. Spine ] 2003; 3:460-465.

250. Sandmark H, Nisell R. Validity of five common manual neck pain provoking tests. Scand J Rehabil Med 1995; 27:131136.

251. Carragee EJ. Validity of self-reported history in patients with acute back or neck pain after motor vehicle accidents. Spine ] 2008; 8:311-319.

252. Tong HC. Specificity of needle electromyography for lumbar radiculopathy in 55- to 79-yr-old subjects with low back pain and sciatica without stenosis. Am J Phys Med Rehabil 2011; 90:233-238.

253. Chiodo A, Haig AJ, Yamakawa KS, Quint D, Tong H, Choksi VR. Needle EMG has a lower false positive rate than MRI in asymptomatic older adults being evaluated for lumbar spinal stenosis. Clin Neurophysiol 2007; 118:751-756.

254. Haig AJ, Geisser ME, Tong HC, Yamakawa KS, Quint DJ, Hoff JT, Chiodo A, Miner JA, Phalke VV. Electromyographic and magnetic resonance imaging to predict lumbar stenosis, low-back pain, and no back symptoms. J Bone Joint Surg Am 2007; 89:358-366.

255. Haig AJ, Tong HC, Yamakawa KS, Quint DJ, Hoff JT, Chiodo A, Miner JA, Choksi VR, Geisser ME, Parres CM. Spinal stenosis, back pain, or no symptoms at all? A masked study comparing radiologic and electrodiagnostic diagnoses to the clinical impression. Arch Phys Med Rehabil 2006; 87:897-903.

256. Tong HC. Incremental ability of needle electromyography to detect radiculopathy in patients with radiating low back pain using different diagnostic criteria. Arch Phys Med Rehabil 2012 Mar 29. [Epub ahead of print]

257. Ackerman SJ, Steinberg EP, Bryan RN, BenDebba M, Long DM. Patient characteristics associated with diagnostic imaging evaluation of persistent low back problems. Spine (Phila Pa 1976) 1997; 22:1634-1640; discussion 1641.

258. Rollins G. Rapid MRI no better than Xray in the treatment of low back pain. Rep Med Guidel Outcomes Res 2003; 14:1, 6-7.

259. Boden SD, Swanson AL. An assessment of the early management of spine problems and appropriateness of diagnostic imaging utilization. Phys Med Rehabil Clin N Am 1998; 9:411-417, viii.

26o. Jensen MC, Brant-Zawadzki MN, Obuchowski N, Modic MT, Malkasian D, Ross JS. Magnetic resonance imaging of the lumbar spine in people without back pain. N Engl ] Med 1994; 331:69-73.

261. Powell MC, Wilson M, Szypryt P, Symonds EM, Worthington BS. Prevalence of lumbar disc degeneration observed by magnetic resonance in symptomless women. Lancet 1986; 2:1366-
1367.

262. Boden SD, Davis DO, Dina TS, Patronas NJ, Wiesel SW. Abnormal magnetic-resonance scans of the lumbar spine in asymptomatic subjects. A prospective investigation. J Bone Joint Surg Am 1990; 72:403-408.

263. Takatalo J, Karppinen J, Niinimäki J, Taimela S, Näyhä S, Järvelin MR, Kyllönen E, Tervonen O. Prevalence of degenerative imaging findings in lumbar magnetic resonance imaging among young adults. Spine (Phila Pa 1976) 2009; 34:1716-1721.

264. Okada $E$, Matsumoto $M$, Ichihara $D$, Chiba K, Toyama Y, Fujiwara H, Momoshima S, Nishiwaki Y, Hashimoto T, Ogawa J, Watanabe M, Takahata T. Aging of the cervical spine in healthy volunteers: A 10-year longitudinal magnetic resonance imaging study. Spine (Phila Pa 1976) 2009; 34:706-712.

265. Wood KB, Blair JM, Aepple DM, Schendel MJ, Garvey TA, Gundry CR, Heithoff $\mathrm{KB}$. The natural history of asymptomatic thoracic disc herniations. Spine (Phila $\mathrm{Pa} \mathrm{1976)} \mathrm{1997;} \mathrm{22:525-529;} \mathrm{discussion}$ 529-530.

266. Okada E, Matsumoto $M$, Fujiwara $H$, Toyama Y. Disc degeneration of cervical spine on MRI in patients with lumbar disc herniation: Comparison study with asymptomatic volunteers. Eur Spine J 2011; 20:585-591.

267. Lebow RL, Adogwa O, Parker SL, Sharma A, Cheng J, McGirt MJ. Asymptomatic same-site recurrent disc herniation after lumbar discectomy: Results of a prospective longitudinal study with 2-year serial imaging. Spine (Phila $\mathrm{Pa}$ 1976) 2011; 36:2147-2151.

268. Matsumoto $M$, Okada $E$, Ichihara $D$, Chiba K, Toyama Y, Fujiwara H, Momoshima S, Nishiwaki Y, Takahata T. Modic changes in the cervical spine: Prospective 10-year follow-up study in asymptomatic subjects. J Bone Joint Surg Br 2012; 94:678-683.

269. Matsumoto $M$, Okada $E$, Ichihara $D$, Chiba K, Toyama Y, Fujiwara H, Momoshima S, Nishiwaki Y, Hashimoto T, Inoue T, Watanabe M, Takahata T. Prospective ten-year follow-up study comparing patients with whiplash-associated disorders and asymptomatic subjects using magnetic resonance imaging. Spine (Phila Pa 1976) 2010; 35:16841690.

270. Manchikanti L, Glaser S, Wolfer L, Derby $\mathrm{R}$, Cohen SP. Systematic review of lum- 
bar discography as a diagnostic test for chronic low back pain. Pain Physician 2009; 12:541-559.

271. Pampati S, Cash KA, Manchikanti L. Accuracy of diagnostic lumbar facet joint nerve blocks: A 2-year follow-up of 152 patients diagnosed with controlled diagnostic blocks. Pain Physician 2009; 12:855-866.

272. Manchikanti L, Pampati S, Cash KA. Making sense of the accuracy of diagnostic lumbar facet joint nerve blocks: An assessment of implications of 50\% relief, $80 \%$ relief, single block or controlled diagnostic blocks. Pain Physician 2010; 13:133-143.

273. Carragee EJ, Tanner CM, Yang B, Brito JL, Truong T. False-positive findings on lumbar discography. Reliability of subjective concordance assessment during provocative disc injection. Spine (Phila $\mathrm{Pa} \mathrm{1976)} \mathrm{1999;} \mathrm{24:2542-2547.}$

274. Wolfer L, Derby R, Lee JE, Lee SH. Systematic review of lumbar provocation discography in asymptomatic subjects with a meta-analysis of false-positive rates. Pain Physician 2008; 11:513-538.

275. Owens DK, Qaseem A, Chou R, Shekelle $P$; Clinical Guidelines Committee of the American College of Physicians. Highvalue, cost-conscious health care: Concepts for clinicians to evaluate the benefits harms, and costs of medical interventions. Ann Intern Med 2011; 154:174180.

276. Chouteau WL, Annaswamy TM, Bierner SM, Elliott AC, Figueroa I. Interrater reliability of needle electromyographic findings in lumbar radiculopathy. Am J Phys Med Rehabil 2010; 89:561-569.

277. Qaseem A, Alguire P, Dallas P, Feinberg LE, Fitzgerald FT, Horwitch C, Humphrey L, LeBlond R, Moyer D, Wiese JG, Weinberger S. Appropriate use of screening and diagnostic tests to foster high-value, cost-conscious care. Ann Intern Med 2012; 156:147-149.

278. Summaries for patients. Radiology tests for patients with low back pain: Highvalue health care advice from the American College of Physicians. Ann Intern Med 2011; 154:136.

279. Chou R, Qaseem A, Snow V, Casey D, Cross JT Jr, Shekelle P, Owens DK; Clinical Efficacy Assessment Subcommittee of the American College of Physicians; American College of Physicians; American Pain Society Low Back Pain Guidelines Panel. Diagnosis and treatment of low back pain: A joint clinical practice guideline from the American College of
Physicians and the American Pain Society. Ann Intern Med 2007; 147:478-491.

280. Chou R, Qaseem A, Owens DK, Shekelle P; Clinical Guidelines Committee of the American College of Physicians. Diagnostic imaging for low back pain: Advice for high-value health care from the American College of Physicians. Ann Intern Med 2011; 154:181-189.

281. Andersen JC. Is immediate imaging important in managing low back pain? J Athl Train 2011; 46:99-102.

282. Weiner DK, Kim YS, Bonino P, Wang T. Low back pain in older adults: Are we utilizing healthcare resources wisely? Pain Med 2006; 7:143-150.

283. Friedman BW, Chilstrom M, Bijur PE, Gallagher EJ. Diagnostic testing and treatment of low back pain in United States emergency departments: A national perspective. Spine (Phila Pa 1976) 2010; 35:E1406-E1411.

284. Jarvik JG, Hollingworth W, Martin B, Emerson SS, Gray DT, Overman S, Robinson $D$, Staiger $T$, Wessbecher $F$, Sullivan SD, Kreuter W, Deyo RA. Rapid magnetic resonance imaging vs radiographs for patients with low back pain: A randomized controlled trial. JAMA 2003; 289:2810-2818.

285. Freeborn DK, Shye D, Mullooly JP, Eraker S, Romeo J. Primary care physicians' use of lumbar spine imaging tests: Effects of guidelines and practice pattern feedback. J Gen Intern Med 1997; 12:619625 .

286. Wilson IB, Dukes K, Greenfield S, Kaplan S, Hillman B. Patients' role in the use of radiology testing for common office practice complaints. Arch Intern Med 2001; 161:256-263.

287. Weishaupt D, Zanetti M, Hodler J, Boos N. MR imaging of the lumbar spine: Prevalence of intervertebral disk extrusion and sequestration, nerve root compression, end plate abnormalities, and osteoarthritis of the facet joints in asymptomatic volunteers. Radiology 1998; 209:661-666.

288. Boos N, Semmer N, Elfering A, Schade V, Gal I, Zanetti M, Kissling R, Buchegger N, Hodler J, Main CJ. Natural history of individuals with asymptomatic disc abnormalities in magnetic resonance imaging: Predictors of low back painrelated medical consultation and work incapacity. Spine (Phila Pa 1976) 2000; 25:1484-1492.

289. Quiroz-Moreno R, Lezama-Suárez G, Gómez-Jiménez $C$. Disc alterations of lumbar spine on magnetic resonance images in asymptomatic workers. Rev Med Inst Mex Seguro Soc 2008; 46:185190.

290. Bouche KG, Vanovermeire O, Stevens VK, Coorevits PL, Caemaert JJ, Cambier DC, Verstraete K, Vanderstraeten GG, Danneels LA. Computed tomographic analysis of the quality of trunk muscles in asymptomatic and symptomatic lumbar discectomy patients. BMC Musculoskelet Disord 2011; 12:65.

291. Yu QY, Yang CR, Yu LT. Imaging study of lumbar intervertebral disc herniation and asymptomatic lumbar intervertebral disc herniation. Zhongguo Gu Shang 2009; 22:279-282.

292. Manchikanti L, Giordano J, Fellows B, Hirsch JA. Placebo and nocebo in interventional pain management: $A$ friend or a foe - or simply foes? Pain Physician 2011; 14:E157-E175.

293. Franklin GM, Rahman EA, Turner JA, Daniell WE, Fulton-Kehoe D. Opioid use for chronic low back pain: A prospective, population-based study among injured workers in Washington State, 20022005. Clin J Pain 2009; 25:743-751.

294. Becker N, Sjogren P, Bech P, Olsen AK, Eriksen J. Treatment outcome of chronic non-malignant pain patients managed in a Danish multidisciplinary pain centre compared to general practice: $\mathrm{A}$ randomised controlled trial. Pain 2000; 84:203-211.

295. Gross DP, Stephens B, Bhambhani $Y$, Haykowsky M, Bostick GP, Rashiq S. Opioid prescriptions in Canadian workers' compensation claimants prescription trends and associations between early prescription and future recovery. Spine (Phila Pa 1976) 2009; 34:525-531.

296. Ballantyne JC, Mao J. Opioid therapy for chronic pain. $N$ Engl J Med 2003; 349:1943-1953.

297. Farrar JT. What is clinically meaningful: Outcome measures in pain clinical trials. Clin J Pain 2000; 16:S106-S112.

298. Salaffi F, Stancati A, Silvestri CA, Ciapetti A, Grassi W. Minimal clinically important changes in chronic musculoskeletal pain intensity measured on a numerical rating scale. Eur J Pain 2004; 8:283-291.

299. Manchikanti L, Hirsch JA, Smith HS. Evidence-based medicine, systematic reviews, and guidelines in interventional pain management: Part 2: Randomized controlled trials. Pain Physician 2008; 11:717-773.

300. Manchikanti L, Benyamin RM, Helm S, Hirsch JA. Evidence-based medicine, 
systematic reviews, and guidelines in interventional pain management: Part 3: Systematic reviews and meta-analysis of randomized trials. Pain Physician 2009; 12:35-72.

301. Bombardier C. Outcome assessments in the evaluation of treatment of spinal disorders: Summary and general recommendations. Spine (Phila Pa 1976) 2000; 25:3100-3103.

302. Hagg O, Fritzell P, Nordwall A. The clinical importance of changes in outcome scores after treatment for chronic low back pain. Eur Spine J 2003; 12:12-20.

303. Noble M, Treadwell JR, Tregear SJ, Coates VH, Wiffen PJ, Akafomo C, Schoelles KM. Long-term opioid management for chronic noncancer pain. Cochrane Database Syst Rev 2010; 1:CDoo6605.

304. Chapman CR, Lipschitz DL, Angst MS, Chou R, Denisco RC, Donaldson GW, Fine PG, Foley KM, Gallagher RM, Gilson AM, Haddox JD, Horn SD, Inturrisi CE, Jick SS, Lipman AG, Loeser JD, Noble M, Porter L, Rowbotham MC, Schoelles KM, Turk DC, Volinn E, Von Korff MR, Webster LR, Weisner CM. Opioid pharmacotherapy for chronic non-cancer pain in the United States: a research guideline for developing an evidence-base. J Pain 2010; 11:807-829.

305. Cepeda MS, Camargo F, Zea CLV. Tramadol for osteoarthritis. Cochrane Database Syst Rev 2006; 3:CDoo5522.

306. Deshpande A, Furlan A, Mailis-Gagnon A, Atlas S, Turk D. Opioids for chronic low back pain (review). Cochrane Database Syst Rev 2007; 3:CDo04959.

307. Cepeda MS, Camargo F, Zea C, Valencia L. Tramadol for osteoarthritis: A systematic review and metaanalysis. J Rheumatol 2007; 34:543-555.

308. Sandoval JA, Furlan AD, Mailis-Gagnon AM. Oral methadone for chronic noncancer pain: A systemic literature review of reasons for administration, prescription patterns, effectiveness, and side effects. Clin J Pain 2005; 21:503-512.

309. King S, Forbes K, Hanks GW, Ferro C), Chambers EJ. A systematic review of the use of opioid medication for those with moderate to severe cancer pain and renal impairment: A European Palliative Care Research Collaborative opioid guidelines project. Palliat Med 2011; 25:525-552.

310. Chan BK, Tam LK, Wat CY, Chung YF, Tsui SL, Cheung CW. Opioids in chronic non-cancer pain. Expert Opin Pharmaco- ther 2011; 12:705-720.

311. Chou R. What we still don't know about treating chronic noncancer pain with opioids. CMA] 2010; 182:881-882.

312. American Geriatrics Society Panel on the Pharmacological Management of Persistent Pain in Older Persons. Pharmacological management of persistent pain in older persons. J Am Geriatr Soc 2009; 57:1331-1346.

313. Chou R, Carson S. Drug Class Review on Long-Acting Opioid Analgesics. Oregon Evidence-based Practice Center. April 2008.

http://health.utah.gov/medicaid/pharmacy/documents/files/University\%20 of $\% 20$ tah $\% 20$ Drug\% $\%$ olnformation\%20Service\%20Opioid\%2olnformation/Opioids_Final_Report_Update. pdf

314. Nicholson B. Benefits of extended-release opioid analgesic formulations in the treatment of chronic pain. Pain Pract 2009; 9:71-81.

315. Pergolizzi J, Böger RH, Budd K, Dahan A, Erdine S, Hans G, Kress HG, Langford R, Likar R, Raffa RB, Sacerdote P. Opioids and the management of chronic severe pain in the elderly: Consensus statement of an International Expert Panel with focus on the six clinically most often used World Health Organization Step III opioids (buprenorphine, fentanyl, hydromorphone, methadone, morphine, oxycodone). Pain Pract 2008; 8:287-313.

316. Saper JR, Lake AE zrd. Continuous opioid therapy (COT) is rarely advisable for refractory chronic daily headache: Limited efficacy, risks, and proposed guidelines. Headache 2008; 48:838-849.

317. Smith HS. Opioids and neuropathic pain. Pain Physician 2012; 15:ES93-ES110.

318. Eisenberg E, McNicol E, Carr DB. Opioids for neuropathic pain (review). Cochrane Database Syst Rev 2006, 3:CDoo6146.

319. Eisenberg E, McNicol ED, Carr DB. Efficacy and safety of opioid agonists in the treatment of neuropathic pain of nonmalignant origin: Systematic review and meta-analysis of randomized controlled trials. JAMA 2005; 293:3043-3052.

320. Everett CR, Novoseletsky D, Cole S, Frank J, Remillard C, Patel RK. Informed consent in interventional spine procedures: How much do patients understand? Pain Physician 2005; 8:251-255.

321. Manubay JM, Muchow C, Sullivan MA.
Prescription drug abuse: Epidemiology, regulatory issues, chronic pain management with narcotic analgesics. Prim Care 2011; 38:71-90, vi.

322. Cheatle MD, Savage SR. Informed consent in opioid therapy: A potential obligation and opportunity. ] Pain Symptom Manage 2012. [Epub ahead of print]

323. Starrels JL, Becker WC, Alford DP, Kapoor A, Williams AR, Turner BJ. Systematic review: Treatment agreements and urine drug testing to reduce opioid misuse in patients with chronic pain. Ann Intern Med 2010; 152:712-720.

324. Kirsh KL, Fishman SM. Multimodal approaches to optimize outcomes of chronic opioid therapy in the management of chronic pain. Pain Med 2011; 12:S1-Sil.

325. Arnold RM, Han PK, Seltzer D. Opioid contracts in chronic nonmalignant pain management: Objectives and uncertainties. Am J Med 2006; 119:292-296.

326. Fishman SM, Wilsey B, Yang J, Reisfield GM, Bandman TB, Borsook D. Adherence monitoring and drug surveillance in chronic opioid therapy. J Pain Symptom Manage 2000; 20:293-307.

327. Fishman SM, Mahajan G, Jung SW, Wilsey BL. The trilateral opioid contract. Bridging the pain clinic and the primary care physician through the opioid contract. J Pain Symptom Manage 2002; 24:335-344.

328. Korff M V, Saunders K, Thomas Ray G, Bourdreau D, Campbell C, Merrill J, Sullivan MD, Rutter CM, Silverberg MJ, Banta-Green C,Weisner C. De facto long-term opioid therapy for noncancer pain. Clin J Pain 2008; 24:521-527.

329. Højsted J, Sjøgren P. Addiction to opioids in chronic pain patients: A literature review. Eur J Pain 2007; 11:490-518.

330. Passik SD, Kirsh KL. The need to identify predictors of aberrant drug-related behavior and addiction in patients being treated with opioids for pain. Pain Med 2003; 4:186-189.

331. Moore RA, McQuay HJ. Prevalence of opioid adverse events in chronic nonmalignant pain: Systematic review of randomised trials of oral opioids. Arthritis Res Ther 2005; 7:R1046-R1051.

332. Akbik H, Butler SF, Budman SH, Fernandez K, Katz NP, Jamison RN. Validation and clinical application of the Screener and Opioid Assessment for Patients with Pain (SOAPP). J Pain Symptom Manage 2006; 32:287-293. 
333. Holmes CP, Gatchel RJ, Adams LL, Stowell AW, Hatten A, Noe C, Lou L. An opioid screening instrument: Longterm evaluation of the utility of the pain medication questionnaire. Pain Pract 2006; 6:74-88.

334. Compton PA, Wu SM, Schieffer B, Pham Q, Naliboff BD. Introduction of a selfreport version of the Prescription Drug Use Questionnaire and relationship to medication agreement noncompliance. J Pain Symptom Manage 2008; 36:383395.

335. Belgrade $M J$, Schamber CD, Lindgren BR. The DIRE score: Predicting outcomes of opioid prescribing for chronic pain. J Pain 2006; 7:671-681.

336. Ramírez-Maestre C, Esteve R, López AE. The path to capacity: Resilience and spinal chronic pain. Spine (Phila Pa 1976) 2012; 37:E251-E258.

337. Smith BW, Tooley EM, Montague EQ, Robinson AE, Cosper CJ, Mullins PG. The role of resilience and purpose in life in habituation to heat and cold pain. J Pain 2009; 10:493-500.

338. Haddadi P, Besharat MA. Resilience, vulnerability and mental health. Procedia-S + BS 2010; 5:639-642.

339. Davydov DM, Steward R, Ritchie K Chaudieu I. Resilience and mental health. Clin Psychol Rev 2010; 30:479495.

340. Scheiderman N, Ironson G, Siegel SD. Stress and health: Psychological, behavioral, and biological determinants. Annu Rev Clin Psychol 2005; 1:607-628.

341. Stanton AL, Revenson TA, Tennen $\mathrm{H}$. Health psychology: Psychological adjustment to chronic disease. Annu Rev Psychol 2007; 58:565-592.

342. Skinner EA, Zimmer-Gembeck MJ. The development of coping. Annu Rev Psychol 2007; 58:119-144.

343. Taylor SE, Stanton AL. Coping resources, coping processes, and mental health. Annu Rev Clin Psychol 2007; 3:377-401.

344. Bonanno GA. Loss, trauma, and human resilience: Have we underestimated the human capacity to thrive after extremely aversive events? Am Psychol 2004; 59:2028.

345. U.S. Food and Drug Administration. Questions and Answers about Oral Prescription Acetaminophen Products to be Limited to $325 \mathrm{mg}$ Per Dosage Unit. www.fda.gov/Drugs/DrugSafety/InformationbyDrugClass/ucm239871.htm

346. Amar PJ, Schiff ER. Acetaminophen safety and hepatotoxicity--where do we go from here? Expert Opin Drug Saf 2007; 6:341-355.

347. Krenzelok EP. The FDA Acetaminophen Advisory Committee Meeting what is the future of acetaminophen in the United States? The perspective of a committee member. Clin Toxicol (Phila) 2009; 47:784-789.

348. Arundel C, Lewis JH. Drug-induced liver disease in 2006. Curr Opin Gastroenterol 2007; 23:244-254.

349. Schneider U, Bevilacqua C, Jacobs R Karst M, Dietrich DE, Becker H, MüllerVahl KR, Seeland I, Gielsdorf D, Schedlowski M, Emrich HM. Effects of fentan$\mathrm{yl}$ and low doses of alcohol on neuropsychological performance in healthy subjects. Neuropsychobiology 1999; 39:38-43.

350. Hale M, Speight K, Harsanyi Z, Iwan T, Slagle N, Lacouture P, Darke A. Efficacy of 12 hourly controlled-release codeine compared with as required dosing of acetaminophen plus codeine in patients with chronic low back pain. Pain Res Manag 1997; 2:33-38.

351. Leung SY. Benzodiazepines, opioids and driving: An overview of the experimental research. Drug Alcohol Rev 2011; 30:281286.

352. Puntillo K, Casella V, Reid M. Opioid and benzodiazepine tolerance and dependence: Application of theory to critical care practice. Heart Lung 1997; 26:317324.

353. Nowell PD, Mazumdar S, Buysse DJ, Dew MA, Reynolds CF 3rd, Kupfer DJ. Benzodiazepines and zolpidem for chronic insomnia: A meta-analysis of treatment efficacy. JAMA 1997; 278:21702177.

354. Young CC, Prielipp RC. Benzodiazepines in the intensive care unit. Crit Care Clin 2001; 17:843-862.

355. Ducharme C, Carnevale FA, Clermont MS, Shea S. A prospective study of adverse reactions to the weaning of opioids and benzodiazepines among critically ill children. Intensive Crit Care Nurs 2005; 21:179-186.

356. Lavie E, Fatséas M, Denis C, Auriacombe $M$. Benzodiazepine use among opiate-dependent subjects in buprenorphine maintenance treatment: Correlates of use, abuse and dependence. Drug Alcohol Depend 2009; 99:338-344.

357. Skurtveit S, Furu K, Bramness J, Selmer $\mathrm{R}$, Tverdal A. Benzodiazepines predict use of opioids--a follow-up study of 17,074 men and women. Pain Med 2010;
11:805-814

358. Currow DC, Abernethy AP. Potential opioid-sparing effect of regular benzodiazepines in dyspnea: Longer duration of studies needed. J Pain Symptom Manage 2010; 40:E1-E2.

359. Guasti L, Marino F, Cosentino M, Cimpanelli M, Rasini E, Piantanida E, Vanoli P, De Palma D, Crespi C, Klersy C, Maroni L, Loraschi A, Colombo C, Simoni C, Bartalena L, Lecchini S, Grandi AM, Venco A. Pain perception, blood pressure levels, and peripheral benzodiazepine receptors in patients followed for differentiated thyroid carcinoma: A longitudinal study in hypothyroidism and during hormone treatment. Clin J Pain 2007; 23:518-523.

360. Caldwell JR, Hale ME, Boyd RE, Hague JM, Iwan T, Shi M, Lacouture PG. Treatment of osteoarthritis pain with controlled release oxycodone or fixed combination oxycodone plus acetaminophen added to nonsteroidal antiinflammatory drugs a double blind, randomized, multicenter, placebo controlled trial. J Rheumatol 1999; 26:862-869.

361. Ayonrinde OT, Bridge DT. The rediscovery of methadone for cancer pain management. Med J Aust 2000; 173:536-540.

362. Rigg KK, March SJ, Inciardi JA. Prescription drug abuse \& diversion: Role of the pain clinic. J Drug Issues 2010; 40:681702.

363. Rome JD, Townsend CO, Bruce BK, Sletten CD, Luedtke CA, Hodgson JE. Chronic noncancer pain rehabilitation with opioid withdrawal: Comparison of treatment outcomes based on opioid use status at admission. Mayo Clinic Proceedings 2004; 79:759-768.

364. Paulozzi LJ, Kilbourne EM, Shah NG, Nolte KB, Desai HA, Landen MG, Harvey W, Loring LD. A history of being prescribed controlled substances and risk of drug overdose death. Pain Med 2012; 13:87-95.

365. Gomes T, Juurlink DN, Dhalla IA, MailisGagnon A, Paterson JM, Mamdani MM. Trends in opioid use and dosing among socio-economically disadvantaged patients. Open Med 2011; 5:E13-E22.

366. Braden JB, Russo J, Fan MY, Martin BC, DeVries A, Sullivan MD. Emergency department visits among recipients of chronic opioid therapy. Arch Intern Med 2010; 170:1425-1432.

367. Webster BS, Verma SK, Gatchel RJ. Relationship between early opioid prescribing for acute occupational low back pain 
and disability duration, medical costs, subsequent surgery and late opioid use. Spine (Phila Pa 1976) 2007; 32:2127-2132.

368. Franklin GM, Stover BD, Turner JA, Fulton-Kehoe D, Wickizer TM, Disability Risk Identification Study Cohort. Early opioid prescription and subsequent disability among workers with back injuries: The Disability Risk Identification Study Cohort. Spine (Phila Pa 1976) 2008; 33:199-204.

369. Pascual ML, Fleming RR, Gana TJ, Vorsanger GJ. Open-label study of the safety and effectiveness of long-term therapy with extended-release tramadol in the management of chronic nonmalignant pain. Curr Med Res Opin 2007; 23:2531-2542.

370. Huse E, Larbig W, Flor H, Birbaumer N. The effect of opioids on phantom limb pain and cortical reorganization. Pain 2001; 90:47-55.

371. Webster LR, Choi Y, Desai H, Webster L, Grant BJ. Sleep-disordered breathing and chronic opioid therapy. Pain Med 2008; 9:425-432.

372. Alattar MA, Scharf SM. Opioid-associated central sleep apnea: A case series. Sleep Breath 2009; 13:201-206.

373. Baron MJ, McDonald PW. Significant pain reduction in chronic pain patients after detoxification from high-dose opioids. J Opioid Manag 2006; 2:277-282.

374. Miller NS, Swiney T, Barkin RL. Effects of opioid prescription medication dependence and detoxification on pain perceptions and self-reports. Am J Ther 2006; 13:436-444.

375. Crisostomo RA, Schmidt JE, Hooten WM, Kerkvliet JL, Townsend CO, Bruce BK. Withdrawal of analgesic medication for chronic low-back pain patients: improvement in outcomes of multidisciplinary rehabilitation regardless of surgical history. Am J Phys Med Rehabil 2008; 87:527-536.

376. Hall AJ, Logan JE, Toblin RL, Kaplan JA, Kraner JC, Bixler D, Crosby AE, Paulozzi L). Patterns of abuse among unintentional pharmaceutical overdose fatalities. JAMA 2008; 300:2613-2620.

377. Cicero TJ, Wong G, Tian Y, Lynskey M, Todorov A, Isenberg K. Co-morbidity and utilization of medical services by pain patients receiving opioid medications: Data from an insurance claims database. Pain 2009; 144:20-27.

378. Lavin R, Park J. Depressive symptoms in community-dwelling older adults re- ceiving opioid therapy for chronic pain. J Opioid Manag 2011; 7:309-319.

379. Kidner CL, Mayer TG, Gatchel RJ. Higher opioid doses predict poorer functional outcome in patients with chronic disabling occupational musculoskeletal disorders. J Bone Joint Surg Am 2009; 91:919-927.

380. Fillingim RB, Doleys DM, Edwards RR, Lowery D. Clinical characteristics of chronic back pain as a function of gender and oral opioid use. Spine (Phila Pa 1976) 2003; 28:143-150.

381. Mahmud MA, Webster BS, Courtney TK, Matz S, Tacci JA, Christiani DC. Clinical management and the duration of disability for work-related low back pain. J Occup Environ Med 2000; 42:1178-1187.

382. Rhee Y, Taitel MS, Walker DR, Lau DT. Narcotic drug use among patients with lower back pain in employer health plans: A retrospective analysis of risk factors and health care services. Clin Ther 2007; 29:2603-2612.

383. Volinn E, Fargo JD, Fine PG. Opioid therapy for nonspecific low back pain and the outcome of chronic work loss. Pain 2009; 142:194-201.

384. Cifuentes M, Webster B, Genevay S, Pransky G. The course of opioid prescribing for a new episode of disabling low back pain: Opioid features and dose escalation. Pain 2010; 151:22-29.

385. Webster BS, Cifuentes M, Verma $S$, Pransky G. Geographic variation in opioid prescribing for acute, work-related, low back pain and associated factors: $A$ multilevel analysis. Am J Ind Med 2009; 52:162-171.

386. Stover BD, Turner JA, Franklin G, Gluck JV, Fulton-Kehoe D, Sheppard L, Wickizer TM, Kaufman J, Egan K. Factors associated with early opioid prescription among workers with low back injuries. J Pain 2006; 7:718-725.

387. White AG, Birnbaum HG, Mareva MN, Daher M, Vallow S, Schein J, Katz N. Direct costs of opioid abuse in an insured population in the United States.] Manag Care Pharm 2005; 11:469-479.

388. Who bears responsibility for the premature adoption of opioids as a treatment standard? The Back Letter 2011; 26:46.

389. Fishbain DA, Rosomoff HL, Rosomoff RS. Drug abuse, dependence, and addiction in chronic pain patients. Clin J Pain 1992; 8:77-85.

390. Keeping Radiation Exposures and Doses "As Low as Reasonably Achievable (ALARA)." G-129, Revision 1. Canadian
Nuclear Safety Commission. October 2004.

http://nuclearsafety.gc.ca/pubs_catalogue/ uploads/G12grevi_e.pdf

391. National Council on Radiation Protection and Measurements. Implementation of the Principle of as Low as Reasonable Achievable (ALARA) for Medical and Dental Personnel. NCRP Report no. 107. Bethesda, MD, NCRP, 1990.

392. Manchikanti L, Cash KA, Moss TL, Pampati $V$. Effectiveness of protective measures in reducing risk of radiation exposure in interventional pain management: A prospective evaluation. Pain Physician 2003; 6:301-305.

393. Manchikanti L, Cash KA, Moss TL, Rivera JJ, Pampati V. Risk of whole body radiation exposure and protective measures in fluoroscopically guided interventional techniques: A prospective evaluation. BMC Anesthesiol 2003; 3:2.

394. Manchikanti L, Cash KA, Moss TL, Pampati V. Radiation exposure to the physician in interventional pain management. Pain Physician 2002; 5:385-393.

395. Falco FJE, Onyewu O, Husain S. Radiology. In: Manchikanti L, Christo PJ, Trescot AM, Falco FJE (eds). Foundations of Pain Medicine and Interventional Pain Management: A Comprehensive Review. ASIPP Publishing, Paducah, KY, 2011, pp 307-318.

396. Falco FJE, Onyewu O, Husain S. Fluoroscopy. In: Manchikanti L, Christo PJ, Trescot AM, Falco FJE (eds). Foundations of Pain Medicine and Interventional Pain Management: A Comprehensive Review. ASIPP Publishing, Paducah, KY, 2011, pp 319-332.

397. Shahabi S. Radiation safety/protection and health physics. In: Dowd SB, Tilson ER (Eds). Practical Radiation Protection and Applied Radiobiology. 2nd ed. Saunders, Philadelphia, 1999, pp 167-196.

398. Axelsson B. Optimisation in fluoroscopy [commentary]. Biomed Imaging Interv J 2007; 3:E47.

399. Wininger KL, Deshpande KK. Radiation exposure during SCS mapping: A new data set [poster/abstract]. North American Neuromodulation Society. Dec. 3-6, 2009.

400. Zhou Y, Singh N, Abdi S, Wu J, Crawford J, Furgang FA. Fluoroscopy radiation safety for spine interventional pain procedures in university teaching hospitals. Pain Physician 2005; 8:49-53.

401. Botwin KP, Freeman ED, Gruber RD, Torres-Rames FM, Bouchtas CG, Sanel- 
li JT, Hanna AF. Radiation exposure to the physician performing fluoroscopically guided caudal epidural steroid injections. Pain Physician 2001; 4:343-348.

402. Wininger KL, Deshpande KK, Deshpande KK. Radiation exposure in percutaneous spinal cord stimulation mapping: A preliminary report. Pain Physician 2010; 13:7-18.

403. Preston KL, Jasinski DR, Testa M. Abuse potential and pharmacological comparison of tramadol and morphine. Drug Alcohol Depend 1991; 27:7-17.

404. Cicero TJ, Inciardi JA, Adams EH, Geller A, Senay EC, Woody GE, Woody GE, Muñoz A. Rates of abuse of tramadol remain unchanged with the introduction of new branded and generic products: Results of an abuse monitoring system, 1994-2004. Pharmacoepidemiol Drug Saf 2005; 14:851-859.

405. Dasgupta N, Kramer ED, Zalman MA, Carino S Jr, Smith MY, Haddox JD, Wright $C$ 4th. Association between nonmedical and prescriptive usage of opioids. Drug Alcohol Depend 2006; 82:135142.

406. Lamb RJ, Preston KL, Schindler CW, Meisch RA, Davis F, Katz JL, Henningfield JE, Goldberg SR. The reinforcing and subjective effects of morphine in post-addicts: A dose-response study. J Pharmacol Exp Ther 1991; 259:1165-1173.

407. Butler SF, Benoit C, Budman SH, Fernandez KC, McCormick C, Venuti SW, Katz N. Development and validation of an Opioid Attractiveness Scale: A novel measure of the attractiveness of opioid products to potential abusers. Harm Reduct J 2006; 3:5.

408. Cicero TJ, Dart RC, Inciardi JA, Woody GE, Schnoll S, Munoz A. The development of a comprehensive risk-management program for prescription opioid analgesics: Researched abuse, diversion and addiction-related surveillance (RADARS ). Pain Med 2007; 8:157-170.

409. Zacny JP, Gutierrez S. Characterizing the subjective, psychomotor, and physiological effects of oral oxycodone in nondrug-abusing volunteers. Psychopharmacology (Berl) 2003; 170:242-254.

410. Zacny JP, Lichtor SA. Within-subject comparison of the psychopharmacological profiles of oral oxycodone and oral morphine in non-drug-abusing volunteers. Psychopharmacology (Berl) 2007; 196:105-116.

411. Walsh SL, Nuzzo PA, Lofwall MR, Holtman JR, Jr. The relative abuse liability of oral oxycodone, hydrocodone and hydromorphone assessed in prescription opioid abusers. Drug Alcohol Depend 2008; 98:191-202.

412. Peterson GM, Randall CT, Paterson J. Plasma levels of morphine and morphine glucuronides in the treatment of cancer pain: Relationship to renal function and route of administration. Eur J Clin Pharmacol 1990; 38:121-124.

413. Zacny JP, Lichtor JL, Zaragoza JG, de Wit $\mathrm{H}$. Subjective and behavioral responses to intravenous fentanyl in healthy volunteers. Psychopharmacology (Berl) 1992; 107:319-326

414. Martin TL, Woodall KL, McLellan BA. Fentanyl-related deaths in Ontario, Canada: Toxicological findings and circumstances of death in 112 cases (20022004). J Anal Toxicol 2006; 30:603-610.

415. Fodale V, Mafrica F, Santamaria LB, Coleman JJ. Killer fentanyl: Is the fear justified? Expert Opin Drug Saf 2008; 7:213-217.

416. Food and Drug Administration. 2007 Public Health Advisories.

www.fda.gov/Drugs/DrugSafety/PublicHealthAdvisories/ucmo51192.htm

417. United States Food and Drug Administration. Safety warnings regarding use of fentanyl transdermal (skin) patches, 7/15/2005. www.fda.gov/Drugs/DrugSafety/PostmarketDrugSafetylnformationforPatientsandProviders/DrugSafetylnformationforHeathcareProfessionals/PublicHealthAdvisories/ucmo51739. $\mathrm{htm}$

418. Tyndale RF, Droll KP, Sellers EM. Genetically deficient CYP2D6 metabolism provides protection against oral opiate dependence. Pharmacogenetics 1997; 7:375379.

419. Romach MK, Otton SV, Somer G, Tyndale RF, Sellers EM. Cytochrome P450 2D6 and treatment of codeine dependence. J Clin Psychopharmacol 2000; 20:43-45.

420. Howard LA, Sellers EM, Tyndale RF. The role of pharmacogenetically-variable cytochrome $\mathrm{P} 450$ enzymes in drug abuse and dependence. Pharmacogenomics 2002; 3:185-99.

421. Reynolds KK, Ramey-Hartung B, Jortani $\mathrm{SA}$. The value of $\mathrm{CYP}_{2} \mathrm{D} 6$ and OPRM1 pharmacogenetic testing for opioid therapy. Clin Lab Med 2008; 28:581-598.

422. Sims SA, Snow LA, Porucznik CA. Surveillance of methadone-related adverse drug events using multiple public health data sources. J Biomed Inform
2007; 40:382-389.

423. Jamison RN, Raymond SA, Slawsby EA, Nedeljkovic SS, Katz NP. Opioid therapy for chronic noncancer back pain. A randomized prospective study. Spine (Phila $\mathrm{Pa}$ 1976) 1998; 23:2591-2600.

424. Gostick N, Allen J, Cranfield R, Currie J, Grillage M, Hildebrand PJ, James I. A comparison of the efficacy and adverse effects of controlled release dihydrocodeine and immediate release dihydrocodeine in the treatment of pain in osteoarthritis and chronic back pain. In: Twycross RG (ed). The Edinburgh Symposium on Pain Control and Medical Education. Royal Society of Medicine Pr, London, 1989, pp 137-143.

425. Hale ME, Fleischmann R, Salzman R, Wild J, Iwan T, Swanton RE, Kaiko RF, Lacouture PG. Efficacy and safety of controlled release versus immediate release oxycodone randomized, double blind evaluation in patients with chronic back pain. Clin J Pain 1999; 15:179-183.

426. Lloyd RS, Costello F, Eves MJ, James IGV, Miller AJ. The efficacy and tolerability of controlled-release dihydrocodeine tablets and combination dextropropoxyphene/paracetamol tablets in patients with severe osteoarthritis of the hips. Curr Med Res Opin 1992; 13:37-48.

427. Salzman RT, Roberts MS, Wild J, Fabian C, Reder RF, Goldenheim PD. Can a controlled release oral dose form of oxycodone be used as readily as an immediate release form for the purpose of titrating to stable pain control? J Pain Symptom Manage 1999; 18:271-279.

428. Seifert CF, Kennedy S. Meperidine is alive and well in the new millennium: Evaluation of meperidine usage patterns and frequency of adverse drug reactions. Pharmacotherapy 2004; 24:776783.

429. Rajagopal A, Bruera ED. Improvement in sexual function after reduction of chronic high-dose opioid medication in a cancer survivor. Pain Med 2003; 4:379383.

430. Daniell HW. DHEAS Deficiency during consumption of sustained-action prescribed opioids: Evidence for opioid-induced inhibition of adrenal androgen production. J Pain 2006; 7:901-907.

431. Daniell HW. Hypogonadism in men consuming sustained-action oral opioids. J Pain 2002; 3:377-384.

432. Pizzi DM. Opioid duration of action linked to increased risk for hypogonadism. Pain Med News, 2012; 10:05. 
433. Roberts LJ, Finch PM, Pullan PT, Bhagat $\mathrm{Cl}$, Price $\mathrm{LM}$. Sex hormone suppression by intrathecal opioids: A prospective study. Clin J Pain 2002; 18:144-148.

434. Rajagopal A, Vassilopoulous-Sellin R, Palmer JL, Kaur G, Bruera E. Hypogonadism and sexual dysfunction in male cancer survivors receiving chronic opioid therapy. J Pain Symptom Manage 2003; 26:1055-1061.

435. Daniell HW. Opioid endocrinopathy in women consuming prescribed sustained-action opioids for control of nonmalignant pain. J Pain 2008; 9:2836.

436. Tuteja AK, Biskupiak J, Stoddard GJ, Lipman AG. Opioid-induced bowel disorders and narcotic bowel syndrome in patients with chronic non-cancer pain. Neurogastroenterol Motil 2010; 22:424430.

437. Mercadante S. Pathophysiology and treatment of opioid-related myoclonus in cancer patients. Pain 1998; 74:5-9.

438. Han PK, Arnold R, Bond G, Janson D, Abu-Elmagd K. Myoclonus secondary to withdrawal from transdermal fentanyl: Case report and literature review. J Pain Symptom Manage 2002; 23:66-72.

439. Zgierska A, Brown RT, Zuelsdorff $M$, Brown D, Zhang Z, Fleming MF. Sleep and daytime sleepiness problems among patients with chronic noncancerous pain receiving long-term opioid therapy: A cross-sectional study. J Opioid Manag 2007; 3:317-327.

440. Mogri M, Khan MIA, Grant BJB, Mador MJ. Central sleep apnea induced by acute ingestion of opioids. Chest 2008; 133:1484-1488.

441. Farney RJ, Walker JM, Cloward TV, Rhondeau S. Sleep-disordered breathing associated with long-term opioid therapy. Chest 2003; 123:632-639.

442. Zutler M, Holty JE. Opioids, sleep, and sleep-disordered breathing. Curr Pharm Des 2011; 17:1443-1449.

443. Guilleminault C, Cao M, Yue HJ, Chawla P. Obstructive sleep apnea and chronic opioid use. Lung 2010; 188:459-468.

444. Koehler U, Augsten M, Cassel W, Jerrentrup A, Nolte J, Dette F. Sleep-disordered breathing in long-term opioid therapy. Dtsch Med Wochenschr 2010; 135:1125-1128.

445. Yue HJ, Guilleminault C. Opioid medication and sleep-disordered breathing. Med Clin North Am 2010; 94:435-446.

446. Nolte JE, Dette F, Cassel W, Riese C,
Augsten M, Koehler U. Long-term opioid therapy and respiratory insufficiency during sleep. Pneumologie 2010; 64:241245.

447. Paturi AK, Surani S, Ramar K. Sleep among opioid users. Postgrad Med 2011; 123:80-87.

448. Jungquist CR, Karan S, Perlis ML. Risk factors for opioid-induced excessive respiratory depression. Pain Manag Nurs 2011; 12:180-187.

449. Mystakidou K, Clark AJ, Fischer J, Lam A, Pappert K, Richarz U. Treatment of chronic pain by long-acting opioids and the effects on sleep. Pain Pract 2011; 11:282-289.

450. Low YH, Clarke CF, Huh BK. Opioidinduced hyperalgesia: A review of epidemiology, mechanisms and management. Singapore Med J 2012; 53:357-360.

451. Krishnan S, Salter A, Sullivan T, Gentgall M, White J, Rolan P. Comparison of pain models to detect opioid-induced hyperalgesia. J Pain Res 2012; 5:99-106.

452. Raffa RB, Pergolizzi JV Jr. Multi-mechanistic analgesia for opioid-induced hyperalgesia. J Clin Pharm Ther 2012; 37:125-127.

453. Martin CM. When medications make pain worse: Opioid-induced hyperalgesia. Consult Pharm 2011; 26:530-542.

454. Tompkins DA, Campbell CM. Opioidinduced hyperalgesia: Clinically relevant or extraneous research phenomenon? Curr Pain Headache Rep 2011; 15:129-136.

455. Sørensen J, Sjøgren P. The clinical relevance of opioid-induced hyperalgesia remains unresolved. Ugeskr Laeger 2011; 173:965-968.

456. Leal Pda C, Clivatti J, Garcia JB, Sakata RK. Opioid-induced hyperalgesia $(\mathrm{OIH})$. Rev Bras Anestesiol 2010; 60:639-647, 355-359.

457. Bekhit MH. Opioid-induced hyperalgesia and tolerance. Am J Ther 2010; 17:498-510.

458. Fishbain DA, Cole B, Lewis JE, Gao J, Rosomoff RS. Do opioids induce hyperalgesia in humans? An evidencebased structured review. Pain Med 2009; 10:829-839.

459. Wang H, Fischer C, Chen G, Weinscheimer N, Gantz S, Schiltenwolf M. Does long-term opioid therapy reduce pain sensitivity of patients with chronic low back pain? Evidence from quantitative sensory testing. Pain Physician 2012; 15:ES135-ES143.

460. Wang $H$, Akbar $M$, Weinsheimer $N$,
Gantz S, Schiltenwolf M. Longitudinal observation of changes in pain sensitivity during opioid tapering in patients with chronic low-back pain. Pain Med 2011; 12:1720-1726.

461. Compton P, Athanasos P, Elashoff D. Withdrawal hyperalgesia after acute opioid physical dependence in nonaddicted humans: A preliminary study. J Pain 2003; 4:511-519.

462. Célèrier $E$, Rivat $C$, Jun $Y$, Laulin JP, Larcher A, Reynier P, Simonnet G. Longlasting hyperalgesia induced by fentan$\mathrm{yl}$ in rats: Preventive effect of ketamine. Anesthesiology 2000; 92:465-472.

463. Rivat C, Laulin JP, Corcuff JB, Célèrier E, Pain L, Simonnet G. Fentanyl enhancement of carrageenan-induced long-lasting hyperalgesia in rats: Prevention by the $\mathrm{N}$-methyl-D-aspartate receptor antagonist ketamine. Anesthesiology 2002; 96:381-391.

464. Koppert W, Sittl R, Scheuber K, Alsheimer M, Schmelz M, Schüttler J. Differential modulation of remifentanilinduced analgesia and postinfusion hyperalgesia by S-ketamine and clonidine in humans. Anesthesiology 2003; 99:152159.

465. Younger J, Barelka P, Carroll I, Kaplan K, Chu L, Prasad R, Gaeta R, Mackey S. Reduced cold pain tolerance in chronic pain patients following opioid detoxification. Pain Med 2008; 9:1158-1163.

466. Prosser JM, Steinfeld M, Cohen LJ, Derbyshire S, Eisenberg DP, Cruciani RA, Galynker II. Abnormal heat and pain perception in remitted heroin dependence months after detoxification from methadone-maintenance. Drug Alcohol Depend 2008; 95:237-244.

467. Taylor-Stokes G, Lobosco S, Pike J, Sadosky AB, Ross E. Relationship between patient-reported chronic low back pain severity and medication resources. Clin Ther 2011; 33:1739-1748.

468. Veizi IE, Hayek SM, Narouze S, Pope $J E$, Mekhail N. Combination of intrathecal opioids with bupivacaine attenuates opioid dose escalation in chronic noncancer pain patients. Pain Med 2011; 12:1481-1489.

469. Edwards RR, Wasan AD, Michna E, Greenbaum S, Ross E, Jamison RN. Elevated pain sensitivity in chronic pain patients at risk for opioid misuse. J Pain 2011; 12:953-963.

470. Chen L, Malarick C, Seefeld L, Wang S, Houghton M, Mao J. Altered quantitative sensory testing outcome in subjects 
with opioid therapy. Pain 2009; 143:6570.

471. Hay JL, White JM, Bochner F, Somogyi AA, Semple TJ, Rounsefell B. Hyperalgesia in opioid-managed chronic pain and opioid-dependent patients. J Pain 2009; 10:316-322.

472. Moore P, Dimsdale JE. Opioids, sleep, and cancer-related fatigue. Med Hypotheses 2002; 58:77-82.

473. Ersek M, Cherrier MM, Overman SS, Irving GA. The cognitive effects of opioids. Pain Manag Nurs 2004; 5:75-93.

474. Lembo AJ, Schneier HA, Shiff SJ, Kurtz $\mathrm{CB}$, MacDougall JE, Jia XD, Shao JZ, Lavins BJ, Currie MG, Fitch DA, Jeglinski BI, Eng P, Fox SM, Johnston JM. Two randomized trials of linaclotide for chronic constipation. N Engl J Med 2011; 365:527-536.

475. Jansen JP, Lorch D, Langan J, Lasko B, Hermanns K, Kleoudis CS, Snidow JW, Pierce A, Wurzelmann J, Mortensen ER. A randomized, placebo-controlled phase 3 trial (Study SB-767905/012) of alvimopan for opioid-induced bowel dysfunction in patients with non-cancer pain. J Pain 2011; 12:185-193.

476. Mao J, Gold MS, Backonja MM. Combination drug therapy for chronic pain: A call for more clinical studies.] Pain 2011; 12:157-166.

477. Irving G, Pénzes J, Ramjattan B, Cousins $M$, Rauck R, Spierings EL, Kleoudis CS, Snidow JW, Pierce A, Wurzelmann J, Mortensen ER. A randomized, placebo-controlled phase 3 trial (Study SB-767905/013) of alvimopan for opioid-induced bowel dysfunction in patients with non-cancer pain. J Pain 2011; 12:175-184

478. Smith HS, Elliott J. Opioid-inducted androgen deficiency (OPIAD). Pain Physician 2012; 15:ES145-ES156.

479. Paulson DM, Kennedy DT, Donovick RA, Carpenter RL, Cherubini M, Techner L, Du W, Ma Y, Schmidt WK, Wallin B, Jackson D. Alvimopan: An oral, peripheral- ly acting, mu-opioid receptor antagonist for the treatment of opioid induced bowel dysfunction: A 21-day treatmentrandomized clinical trial. J Pain 2005; 6:184-192.

480. Webster LR, Butera PG, Moran LV, Wu N, Burns LH, Friedmann N. Oxytrex minimizes physical dependence while providing effective analgesia: A randomized controlled trial in low back pain. J Pain 2006; 7:937-946.

481. Wilhelmi BG, Cohen SP. A framework for 'driving under the influence of drugs' policy for the opioid using driver. Pain Physician 2012; 15:ES215-ES230.

482. Daitch J, Frey M, Silver D, Mitnick C, Daitch D, Pergolizzi J. Conversion of chronic pain patients from full-opioid agonists to sublingual buprenorphine. Pain Physician 2012; 15:ES59-ES66.

483. Colson J, Helm S, Silver S. Office-based opioid dependence treatment. Pain Physician 2012; 15:ES231-ES236. 